ASSESSMENT

AND

FEEDBACK

IN HIGHER

EDUCATION

A Guide for Teachers

$2+2$

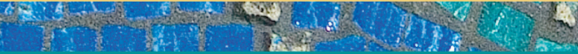 \\ Teresa McConlogue
}

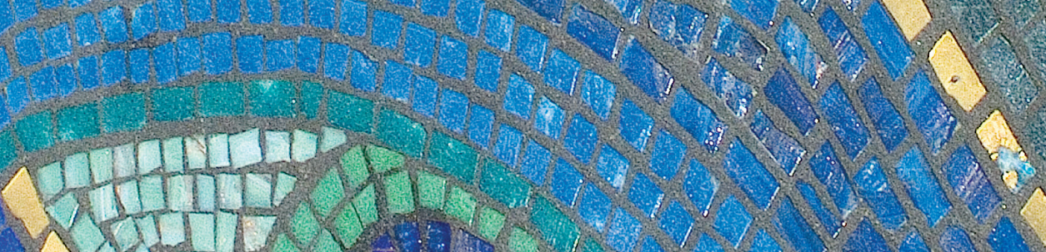

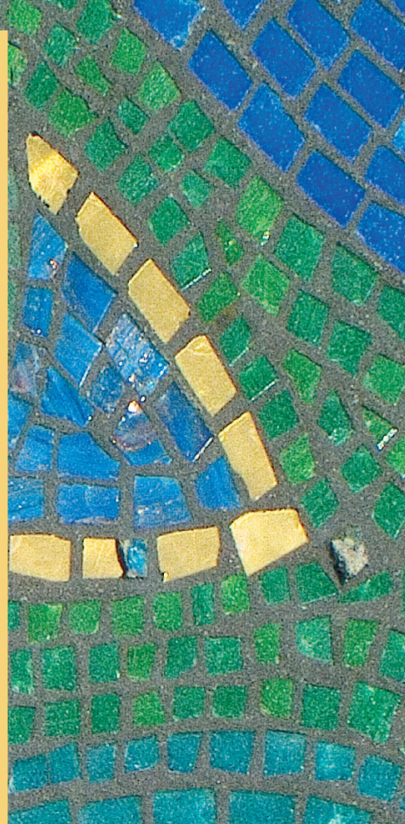

(1) 8719

(8)

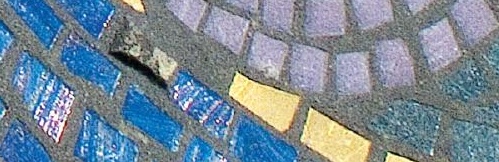


Assessment and Feedback in Higher Education 



\section{Assessment and Feedback \\ in Higher Education}

A Guide for Teachers

Teresa McConlogue

*UCLPRESS 
First published in 2020 by

UCL Press

University College London

Gower Street

London WC1E 6BT

Available to download free: www.uclpress.co.uk

(C) Teresa McConlogue, 2020

The author has asserted her rights under the Copyright, Designs and Patents Act 1988 to be identified as author of this work.

A CIP catalogue record for this book is available from The British Library.

This book is published under a Creative Common 4.0 International licence (CC BY-NC-ND 4.0 International). This licence allows you to share, copy, distribute and transmit the work; to adapt the work and to make commercial use of the work providing attribution is made to the author (but not in any way that suggests that she endorses you or your use of the work). Attribution should include the following information:

McConlogue, Teresa. 2020. Assessment and Feedback in Higher Education: A Guide for Teachers. London: UCL Press. https://doi.org/10.14324/111.9781787353640

Further details about Creative Commons licences are available at http://creativecommons.org/licenses/

Any third-party material in this book is published under the book's Creative Commons licence unless indicated otherwise in the credit line to the material. If you would like to reuse any third-party material not covered by the book's Creative Commons licence, you will need to obtain permission directly from the copyright holder.

ISBN: 978-1-78735-366-4 (Hbk.)

ISBN: 978-1-78735-365-7 (Pbk.)

ISBN: 978-1-78735-364-0 (PDF)

ISBN: 978-1-78735-367-1 (epub)

ISBN: 978-1-78735-368-8 (mobi)

DOI: https://doi.org/10.14324/111.9781787353640 


\section{Contents}

List of Figures and Tables vi

Glossary vii

Acknowledgements xi

1. Introduction 1

2. Key Perspectives 11

\section{Part 1: Designing Assessment}

3. Designing Assessment for a Course Unit/Module 31

4. Designing Assessment Across a Programme 53

5. Reaching Out: Making Links with Communities 64

\section{Part 2: Making Judgements}

6. Marker Reliability 85

7. Peer and Collaborative Assessment 99

8. Giving Good Quality Feedback 118

\section{Part 3: Inclusivity}

9. Developing Inclusive Curriculum and Assessment Practices 137

$\begin{array}{ll}\text { 10. Conclusion } & 151\end{array}$

$\begin{array}{ll}\text { References } & 154\end{array}$

$\begin{array}{ll}\text { Index } & 163\end{array}$ 


\section{List of Figures and Tables}

$\begin{array}{lll}\text { Figure 7.1 Organising peer assessment } & 111\end{array}$

Figure 7.2 Stage 1-3 activities (preparation to partnership) 113

Table 1.1 Assessment and feedback troubleshooting guide $\quad 7$

Table 1.2 Illustrative case studies 8

Table 1.3 Teaching ideas 9

Table 1.4 Design and review tools and questionnaires 9

Table 3.1 Advantages and disadvantages of types of assessment (adapted from Epstein 2007)

Table 3.2 Assessment brief review questionnaire (sources: adapted from Bean 2011; University of Suffolk 2019; University of Plymouth 2019)

Table 4.1 Reviewing an existing programme (sources: adapted from Bean 2011; University of Suffolk 2019; University of Plymouth 2019)

Table 7.1 Peer assessment issues (sources: Liu and Carless 2006; Cartney 2014; McConlogue 2012; Wilson et al. 2015)

Table 8.1 Feedback profiling tool 


\section{Glossary}

Academic

standards

Assessment for

learning (AfL)

Assessment

literacy

Collaborative assessment
Fixed levels of achievement that students are expected to reach on their programmes of study. Assessment for learning recognises the power of assessment to drive student learning and the importance of fully integrating assessment into the curriculum through formative activities. Knowledge of the processes and standards of assessment, e.g. understanding assessment tasks, assessment criteria and academic standards on a programme of study.

Backward design Beginning the design process by describing what students are expected to know, do and become by the end of the programme, and the standards they are expected to reach, and then working backward to design a syllabus that will support them to reach this goal.

Involving students in the co-design of assessment activities (formative and summative), co-construction of assessment standards, marking and making judgements and giving feedback on peers' assignments. 
Credit

Criterionreferenced

Dialogic feedback

Framework for Higher Education Qualifications (FHEQ)

Inclusive assessment

Module

Norm-referenced assessment
A credit is a unit of notional learning hours. One FHEQ (see below) credit is equal to 10 notional learning hours; learning hours include lectures, seminars, tutorials, online discussions, formative and summative assessments.

In criterion-referenced assessment, performance is judged against a standard, described in a set of criteria. It is possible for all learners to achieve the highest grades, if their work is excellent. Driving tests are criterion-referenced; it does not matter how many people pass as long as they reach the standard (cf norm-referenced).

Feedback practices that provide opportunities for students to discuss, raise questions and critique the feedback they receive.

Framework for Higher Education Qualifications (FHEQ) sets out the levels/standards expected for degree classifications in the UK.

Assessment tasks and processes that accommodate all learners and their diverse needs. Well-designed inclusive assessment avoids the need for reasonable adjustments as the tasks and processes do not exclude any groups of learners (see Chapter 9).

A unit of study. Modules can have different lengths, e.g. 15, 30 or 60 credit modules (see 'credit' above) and can be combined to make a programme of study.

Norm-referenced assessment involves comparing student performance and ranking students against each other and against a 'norm'. In normreferenced assessment, students are not judged against a fixed standard but against each other. Unlike criterion-referenced assessment (see above), it is impossible for all students to achieve the highest grades. 


$\begin{array}{ll}\begin{array}{l}\text { Observed } \\ \text { structured clinical } \\ \text { exam (OSCE) }\end{array} & \begin{array}{l}\text { Observed structured clinical exams are used in } \\ \text { professional programmes to assess competencies. } \\ \text { In medicine, students move through 'stations' } \\ \text { designed to test their competencies in interacting }\end{array} \\ & \begin{array}{l}\text { with patients and making clinical judgements. } \\ \text { Each station is assessed by observers and } \\ \text { performance is evaluated using a mark sheet. }\end{array} \\ \text { Peer assessment } & \begin{array}{l}\text { Student assessments (or oral presentations, videos } \\ \text { etc.) are read (or viewed) and marked by their }\end{array} \\ & \begin{array}{l}\text { peers. Marking involves giving feedback and/or } \\ \text { grades. Peer assessment can be used for formative }\end{array} \\ & \text { or summative assessment (see Chapter 7). } \\ \text { Problem-based } & \begin{array}{l}\text { Problem-based learning is a type of inquiry-based } \\ \text { learning }\end{array} \\ \text { learning (also known as enquiry-based learning) } \\ \text { often used in professional studies. Typically, } \\ \text { students work in groups to solve a professional } \\ \text { problem; problems are suitably complex and have } \\ \text { a range of possible solutions. } \\ \text { A programme of study is a series of modules or } \\ \text { course units at undergraduate or postgraduate } \\ \text { level. Some programmes (typically professional } \\ \text { programmes) are tightly constructed with core } \\ \text { modules and very few options; other programmes } \\ \text { study }\end{array}$


Validity

Writing-to-learn (WTL)
Valid assessment tasks allow students to demonstrate that they have met the aims of the module/programme to the expected standard. Writing-to-learn tasks are typically short writing tasks that help students to learn disciplinary concepts, explore disciplinary knowledge and skills, and give practice in writing for a range of diverse audiences. 


\section{Acknowledgements}

I am indebted to the many colleagues who have helped me develop ideas for this guide. I would firstly like to thank colleagues involved in the Degree Standards Project, especially Professor Sue Bloxham for inspiration and encouragement.

My colleagues in the UCL Arena Centre and colleagues across faculties and departments at UCL have also motivated and encouraged me. In particular, I would like to thank Gwyneth Hughes, Mira Vogel, Rachel Rees, Professor Alastair McClelland, Jenny Marie and Julie Evans (to the first of whom thanks also for permission to reproduce the JISC Feedback Profiling Tool in Chapter 8). A special thanks to Rosalind Duhs who was instrumental in getting me started and motivating me to continue writing. Thanks also to Victoria Showunmi who has guided my thinking on inclusivity over many years and to Cathy Elliott for guidance and support.

I also owe a debt of gratitude to former Thinking Writing colleagues at Queen Mary University of London, especially Sally Mitchell who has been an inspiration and, at times, a muse. The extracts from the Thinking Writing website quoted in chapters 2 and 3 are reproduced by their kind permission. I have a great admiration for and have learned much from Professor Jane Wills' work in east London communities and her involvement with local campaigns and democratic change. Much of my thinking around peer and collaborative assessment has been influenced by Professor David McConnell's work and also co-operative working with Professor Julia Shelton in the School of Engineering at Queen Mary University of London. 
Finally, I would like to thank all the researchers and writers, many of whom I have not met, whose work has fuelled and developed my thinking and who feature in this guide. 


\section{Chapter 1 \\ Introduction}

Welcome to this guide to assessment in higher education.

\section{Why a Guide on Assessment}

Assessment is a high-risk activity. Quality assurance procedures, the employability agenda and equality and diversity concerns all affect assessment practices. Governments, employers, funders, professional bodies and parents are all concerned stakeholders, and this makes assessment a high-risk, pressurised activity for both students and teachers.

Teachers spend a lot of time on assessment and feedback, but often have very little professional development in how to design assessments and make reliable assessment judgements. Teachers grapple with issues such as unreliable marking and grade inflation. Inexperienced teachers can be asked to design courses and assessments with little pedagogical support. Greater access to higher education has resulted in a much more diverse student body and an increased need for inclusive assessment practices. Professional development is often done on the job, with variable amounts of guidance from more experienced colleagues.

Assessment dominates students' thinking in higher education and determines what they will focus on in their studies. Students entering higher education may face unfamiliar assessment processes and tasks. They may lack or have different understandings of academic standards and teacher expectations. They may misunderstand plagiarism guidance and encounter the perils of contract cheating and essay mills. Perhaps 
it is not surprising that student surveys report dissatisfaction with assessment and feedback (Office for Students 2019; Advance HE 2019a).

However, there are existing solutions, or partial solutions, to these problems. Research on assessment in higher education and evidence from practice suggest many helpful strategies and activities that have been shown to be effective in creating less pressurised, more constructive assessment environments which benefit both learners and teachers. This guide to current research, theoretical and practical thinking on assessment in higher education aims to help you design more valid, inclusive assessments and develop strategies for ensuring more reliable assessment judgements.

\section{Academic Standards}

A key concept in the guide is the importance of academic standards, defined as 'fixed reference levels of attainment' (Sadler 2005, 193). Both students and teachers need to develop an understanding of academic standards for the particular modules and programmes they are involved in. Shared understanding of academic standards is key to ensuring assessment is reliable; reliable assessment promotes student satisfaction with their programme of study, as students better understand what they are aiming for and how they can better direct their own learning (Sadler 2010). Sadler (2010) argues that to move forward in their learning, students must conceptualise the gap between their current level, and the level they want to reach. They gain an understanding of how to bridge this gap through studying exemplars of their peers' work and being guided to make judgements about the quality of these. In this way, students come to understand what makes good quality work in their discipline and can better peer- and self-assess. In Boud et al.'s (2018) terms, through this process students develop evaluative judgement and are better able to judge the quality of their own and others' work and so direct their learning.

This book proposes that curriculum and assessment design need to focus on helping students (and teachers) develop and share an understanding of academic standards on their programmes of study. Practical ways of developing this understanding are suggested, e.g. through the use of exemplars (see Chapter 7 on Guided Marking), dialogic feedback (Chapter 8), and self-, peer- and collaborative assessment (Chapter 7). 
Like many professions, there is a gap in education between theoretical thinking and research work and educational practice. Ideas that are commonly discussed in the literature, such as dialogic feedback, collaborative assessment and inclusive assessment, may not be reflected in educational practice in a programme of study. This guide offers a review of key ideas in the literature followed by illustrations which demonstrate how these ideas can be put into practice. Perspectives from theoretical and research literature are discussed, narratives of evidence-informed practice are presented in case studies and practical teaching ideas are suggested. The case studies and teaching ideas illustrate how you can draw on current perspectives in designing programmes of study and assessment. Each chapter ends with guidance on follow-up activities, such as further reading, links to assessment resources and ideas for small-scale investigations to help you better understand your educational context, your students and your assessment practices.

\section{Investigating Your Practice (and Why It is Important)}

This guide is aimed at academic teaching staff in higher education, both early career and experienced academics. I aim to give an overview of current issues in assessment, review theoretical and research literature, and show how practice can be informed by key perspectives so that theoretical ideas and research literature are linked with the practice of teaching and learning. This may seem an obvious statement, but often educational practice does not connect with research findings and theoretical thinking.

There is a complex relationship between, on the one hand, research into education (which may be carried out by non-practitioners) and, on the other hand, the vast store of practical knowledge (Elbaz [1983] 2019) which teachers acquire through their educational experience. Practical knowledge is rich, tacit and vague. Practical knowledge strongly influences practice; research on teacher beliefs and academic conceptions shows that previous learning and teaching experiences have a profound impact on a teachers' practice (Elbaz 2019/1983; Borg 2015; Samuelowicz and Bain 2001; Kember 1997). Teachers have deep and valuable knowledge about their discipline(s) and how best to learn and assess fundamental concepts. This valuable practical knowledge is often not connected, or not fully connected, with current educational research and theoretical thinking. Similarly, research findings from one 
educational environment may not be applicable to another. Teachers need to make judgements about what will work in their context and with their diverse groups of learners.

Teachers' practical knowledge (see Chapter 2 for a detailed discussion) is a rich and powerful influence but is often not scrutinised. We know, or think we know what works; we might not know why it works. Small-scale action research and other methodologies are useful in helping academics explore practical knowledge, challenge assumptions and develop a reflective stance (Schön 2017). The follow-up activities in this guide suggest ways of exploring your own conceptions of teaching and learning, thinking about how these influence your teaching and assessment practices and what you might need to challenge. It is the premise of this book to try to bring together accounts of practice and theoretical and research work to offer academics a rich tapestry of ideas for supporting and assessing learning, to suggest ways of investigating your practice and of collecting evidence of effectiveness.

Each learner is unique with a range of characteristics (e.g. age, disabilities, race, sexuality, access to wealth), prior learning experiences and diverse needs, and each teacher is equally unique. To investigate teaching and learning, it is important to choose a methodology that recognises and explores this uniqueness. Case study research is frequently used in education as it is suitable for small-scale research, is context specific and rich in detail (Simons 2014; Bassey 2003; Stake 1995). There are different traditions within case study research; Stake's (1995) seminal work sets out a vision of case study research as an exploration of a unique phenomenon. He argues that generalisation is not the aim of case study research, instead it is the responsibility of the researcher to collect rich data on the case and come to know it well (Stake 1995, 8). Case studies may be designed to investigate a range of phenomena, for example, aspects of a degree programme, a group of learners, an individual learner and educational practices and beliefs of teachers. The type of data collected can range from interviews, observations, surveys, reflective journals (audio or written), analysis of students' work and an enquiry into procedures and processes through the analysis of documentation (e.g. syllabi, module handbooks, assessment briefs and criteria, marking and moderation procedures).

This approach to case study research fits well with an interpretivist research paradigm (Lincoln and Guba 1985). An interpretivist approach acknowledges the role of the researcher as constructor and interpreter of the research. As an investigator of your practice you will devise the study and interpret the data. The interpretation is yours, but through 
working in collaboration with students and colleagues, you can collect and reflect on alternative perspectives. Co-operating with colleagues and working in a community of practice (see Chapter 2) is key to developing as a practitioner. Wenger-Trayner et al. (2015) explain the importance of belonging to a community of practice:

You trust practitioners like your doctor to help you both for their experience and personal characteristics, and also because their actions reflect a competence defined by their community. Connection, engagement, status and a legitimacy in that community are all part of what makes someone a trustworthy practitioner. $(2015,14)$

Engagement with a professional community, with educational research, with investigation and reflection on one's own knowledge and practice creates trustworthy teachers.

\section{How to Use this Guide}

This guide presents current issues in assessment, research and theoretical thinking in these areas and proposes principles of good practice. These principles are illustrated in cases studies and embodied in teaching ideas (see the tables below). However, what works in one context with one student cohort may not work with another. Teachers need to consider their own context and learner diversity and make judgements about how to adapt these principles to fit their context. A key principle in this book is that teachers and students work together to develop consensual understandings of academic standards (this entails improving assessment literacy for both staff and students) and how programme design and learning activities can facilitate this.

Chapter 2 gives an overview of key educational ideas and theories. These ideas are then explored further in each chapter. Chapter 2 covers:

- how adults learn

- academic standards

- the role of exemplars

- academic literacies

- research-based learning

- validity and reliability in assessment. 
A key idea in this guide is that teachers and students require a shared understanding of academic standards. Without this understanding, teachers cannot make reliable judgements about the quality of students' work, and students cannot judge their peers' and their own work. Students who understand academic standards on their programme of study, can reliably self-assess and determine how to develop their work.

Chapters 3 to 5 explore assessment design: Chapter 3 considers ways of ensuring validity in assessment through backward design of assessment, authentic assessment and preparing students for assessment. Chapter 4 focuses on assessment design across a programme; it discusses the problem of modularisation and the importance of connecting assessments across a programme. Authentic assessment is discussed in Chapter 3; this topic is then taken up and explored in detail in Chapter 5, which covers ways of reaching out to groups and organisations beyond higher education institutions and involving partners and students in research-based learning.

While Chapters 3 to 5 focus on designing valid assessments, Chapters 6 to 8 problematise making reliable judgements. In Chapter 6 the thorny issue of reliability in assessment is explored in conjunction with both teacher and student understanding of academic standards. Ways of ensuring more reliable assessment judgements are proposed. Chapter 7 focuses on students as assessors and explores the benefits and problems of involving students in assessment through peer and collaborative assessment. Finally, feedback, and helping students to understand, construct and use feedback, is discussed in Chapter 8. Throughout this guide, I stress the importance of ensuring that assessment and feedback practices are inclusive; Chapter 9 deals in detail with inclusive practice, arguing that good assessment practices are inclusive practices. I consider the benefits and challenges of offering choice in assessment. Chapter 10 concludes the guide.

If you want to dip into parts of the guide that are relevant for you, then you can use the assessment and feedback troubleshooting guide (Table 1.1) to find solutions to common assessment and feedback issues. If you are looking for practical ideas, Tables 1.2 and 1.3 will direct you to case studies and teaching ideas presented in the guide. Finally, if you want help with designing or reviewing aspects of assessment, Table 1.4 will direct you to the design and review tools. 
Table 1.1: Assessment and feedback troubleshooting guide

This troubleshooting guide suggests solutions to some common assessment issues

\begin{tabular}{|c|c|}
\hline Issue & Action \\
\hline $\begin{array}{l}\text { Inconsistent feedback from a team of } \\
\text { markers } \\
\text { Differences in quantity and quality of } \\
\text { feedback given }\end{array}$ & $\begin{array}{l}\text { Involve the team in peer review of } \\
\text { feedback (Chapter 6). } \\
\text { Use the feedback profiling tool } \\
\text { to analyse feedback and improve } \\
\text { the quality of feedback. Develop } \\
\text { guidelines for the team of markers, } \\
\text { standardising the format and amount } \\
\text { of feedback. } \\
\text { Use a feedback form to guide teachers' } \\
\text { comments. }\end{array}$ \\
\hline $\begin{array}{l}\text { Inconsistent marking } \\
\text { Lack of marker reliability } \\
\text { Large team of inexperienced teaching } \\
\text { assistants (TAs) }\end{array}$ & $\begin{array}{l}\text { Organise harmonisation/ } \\
\text { pre-moderation sessions before any } \\
\text { marking (Chapter 6). } \\
\text { Get involved in calibration activities } \\
\text { across a department or across a } \\
\text { discipline (Chapter 6). }\end{array}$ \\
\hline $\begin{array}{l}\text { Too many assessments } \\
\text { No connections between assessments } \\
\text { Students cannot use learning from one } \\
\text { assessment in the next }\end{array}$ & $\begin{array}{l}\text { Carry out a Transforming the } \\
\text { Experience of Students Through } \\
\text { Assessment (TESTA). } \\
\text { Focus on reducing assessments and } \\
\text { ensuring links between assessments } \\
\text { (Chapter } 4 \text { ). }\end{array}$ \\
\hline $\begin{array}{l}\text { Late feedback or students do not } \\
\text { receive feedback }\end{array}$ & $\begin{array}{l}\text { Use a tracking system for student } \\
\text { submission of assignments and issue } \\
\text { deadline reminders to markers. } \\
\text { Flag any late return of feedback and } \\
\text { take immediate action. } \\
\text { Tell students why their feedback is late } \\
\text { and when they will receive feedback. }\end{array}$ \\
\hline $\begin{array}{l}\text { Students do not understand the } \\
\text { assessment task and/or the standard } \\
\text { they are required to reach and/or the } \\
\text { feedback they receive }\end{array}$ & $\begin{array}{l}\text { Help students understand assessment } \\
\text { and feedback by organising guided } \\
\text { marking at the beginning of a module } \\
\text { and introducing dialogic feedback } \\
\text { (Chapter 7). }\end{array}$ \\
\hline
\end{tabular}




\begin{tabular}{|l|l|}
\hline $\begin{array}{l}\text { Students do not collect or open } \\
\text { feedback and/or do not use it to } \\
\text { improve their next assignment }\end{array}$ & $\begin{array}{l}\text { Ensure assessments are connected and } \\
\text { show progressions so students need to } \\
\text { take account of feedback (Chapter 4). } \\
\text { Use a submission cover sheet that } \\
\text { asks students to explain how they } \\
\text { have used feedback from their last } \\
\text { assignment to develop their submitted } \\
\text { work. } \\
\text { Remind students when grades and } \\
\text { feedback have been returned and send } \\
\text { a further reminder if they have not } \\
\text { opened or collected their feedback } \\
\text { within a week. }\end{array}$ \\
\hline $\begin{array}{l}\text { Assessments do not test the } \\
\text { knowledge, skills and competencies } \\
\text { students are expected to learn } \\
\text { Students do not perceive assessments } \\
\text { as valid }\end{array}$ & $\begin{array}{l}\text { Use backward design (Chapter 4). } \\
\text { Ensure that the syllabus links to the } \\
\text { assessment and covers appropriate } \\
\text { knowledge and skills. Provide } \\
\text { opportunities for formative tasks that } \\
\text { practise the knowledge and skills } \\
\text { needed for the final assessment. }\end{array}$ \\
\hline
\end{tabular}

Table 1.2: Illustrative case studies

\begin{tabular}{|l|l|l|l|}
\hline Topic & Level & Discipline & Chapter \\
\hline $\begin{array}{l}\text { Research-based learning } \\
\text { Meet the Researcher }\end{array}$ & Undergraduate & $\begin{array}{l}\text { Psychology } \\
\text { and language } \\
\text { sciences }\end{array}$ & 2 \\
\hline $\begin{array}{l}\text { Research-based learning } \\
\text { Mystery specimen }\end{array}$ & Undergraduate & $\begin{array}{l}\text { Biology and } \\
\text { zoology }\end{array}$ & 5 \\
\hline $\begin{array}{l}\text { Research-based learning } \\
\text { Creating a community of } \\
\text { researchers }\end{array}$ & Undergraduate & $\begin{array}{l}\text { History of } \\
\text { science }\end{array}$ & 5 \\
\hline $\begin{array}{l}\text { Calibration of academic } \\
\text { standards }\end{array}$ & Undergraduate & $\begin{array}{l}\text { Accountancy } \\
\text { (Australia) }\end{array}$ & 6 \\
\hline $\begin{array}{l}\text { Collaborative assessment } \\
\text { on an online masters } \\
\text { programme }\end{array}$ & Postgraduate & Education & 7 \\
\hline $\begin{array}{l}\text { Feedback and peer assessment } \\
\text { Learning from composing peer } \\
\text { feedback }\end{array}$ & Undergraduate & Engineering & 8 \\
\hline
\end{tabular}


Table 1.3: Teaching ideas

\begin{tabular}{|l|l|}
\hline Topic & Chapter \\
\hline Writing-to-learn (WtL) tasks & 2 \\
\hline Paraphrasing assessment criteria & 7 \\
\hline How to set up guided marking & 7 \\
\hline How to create a marker's commentary & 7 \\
\hline Helping students understand assessment criteria (paraphrasing) & 7 \\
\hline Helping students understand feedback (paraphrasing) & 8 \\
\hline
\end{tabular}

Table 1.4: Design and review tools and questionnaires

\begin{tabular}{|l|l|}
\hline Tool & Chapter \\
\hline Module assessment design questionnaire & 3 \\
\hline Programme assessment design questionnaire & 4 \\
\hline Feedback profiling tool & 8 \\
\hline
\end{tabular}

\section{Follow-Up}

If you are interested in following up some of the ideas in this chapter, you might like to explore these resources. But you don't have to! This isn't a programme of study and this book is designed so that you can dip into sections that are relevant to your needs at any moment. I hope you will come back and explore further as your thinking develops.

\section{Reading}

Action research is suited to small-scale investigations of your practice. Jean McNiff's (2013) guide explains the theory and practice of action research.

McNiff, Jean. Action Research: Principles and Practice. 3rd ed. London: Routledge, 2013.

Hutchings et al.'s (2011) guide to the scholarship of teaching and learning (SoTL) considers how teaching colleagues can work together with students to improve higher education.

Hutchings, Pat, Mary Taylor Huber and Anthony Ciccone. The Scholarship of Teaching and Learning Reconsidered: Institutional Integration and Impact. San Francisco: Jossey-Bass, 2011. 


\section{Thinking}

Think about your disciplinary research practices. How do they differ from practices used in education, such as action research and case study research?

\section{Investigating Your Practice}

Investigate a learner. Meet informally with a learner (a current student on your programme, a past student, or a prospective student). Find out about their prior learning experiences, learning needs, concerns and ambitions.

Discuss your findings with students and colleagues. What have you learned about teaching and learning on your programme and what changes would you advise?

Investigate the learning environment. Shadow a student for a day. Find out how their day is organised, what pressures they are dealing with and what helps them study effectively. Are there aspects of the learning environment that hamper effective learning? What are they and how can they be improved?

Investigate assessment documentation, e.g. assessment information in module handbooks. What do staff and students think of the information presented? Could the information be presented more clearly? Read more about designing assessment in Chapters 3 and 4. 


\section{Chapter 2}

\section{Key Perspectives}

This chapter explores some key ideas in current thinking on assessment. I begin by considering how adults learn, since an understanding of learning guides how we design and assess programmes of study. Following this, I explore the nature of academic standards and why it is difficult for assessors to make reliable assessment judgements. An understanding of academic standards is essential for designing assessment. The teacher needs to be clear about what standard of work they expect from students and students need to know what standard they need to reach. Academic standards guide the design of formative and summative assessment, facilitating student learning and achievement.

Students benefit from being active participants in assessment, capable of self- and peer-assessing. To do this they need to be competent assessors with a good knowledge of academic standards. In order to achieve this, Tai et al. $(2018,5)$ argue that they need to develop evaluative judgement, which is defined as the 'capability to make decisions about the quality of work of self and others'. Evaluative judgement is a prerequisite for successful peer and collaborative assessment, as discussed below. Developing evaluative judgement enables students to make judgements about their own and others' work and to direct their own learning.

In this guide, students are conceptualised as active learners making links between their higher education studies and the community beyond. There is a need to design assessment opportunities that allow students to make these links and to consider how research can benefit their communities. Research-based learning (RBL) is proposed as a way forward; there is a short introduction to RBL in this chapter with more consideration given to the approach in Chapter 5. In this chapter, how students learn to communicate their work and develop oral and written 
communication skills is considered, drawing on the concept of academic literacies. This chapter concludes by considering two key concepts in assessment, namely, reliability and validity.

\section{How Adults Learn: the Concept of Communities of Practice}

How do students learn in higher education and how can they be supported to develop? To answer these questions, it is helpful to begin with some thinking around how professionals develop, including teachers' professional development. A dominant view in the literature is that professionals learn in a 'community of practice'. Since it was first proposed in Jean Lave and Etienne Wenger's much cited book, Situated Learning (1991), this idea has become hugely influential in education and professional learning programmes. They coined the term 'situated learning' to describe the experiences of apprentices learning through practice and participation in a community. Wenger (1999) argues that we are learning all the time; learning is not something that happens within the confines of educational institutions. He argues that, throughout our daily lives, we are constantly learning and that we do most of this learning through social participation in communities of practice. Wenger characterises social participation 'as a process of learning and knowing', identifying four components:

1. Meaning: a way of talking about our (changing) ability - individually and collectively - to experience our life and the world as meaningful.

2. Practice: a way of talking about the shared historical and social resources, frameworks, and perspectives that can sustain mutual engagement in action.

3. Community: a way of talking about the social configurations in which our enterprises are defined as worth pursuing and our participation is recognised as competence.

4. Identity: a way of talking about how learning changes who we are and creates personal histories of becoming in the context of our communities. $(1999,5)$

We belong to multiple communities of practice, e.g. families, work communities, disciplinary communities, and universities, and we learn through being active participants in these communities. The community 
establishes practices and shares knowledge through participation in tasks. Individuals learn through engaging and contributing to community activities; knowledge is socially constructed within the community. Wenger argues that practices owned by a community change over time; he emphasises the 'historical and social context' of a community of practice $(1999,47)$. A community of practice is not a hermetically sealed entity but part of a wider social context (Wenger 1999).

Lave and Wenger developed the idea of a community of practice through studying apprenticeships; they were interested in how novice apprentices learn and develop through participation in a community and how they experience 'identity transformation' $(1999,11)$. Wenger argued that new participants are initiated into the community's practice through 'modified forms of participation that are structured to open the practice to non-members' $(1999,100)$; Lave and Wenger $(1991,27)$ describe this process as 'legitimate peripheral participation'. Legitimate peripheral participation entails engaging in introductory tasks that initiate the new member into the community of practice. Applying this idea to higher education, undergraduate students entering the university are novices who, through participation in the community's activities, for example, research-like activities, gradually become members of a disciplinary community and begin to know and critique disciplinary practices. In online fora, inactive members who do not contribute to a discussion, but are reading posts and following the discussion, are called 'lurkers', though a more neutral term is vicarious learners. However, lurking in a community of practice is legitimate peripheral participation (Wenger et al. 2009, 9); lurkers are learning about the community, absorbing knowledge and practice, even if they do not feel ready to contribute to the discussion.

Higher education teachers belong to multiple communities of practice, e.g. disciplinary groups, research groups, professional societies, research teams and programme teams. Their experience of learning within these teams influences their beliefs about teaching and learning in their discipline. Working together as a teaching team they develop community practices around teaching and assessment, so that the academic standards on their programmes become 'socially constructed' (Sadler 2014) within the teaching team.

Introductory activities, such as Meet the Researcher (see Case study), bring students into the community of practice and facilitate learning about disciplinary thinking and research methodologies. 
Case Study: Meet the Researcher - a Legitimate Peripheral Participation Activity

Level - first year, first term, undergraduate

Discipline - psychology and language sciences

Cohort - 150 undergraduate students (home and international students) Learning approach - communities of practice and research-based learning

The activity helps introduce students to the research communities in the faculty and promotes legitimate peripheral participation. Students entering the department engage in an activity to develop an understanding of departmental research.

In induction week, the activity is explained to students and there is further guidance on the virtual learning environment (VLE) (Evans et al. 2018). Students view short, professionally made videos of 42 researchers talking about their research. The researchers were asked to answer the following questions.

What is your major research question?

Why is it important?

What have you found?

(Evans et al. 2018, 304)

Students are divided into groups of three to five and after viewing the videos, choose a researcher to interview. In order to formulate interview questions, they need to find out more information about the researcher's work. The interview lasts from 30-60 minutes and students then prepare a short presentation on the researcher to present to their seminar group (seminar groups are composed of six to ten students). Students receive guidance on how to structure the presentation and use slides. After the seminar presentation, the personal tutor gives feedback.

A follow-up survey showed that students valued the activity ( $\mathrm{n}=47$ respondents); 90 per cent agreed with the statement: 'I enjoyed meeting my allocated researcher.' And 94 per cent agreed that the Meet the Researcher activity was an 'overall good experience'. However, students complained about having to watch all 42 videos.

The researchers who participated in the activity were very positive about the experience, e.g. one commented that students were well prepared and the videos of good quality. Personal tutors also gave positive feedback, commenting, for example, on how the activity motivated 
students and helped them learn about presentation skills, the research culture in the department and interviewing skills. One student who took part in the activity, reflected at length on what he had learned and suggested that the interview should be about 'the process of becoming a researcher' (Evans et al. 2018, 309) as well as the research topic.

Dwyer (2001) reported on a similar activity in geography. She saw the value of the activity in linking teaching and research and in introducing students to geography theory and philosophy. However, her study on the students involved in the activity suggested that they had variable experiences. She proposed facilitating a workshop before and after the activity to draw together key ideas.

This sort of activity is a useful identifying activity (Levy and Petrulis 2012; and see Chapter 5 below for more on identifying activities) that begins to induct students into ways of thinking within the discipline and enables them to enter a community of practice. The activity can be adapted so that it is more open, with students deciding how they will investigate and report on the researcher (suitable for postgraduate programmes), or more controlled with allocated researchers and set questions (more suitable for first year undergraduate programmes). The activity can be extended by involving researchers in talking about peer review comments on recently published work. The researchers share their responses to the feedback and describe how they used peer review comments to develop their work. This activity mirrors experiences that undergraduate and postgraduate students will have of receiving feedback on academic work, and hopefully provides them an insight into academic disciplinary practices. Both students and researchers are engaged in receiving and making sense of feedback; both are members of the same community of practice, though students may be peripheral participants.

\section{Further Reoding}

Evans, Julie, Alex Standen, Alastair McClelland and Siir Saydam. 'Meet the Researcher: The Use of Interviews to Connect First-Year Undergraduate Students to Research Staff at UCL'. In Shaping Higher Education with Students: Ways to Connect Research and Teaching, edited by Vincent C.H. Tong, Alex Standen and Mina Sotiriou, 303-10. London: UCL Press, 2018.

Dwyer, Claire. 'Linking Research and Teaching: A Staff-Student Interview Project', Journal of Geography in Higher Education 25, no. 3 (2001): 357-66. 


\section{Academic Standards}

Academic standards are the standards students are expected to achieve in their assessed work on a course. These standards are often described in written documentation such as subject benchmark statements (see Glossary) and assessment criteria. Markers make assessment judgements about the quality of student work, drawing on their understandings of academic standards (see Chapter 6 for a discussion of marker reliability). These judgements are based on the individual marker's construction of the standard, which will be influenced by a range of factors, such as experiences as a learner, as a marker and disciplinary practices. The range of influences on the markers' standards can create very different judgements on the quality of student work; documentation may be helpful, but written standards are open to interpretation. Documents and regulations do not create standards - practitioners do, through engaging in activity, such as calibration (Sadler 2014; Watty et al. 2014), creating socially constructed (Sadler 2014; Shay 2005) standards through discussion of exemplars, and a common interpretation of documented standards (see Chapter 6).

A team of teachers, working together on assessment can be conceptualised as a community of practice. The team may come from different disciplinary communities, each with their divergent epistemological understandings. With the rise in interdisciplinary programmes of study and new fields of study, e.g. biomedical engineering, academics and students are increasingly working in multi-disciplinary fields of study. Programme teams hail from a range of disciplines, with potentially different practices and epistemological understandings. In Lave and Wenger's terms, individuals in those teams will belong to several communities of practice; for example, their initial disciplinary community of practice, their professional community of practice, and their interdisciplinary team community of practice. These individuals develop a complex range of identities and values. Teams that work closely together and engage in calibration activities can create socially constructed academic standards and develop agreed assessment practices (e.g. around assessment design, academic standards, range of grades, good quality feedback). New markers joining the group are initiated, through legitimate peripheral participation into assessment practices and can develop an understanding of socially constructed standards and how to uphold them (see Chapter 6 for a fuller discussion). 
In a team with a range of disciplines, the interplay between different communities of practice, and the overlap between different professions can be a source of conflict. A community of practice is socially constructed; practices are influenced by power dynamics within the group (hierarchies) and can change over a period of time as the membership of the community changes. Written rules and regulations cannot 'fix' the practices and standards in the group, as the written rules are always open to interpretation. Power dynamics in the team can mean that minority voices are silenced (Wenger-Trayner et al. 2015, 15-16). In a programme assessment team, the team would work together to create shared academic standards about the quality of student work. Through participation in activities such as marking, moderation and harmonisation, they would agree academic standards. As the membership of the team changed over time, practices and standards would also shift as new members and external influences, such as government policies, influenced the community. This perspective implies that academic standards can be shared within a community but cannot be fixed over time as shifting membership in the group will create new interpretations of standards.

Students are also participants in a disciplinary community of practice, though at the early stages of their study programmes this participation will be peripheral. As they move from the periphery, students need to develop an understanding of the community's standards. This is often interpreted as explaining assessment criteria to students, but as I have argued above, assessment criteria do not describe standards. Students gain an understanding of academic standards through participation in the assessment practices of the community; this entails involving students more in assessment processes; for example, as peer reviewers, peer assessors and in collaborative assessment. However, we know that students who have engaged in peer and collaborative assessment are often critical of their experiences (Wilson et al. 2015). The discussion below outlines some of the problems with peer and collaborative assessment, and possible solutions (see also Chapter 7).

Research on marking in higher education provides evidence that teachers draw on a range of tacit knowledge in making a judgement about the standard of students' work, and this practice of drawing on tacit knowledge results in variation in judgements (Sadler 2014; Bloxham et al. 2015). Regulations and criteria are designed to promote common standards, but they are limited in that the discourse used needs to be interpreted and can be interpreted differently by different markers and teams of markers. In the UK, the Quality Assurance Agency (QAA) 
facilitates the writing of subject benchmark statements, which 'describe the nature of study and the academic standards expected of graduates in specific subject areas. They show what graduates might reasonably be expected to know, do and understand at the end of their studies' (QAA 2019a).

\section{The Role of Exemplars}

Exemplars can help teaching teams to explore their understandings of criteria and, through discussion, create either consensus or a better understanding of differences in standards. Exemplars are used in premoderation (Bloxham et al. 2016) or harmonisation meetings, allowing the team to share their marking judgements and through discussion, explain what they value. These values can be more clearly illustrated through reference to exemplars, helping the team to come to a more consensual understanding of academic standards. For example, it may be difficult to describe criticality, but, by referring to exemplars, teachers can explain what they mean by 'criticality' and, importantly, what that looks like in students' work. With a range of exemplars, different levels of criticality can be explored, e.g. exemplars can show both excellent and borderline attempts at criticality.

Where national disciplinary standards are required, an approach piloted in Australia entails using calibration activities to construct national standards. Disciplinary teams from a range of institutions engage in a scaffolded discussion of exemplars, in order to agree the characteristics of excellent, good and borderline assignments at threshold and final year degree classifications (Watty et al. 2014, see Chapter 6 for a fuller discussion). It is not just teachers who need to develop assessment literacy and engage in calibration of standards; learners also need to have a clear understanding of the academic standards on their programme and what good quality work looks like. This aspect is often neglected in higher education; quality assurance processes often require programmes to describe academic standards through assessment briefs and assessment criteria and to ensure that students have this information. Teachers provide feedback to students, explaining the quality of their work. However, students find the professional discourse in briefs, assessment criteria and feedback difficult to understand (Price et al. 2010; Ivanič et al. 2000). It also takes time for them to acquire assessment literacy and develop a full understanding of the disciplinary standards. Sharing and discussing exemplars can 
help develop a shared understanding of academic standards; sharing standards brings students into the disciplinary community of practice and prepares them for involvement in other assessment practices (see Chapter 7).

\section{Peer and Collaborative Assessment}

With the emphasis on assessment for learning, rather than assessment of learning, more attention has been given to involving students in assessment (Sambell et al. 2013). There are good reasons for this; the better students understand assessment standards and processes and develop assessment literacy around standards, the more likely they are to produce work which reflects their capabilities. Ways of involving students in assessment include collaborating with them to design the task and assessment criteria. As students develop competency in making assessment judgements, they can be involved in assessing and giving feedback to peers' work. While peer assessment has been widely advocated and researched (Wilson et al. 2015), it is less widely implemented. Research literature on peer assessment provides a mixed view of its effectiveness (Wilson et al. 2015; McConlogue 2012; Kim 2009). Students frequently complain about the quality of their peers' marking (Wilson et al. 2015; Cartney 2014; McConlogue 2015). Other issues reported in the literature are friendship marking and collusion, poor quality feedback from lazy peers, incorrect feedback and unreliable marking with a wide variation in marks (Wilson et al. 2015; Cartney 2014).

Many of these problems occur because students are not in a position to make good quality judgements about their peers' work, and lack competency to make reliable judgements. Preparation is essential in order to develop competency and integrity (Carless 2013) in peer assessors. This can be done through staged activities planned across a programme of study; students can begin to develop an understanding of academic standards on the programme and can then more reliably judge the quality of their own and others' work (see Chapter 7 for details).

\section{Academic Literacies}

The writing in the disciplines (WID) movement in the US (Crossley et al. 2017; Russell 2002) and academic literacies scholars in the UK (Lea and 
Street 1998; Lillis et al. 2015; Lillis and Scott 2007; Hyland 2009; Ivanič 2000) have studied the complexities of writing in higher education. When students begin their studies, they are entering a disciplinary community with its own, unique discourse. Disciplines have specific epistemological understandings, sometimes these overlap with other disciplines and sometimes they are contradictory. Students need to become part of this disciplinary community through practising the specific writing genres used to communicate e.g. lab reports, briefing reports, case studies, essays, reflective journals, blogs. Each of these genres have particular rhetorical conventions; for example, in some disciplines the use of the first person ' $\mathrm{I}$ ' is avoided, and the passive voice is used extensively while in others the first person is used extensively, especially in reflective journals. These genres and their rhetorical conventions may not be familiar to students, especially students from non-traditional backgrounds, so it is important that programmes of study are planned to provide opportunities to practise and learn disciplinary discourse.

Within academic disciplines there are established ways of thinking, investigating, creating and communicating knowledge (Entwistle 2005). As expert members of their discourse communities, academics are skilled in ways of thinking in their discipline and in communicating this thinking. Research on academic literacies has provided evidence of disciplinary differences in the way knowledge is constructed and communicated. The academic's view of what counts as evidence, how arguments are constructed, how analysis is carried out and what counts as criticality, are all influenced by the underlying epistemological belief system of the discipline. An example of how this affects students comes from an empirical study in a widely cited paper by Lea and Street (1998). Lea and Street present a case study of a first-year student who received widely different grades for his essays; one in history and one in anthropology. For the history essay, he drew on his previous experiences of writing school essays and received a good grade and feedback. For the anthropology essay, a new discipline for him, he received a fail grade and comment that he needed help with writing and structuring an argument. The authors make the point that the different grades don't reflect the student's writing skills, but rather the different epistemological stances of the markers. Learners need guidance to enter particular discourse communities, understand ways of thinking within a discipline and how to communicate that thinking within disciplinary rhetorical conventions.

Writing is a valuable tool for developing thinking. Through short writing tasks and writing-to-learn tasks, students can explore disciplinary 
ideas and practice ways of expressing these ideas in writing. Short writing tasks can help develop student thinking and writing, without creating additional work for the teacher (QMUL 2019). The Thinking Writing website has examples of short, writing-to-learn tasks which can be used in lectures, seminars and online discussion fora. For example, in

Teaching ideas - Writing-to-learn tasks

The Thinking Writing website suggests these writing-to-learn tasks 'for introducing writing to lectures and seminars:

Before the start of a lecture or seminar ask your students to write down the main points they learnt in the previous week and what they hope to learn today.

Stop in the middle of your lecture and ask your students to formulate in a couple of sentences what they think is the main point so far, or a question/confusion they have in their minds.

Vary the kind of prompts you give, so that students have to do different kinds of thinking. For example, ask students to write for a minute or two about their own experiences of some concept or phenomenon the lecture or seminar is covering. This may help make connections that help to build understanding.

At the end of your lecture/seminar ask students to summarise what they feel they have learnt or pose a question. Collect a sample in or ask individuals to read theirs out - the students have had to think, and you've had valuable feedback which may alter what you do next time you meet.

Writing can help students to explore concepts and identify what they know and what they need to learn more about. Getting students to write means they externalise what they know (or, as usefully, recognise what they don't know) and how they are thinking, in writing. Once they have done this, they can do things with what they've written: look back at it, speak about it, compare it, shape and extend it.

Ask your students to pick out a key phrase or word in what they've written, put it at the top of a new page, and write for a further two minutes on that phrase or word. This will extend their thinking and begin to give shape to their initial thoughts.'

(The Thinking Writing website, QMUL 2019) 
a lecture you can stop at an appropriate point and ask students to spend a couple of minutes individually writing down the main points of the lecture. Often lectures introduce a lot of new content and processing this information can be demanding for students. A short pause during which they have time to reflect, remember and formulate understandings of the main points, helps to consolidate learning (see box on previous page).

For students, moving from short writing tasks to longer examples of disciplinary writing, should involve the teacher designing and setting short writing assignments. For example, Troy et al. (2016) suggest tasks such as these in engineering as an alternative to longer lab and project reports. The different tasks help prepare students for the kind of thinking and writing they will need for longer, more complex assignments. The tasks are categorised as: Explain a Concept, Explain a Problem, How Stuff Works, Real World Example, and Pick a Side (all quoted from Troy et al. 2016).

\section{Short Writing Tasks in Engineering}

\section{Developing on Assignment}

\section{EXPLAIN A CONCEPT}

For Explain a Concept questions, instructors are asking students to explain different terminology, equations, and theory in their own words. These types of problems typically involve minimal deep thinking on the students' parts, and answers are often found within supporting texts such as textbooks. Example: 'In your own words, explain the meaning of Bernoulli's equation.'

\section{EXPLAIN A PROBLEM}

Instructors looking for students to understand the reason behind solutions to problems can opt for assigning Explain a Problem questions. Explain a Problem questions are potentially the easiest to assign because they can be created simply by placing the words 'Explain' or 'Why?' at the end of any calculation-based problem. Example: 'Calculate the maximum velocity achieved by wheel A and wheel B. Explain why they are different.' The format of such explanations can be as detailed or simplistic as the instructor desires. 
Assigning problems that ask students to explain how different objects work helps students link classroom concepts to concrete objects, in turn reinforcing the real-world applications of their learning. How Stuff Works problems require students to understand concepts in more detail compared to previously discussed writing questions. Example: 'How does an air compressor work?' The instructor can prompt students with concepts to include or leave the problem open-ended.

Real World ExAMPLE

Similar to How Stuff Works problems, a Real World Example question requires students to link theory and concepts they have learned in class to objects they interact with on a regular basis. The level of learning required for Real World Example problems is higher than Explain a Concept or Explain a Problem, and help students connect knowledge to practice. Example: 'Explain how the water distribution system of a tall building works and use a specific example to help illustrate.' These questions are effective at linking classroom material to actual examples, which is an important motivator for student learning.

PICK A SIDE

Pick a Side problems require students to link information learned in class to real world situations, but also requires them to take learning a step further and defend a particular side. Typically, these questions look at engineering problems from a broader perspective like the environmental, societal or political viewpoint, and as such are good questions for addressing learning outcomes beyond the technical concepts. Example: 'Choose an environmental, economic, or societal standpoint, and argue for or against the construction of the Keystone XL Pipeline.' (Troy et al. 2016)

\section{Research-Based Learning}

Research-based learning (RBL) covers a range of practices, namely, inquiry-based learning, object-based learning, case studies or scenariobased learning and problem-based learning. These activities can be 
more or less structured depending on the programme and the expertise of the teachers and students involved. Through well-designed activities involving research, students learn about knowledge building and creation in their discipline, and how disciplinary knowledge affects their profession and their communities.

There are a range of RBL practices; some focus on requiring students to learn research skills, while others are more ambitious and aim to initiate students into the disciplinary community as an equal knowledge builder (Brew 2006). Levy and Petrulis (2012) propose modes of RBL ranging from identifying to authoring. Identifying characterises work at the start of a programme where students will be carrying out research tasks designed by the teacher with the aim of exploring existing knowledge. Authoring characterises research tasks where students are involved in designing their own studies, critiquing existing knowledge and are engaged in knowledge building. Typically, authoring research would be carried out by final year students or postgraduate students, but this is not exclusively true. It can be difficult for students to make much progress in a research study in the space of a year; Chang overcame this limitation by developing an 'inheritance mechanism' (2005, 391); this entailed students documenting their research and findings and then handing these over to the next cohort. In this way, the next group makes more rapid progress, adds to the previous group's work, and over a period of years there is accumulation of data and knowledge that leads to expertise in the field. Chapter 5 discusses RBL more fully, provides example tasks and a discussion of the advantages and challenges of designing RBL.

\section{Validity and Reliability}

A valid assessment measures what it claims to measure at the appropriate level. Validity is linked to the aim of the programme and the level of programme. If students have learned about $\mathrm{X}$, and are then tested on $\mathrm{Y}$, the test is not valid. Reliability means that assessors make similar judgements about the quality of students' work; reliable assessors have a common understanding of the standards students are required to meet and how these standards are represented in the assignment. With this understanding they are able to make similar judgements about student performance.

Validity and reliability are often at variance. Setting a task which requires students to be creative, critical thinkers, and then assessing it through multiple-choice questions which focus mainly on factual recall, 
is an example of an assessment that is high in reliability but low in validity. The type of assessment task and complexity of learning affect validity and reliability. More complex tasks are often high in validity as they enable students to demonstrate higher order achievement, but assessing these tasks is more problematic. Judgements on the quality of students' work are often subjective and less reliable.

The assessment tasks in a module need to be designed so that they provide an opportunity for students to learn, show what they have learned and demonstrate that they have achieved competency in the knowledge, skills and becoming the module covers. If assessors believe the assessment tasks provide these opportunities, then the tasks are seen as having validity; similarly, students perceive tasks as valid if they provide them the opportunity to explore their understandings of module knowledge and skills.

Designing valid tasks can be tricky and difficult to balance with the need for reliability in assessment judgement (see Chapter 5); in general, the greater the task validity, the less reliable the assessment judgements. The nature of learning in higher education typically requires assessment tasks to be open-ended, ill-structured tasks (Voss and Post 1988), which provide opportunities for students to demonstrate higher order thinking, such as synthesis, analysis, argument and criticality. Ill-structured problems are 'open' tasks with no one correct answer. For example, a well-structured task such as converting 50 pounds to dollars at the current rate of exchange would have one 'correct' answer, so the assessors' job is fairly straightforward. Assessing student responses to an ill-structured problem, such as 'What was Einstein looking for when he discovered relativity?' [I'm indebted to Professor David Dunstan, Professor of Experimental Physics, Queen Mary University of London for this question] is less straightforward. Answering the question requires analysis, judgement and creation of an argument with supporting evidence. Assessment of ill-structured tasks is far less reliable than assessment of well-structured tasks (see Chapter 5 for a detailed discussion of marker reliability). Typical assessment tasks in higher education, such as essays, reports, oral presentations, objective structured clinical examination and project-based learning are all illstructured tasks.

Studies on marker reliability in higher education have found evidence of huge variations in assessor judgements (Williams and Kemp 2019; Bloxham et al. 2015; Tisi et al. 2013). Williams and Kemp investigated agreement between internal and external markers of master's dissertations. Of the 324 theses grades investigated, only 9 per cent 
required moderation. However, most theses were awarded $\mathrm{B}+$ to $\mathrm{A}$ grades. The small range used makes agreement more likely. They argue that assessment criteria do not make marking more reliable and that 'there simply is no objective way to determine the academic value of a thesis' (Williams and Kemp 2019, 769).

One reason advanced for this variation is that assessment tasks are ill-structured, and a range of responses are possible, making reliable judgements more difficult. Ways of increasing reliability centre around developing documentation of standards through explicit assessment criteria and the use of rubrics in order to pin down what markers should be attending to when making a judgement. Documenting standards involves writing standards in explicit language. Rubrics contain both assessment criteria and a description of levels of attainment. Panadero and Jonsson (2013, 142-3) provide an example of a rubric for summary writing. For one criterion, 'secondary ideas', high-level attainment is described as expressing 'important ideas ... with an economy of words'. In the next level down, there is an expectation that students will express 'important ideas ... but with an excess of words'. Markers need to interpret what an 'economy of words' and an 'excess of words' looks like in students' work. Similarly, for the 'precision of terms' criterion, high-level attainment is described as choosing words that are 'efficient and concise' while at the next level 'words chosen are to some extent concise'. The rubric makes use of 'hedge words' (Sadler 2014, 279) in describing levels. For example, hedge words such as 'to some extent' and 'more or less' are used. The marker needs to make a judgement as to what 'to some extent' would look like in students' work. The aim of the rubric is to make marking more reliable and standards more explicit, but the fuzziness of the hedge words thwarts this aim.

Research shows that markers interpret rubrics and assessment criteria differently. For example, critical thinking features strongly in assessment in higher education, but interpretations of what is good or poor quality critical thinking differ. Studies show that markers interpret criteria differently, ignore criteria and add their own personal criteria (Bloxham et al. 2011). There is also evidence that markers make holistic judgements about the quality of student work and then use criteria to retrospectively justify their judgements (Grainger et al. 2008). Moreover, Sadler argues that the nature of learning in higher education, and the complex tasks that students are involved in, makes it impossible to tie down standards into a small set of explicit assessment criteria and level descriptors (Sadler 2014). Judgement draws on a vast range of tacit knowledge (Polanyi 2009) drawn from previous learning and 
previous experience of marking. This rich bundle of tacit knowledge is particular to each marker, so it is important that markers have opportunities to explore and compare their judgements. Standards are held within disciplinary communities and it is only through discussion in these communities that markers can reach agreement on standards. Watty et al. (2014) describe a calibration activity where a disciplinary community came together to discuss exemplars of students' work, compared their judgements and tried to reach consensus. There is increasing research on calibration as a way of establishing academic standards within a discipline (Watty et al. 2014; O'Connell et al. 2016). Chapter 6 discusses ways of bolstering marker reliability.

\section{Follow-Up}

This chapter provides an overview of key ideas in higher education; there are many ideas to follow-up. Choose an idea you are interested in and read the relevant chapter, which has further ideas for reading and follow-up activities.

\section{Reading}

Explore Wenger's writing on communities of practice. Start with Wenger, Etienne. Communities of Practice: Learning, Meaning, and Identity. Cambridge: Cambridge University Press, 1999.

\section{Thinking}

Think about academic standards on your programme. How are standards shared within the programme team and with students?

\section{Investigating Your Practice}

Investigate writing on your programme. How many different genres are students required to write? What preparation do students receive? Are there any writing-to-learn tasks or short writing assignments? Are there opportunities to submit and receive feedback on writing drafts?

Investigate which assignments students find most difficult and why. Ask final year students to tell you which assignments they struggled with and what caused them difficulties. 



\section{Part 1 \\ DESIGNING ASSESSMENT}





\section{Chapter 3}

\section{Designing Assessment for a Course Unit/Module}

This chapter will help you think through the process of assessment design for your course unit or module. A course unit or module is a discrete unit of study, involving teaching time (either face-to-face or online), individual study, possibly group work and typically at least one summative assessment. In the UK the size of modules vary, some may run throughout the academic year while others may be short, one-week intensive courses. Regulations stipulate how many hours of learning (and thus how many modules) need to be completed for a degree programme. Learning hours are measured in credits; in the UK, fifteen credits are equivalent to 150 notional hours of learning (this includes taught sessions, self-study time and time spent on assessments). A bachelor's degree with honours is typically equivalent to 360 credits and a master's degree, 180 credits in England, Wales and Northern Ireland (see QAA 2014). Modules are combined to make a degree programme. There can be considerable flexibility in how modules are combined and a wide range of choice for students in some programmes. In other programmes of study, typically professional programmes, there may be many compulsory core modules with very little choice. Whether you are working in a modular system or not, you will be involved in designing course units and appropriate assessments. Early career teachers are often asked to design new course units/modules, and once they gain more experience, may be involved in programme design. For this reason, the chapter on course unit/module design comes before the chapter on programme design (Chapter 4) though you are encouraged to read both chapters. This chapter covers the following. 
- Backward design to help you think about what you want students to learn from the course unit/module and how the course unit/module aligns with others in the programme (see Chapter 4 for programme-level assessment design). This chapter proposes that you begin by thinking about what you want students to know, do and become as a result of the course unit/module and to consider how the course unit/module fits in with and supports student learning across the programme.

- The concept of validity, ensuring that the assessment tasks test the aims of the course unit/module, is discussed and strengths and weaknesses of different task types are compared.

- Ways of developing clear assessment guidance and communicating these to students are discussed.

- An introduction to designing authentic assessment tasks and tasks that involve external participants (more detail can be found in Chapter 5).

- Assessment design should include setting formative tasks which help students develop the knowledge and skills they need to tackle summative assessments. This involves developing writing and speaking and designing opportunities, which give students practice in the assessment genre and appropriate rhetorical conventions (see Chapter 2 for more on academic literacies).

\section{What Should you Assess and How Should you Assess It?}

Start with a clear idea of what you want students to learn in your course unit/module and how their learning links with learning in the programme. In many fields, content dominates, and syllabi are often packed full of content that students are expected to learn and memorise. Assessment of this learning then becomes a matter of checking that students have a good knowledge of all this content; typically, in content heavy programmes this is done through multiple-choice questions or short answer questions, especially in science, technology, engineering and mathematics (STEM) subjects. However, these methods are limited when it comes to assessing higher order thinking and complex learning, and the construction of valid multiple-choice questions requires expertise.

In Chapter 2, complex learning was discussed. In higher education, learners are concerned with critically evaluating theoretical papers and research findings, with constructing coherent arguments and 
understanding professional practice protocols. Crucially, learners are expected to become part of a disciplinary and professional community (Sambell 2013; Barnett 2009), understand ways of thinking and practising (WTP) within a discipline (Entwistle 2005) and understand the rhetorical conventions used to express that thinking in spoken and written language (Bean 2011). Barnett expresses the belief that higher education can be transformational; learning in higher education is not a matter of memorising content, acquiring knowledge and skills; it is a '... vehicle for effecting changes in human beings ...' $(2009,432)$. He views the curriculum, not as a series of content to be learned, but as transformational. Knowledge in the modern world is not static; knowledge is contested and open to change. Barnett describes the world as 'supercomplex', open to manifold interpretations which create uncertainty and insecurity $(2009,439)$. Having knowledge and skills does not help an individual cope with this supercomplexity, but, through personal development and reflection, students' world view can be transformed. As they become members of a professional or knowledge community they develop their sense of being in the world and their understanding of their profession becomes based on 'well-founded claims' (Barnett 2009, 432) arrived at through a critical stance.

Entwistle comments on the importance of recognising the limitations of learning outcomes and designing open-ended assessments (or ill-structured tasks, Voss and Post 1988), to capture complex learning.

While WTPs, by their very nature, are more difficult to assess, limiting the assessed outcomes to more precisely defined outcomes is potentially damaging to students' understanding of the subject itself. The broader understanding of the subject can be encouraged through more open-ended forms of assessment and through ensuring that students cover general or problem-based questions or assignments. (Entwistle 2005, 79)

A syllabus cannot be a description of course unit/module content. In some fields, such as medicine, the content to be covered has increased exponentially; adding more content to a saturated syllabus is not an option. Focusing on developing the learners' capacity to understand how members of the academic and/or professional community think and how knowledge is created within that discipline, enables students to critique and deconstruct knowledge. Learners are enabled to independently explore areas of interest in the discipline, equipped with the tools needed to understand, question and construct new knowledge. They 
become a part of the disciplinary community, contributing to knowledge building in the discipline and/or in professional practice.

\section{Backward Design}

Assessment is a fundamental part of learning and has more impact on student learning than teaching. Assessment '... directs attention to what is important. It acts as an incentive for study. And it has a powerful effect on what students do and how they do it' (Boud and Falchikov 2007, 3). But often assessment is the last item to be considered in course unit/ module design. Backward design ensures better connections between assessments by starting with the last assessment task and planning teaching activities around assessments. The earlier assessments are 'scaffolding assignments' (Bean 2011, 96) providing students opportunities to develop the knowledge and skills needed for the final assessment. Assessment tasks need to be motivating, relevant and create opportunities for learning. As Graham explains:

With this approach to planning, teachers begin with a clear statement of goals and design assessments to determine student progress toward those goals. The selection and organization of activities, texts, and materials into daily plans come last in the teacher's thinking process. Through this lens, assessment provides opportunities for students to demonstrate their learning in productive ways, including, but not exclusive to, final performances based on complex learning goals. $(2005,609)$

The planning process starts with an 'overarching question', and assessment is designed to explore this question. The overarching question and learning activities need to be appropriate for the level of study. Teaching and learning activities support learners to complete the assessments. Backward design aims to ensure that assessment is fully integrated into the course unit/module and programme.

Having worked out what you want students to learn, the next step is to design a syllabus to support that learning, thinking and communicating, with valid assessment tasks that enable students to further their learning and share what they have learned. For example, in a first year undergraduate political analysis course unit/module, the goal was to help students understand the fundamentals of political analysis and to prepare them to write a fine-grained analysis of political texts. The 
overarching question was 'What is Politics?'. Assessment was through an essay. Learning activities involved analysing papers presenting contrasting views of politics, discussing these views in seminars, writing summaries of key papers and writing-to-learn activities (Chapter 2). To gain an understanding of standards on the course unit/module, students marked three essays from a previous year and discussed grades and comments. Writing activities, including synthesising ideas from a range of sources using a reading grid, prepared students for expressing their ideas in appropriate disciplinary discourse. A draft essay, drawing on the texts studied in seminars, was submitted and feedback provided by the seminar leader. Students had the opportunity to ask questions about the feedback and areas for development before submitting their essay for summative assessment at the end of the first term. (This video shows the course unit/module leader talking about fine-grained analysis and using an exemplar student text to illustrate his talk: http://www.thinkingwriting.qmul.ac.uk/node/196.)

Scaffolding tasks guide students' thinking and help initiate students into ways of thinking in the discipline. Thinking Writing provide a series of worksheets guiding students' reading of literature in geography (see below). The first worksheet, reproduced in the following box (Thinking Writing 2019), requires students to identify key sentences in an article and also sentences they cannot understand. The worksheet gives practice in paraphrasing and citing references; students practise expressing their opinion of the article in disciplinary discourse.

\section{Geographical Ideas in Practice \\ Worksheet 1: Reading and discussion}

Theme:

Due date:

Reading(s):

Read the article suggested by your tutor and complete the following activities.

1. Make a list of the key terms in the field; make sure you know what they mean as you will be discussing them in the next tutorial.

2. After/while reading the article, write down the following (your tutor will give you one or two of these): 
- the sentence/paragraph that you feel is most important in the article

- the sentence/paragraph that you disagree with most, or feel has the most problems

- the sentence/paragraph that you just cannot understand or see the significance of

- the sentence/paragraph that you like the most

- the sentence/paragraph that you feel has the most striking piece of data/information in it.

In addition to this, include the citation and the full reference for the article in the correct form.

3. Rewrite the sentence/paragraph in your own words, again using a citation in the text. You do not have to repeat everything from the original, but you do have to cover the main points.

For example:

Watson $(1980,357)$ believes that the majority of people find writing hard.

or

The majority of people appear to find writing hard (Watson 1980, 357).

4. Write a paragraph of five to six sentences that explain why you chose this section, and why you feel it is most important/has problems/is most striking/etc. If you can, try not to use the words 'I think ...'.

'Writing - in the sense of producing texts composed of written words seems to be difficult for most of us.' (Watson 1980, 357)

\section{References}

Watson, P. 'Conformity and commitment in writing', Visible Language, 14 (1980): 351-63.

Source: Worksheet from Thinking Writing. www.thinkingwriting.qmul.ac.uk 


\section{The Trouble with Intended Learning Outcomes}

Intended learning outcomes (ILOs) describe the knowledge, skills and competencies which are to be learnt in the course unit/module. They attempt to describe what the student will be able to know and do, and to what level by the end of the course unit/module. The allure of ILOs is the assumption that learning can be precisely described, and assessment tasks designed to measure to what extent students have achieved the outcomes. But, from what we have discussed about the nature of learning in higher education (Chapter 2) and the nature of students' performance and judgements about the quality of that performance (see Chapters 2 and 5), such precise 'codifications' (Sadler 2014) and specification of learning and student achievement appears to be limiting and impossible. Hussey and Smith (2008) point out that ILOs have become part of a process of monitoring and evaluating higher education. However, the nature of learning in higher education, the complex learning that students are involved in and the ill-structured tasks (Voss and Post 1988) that are necessarily set, make precise specifications of learning outcomes difficult. Hussey and Smith (2008) argue that ILOs are part of a process that tends towards the commodification of knowledge (2008, 221), but contend that learning in higher education cannot be neatly commodified and specified. Similarly, Rotthoff argues that in medical education, competency-based education which depends on ILOs is inappropriate because it is, '... poorly suited to highly skilled professions [...] such as doctors because they require highly complex skills such as analysis, judgment and reflection, professionalism and empathy. These [...] cannot be adequately achieved with the predominant methods of didactic learning objectives' $(2018,1)$. A narrow focus on competencies is detrimental as medical students need ill-structured assignments in order to develop these complex skills.

\section{Motivating Learners Through Authentic Assessment}

'Authentic assessment' has been coined to describe assessment tasks which link knowledge with the kind of problems we face in society (Villarroel et al. 2018). Authentic assessment aims to help students develop strategies for applying knowledge and solving problems. Authentic tasks may take the form of scenario-based learning, case studies, research-based learning, object-based learning and problembased learning (see Chapter 5). Authentic tasks may be carried out in 
groups to replicate teamwork in professional and community contexts. Authentic assessment tasks, when well-designed, are inherently meaningful and relevant' (Sambell et al. 2013, 12) and have long-term value fitting Boud and Falchikov's (2007) description of sustainable assessment. Authentic tasks may involve students producing work which is not viewed as academic but has a clear link with professional practice, such as information leaflets for patients on health care issues, videos of case studies for psychiatric practice, briefing reports for charities and non-governmental organisations and mathematical teaching resources for teaching maths in schools. Other tasks may involve students in more typical academic work, such as creating annotated bibliographies, collaborating in writing articles for journal publication, or a book chapter or edited book. Chapter 5 has a full discussion of ways of involving external bodies in assessment and further examples of authentic assessment.

These innovative assessment tasks can be hugely motivating for students but can also cause stress. New forms of assessment (new genres) which are unfamiliar to students can cause anxiety. Students prefer familiar assessments; Iannone and Simpson (2017) discuss the influence of discipline and institutional contexts on students' perceptions of summative assessment. In a mixed-methods study of education and mathematics students in the UK they found that mathematics students preferred closed-book exams over projects, while education students preferred projects and dissertations, which they considered to be better at distinguishing 'those who are good at academic studies in education from those who are poor at academic studies in education' (Iannone and Simpson 2017, 789). Both mathematics and education students thought multiple-choice exams to be a poor discriminator of ability. They concluded, 'In short, students in our studies have distinct epistemic beliefs and these appear to be one of the factors influencing their perceptions of assessment, and these are grounded in disciplinary differences' (Iannone and Simpson 2017, 798).

Table 3.1 sets out some common assessment methods and their advantages, disadvantages and disciplinary match. In choosing an appropriate assessment, you need to think about:

- the time taken to plan and design the assessment

- the knowledge, skills and competencies you want learners to develop

- the disciplinary epistemic beliefs which influence assessment

- the familiarity of the assessment to students 
- the ease of administration

- the workload for both students and teachers

- the amount of preparation and practice students need (this increases with lack of familiarity)

- $\quad$ the validity of the tasks

- marking reliability (see Chapter 6 for a discussion of academic standards and marker reliability).

Table 3.1: Advantages and disadvantages of types of assessment (adapted from Epstein 2007)

\begin{tabular}{|c|c|c|c|c|}
\hline $\begin{array}{l}\text { Assessment } \\
\text { type }\end{array}$ & $\begin{array}{l}\text { Marker } \\
\text { reliability }\end{array}$ & Advantages & Disadvantages & $\begin{array}{l}\text { Typically } \\
\text { used in }\end{array}$ \\
\hline $\begin{array}{l}\text { Multiple- } \\
\text { choice } \\
\text { questions/ } \\
\text { Single best } \\
\text { answer } \\
\text { questions }\end{array}$ & High & \begin{tabular}{|l|} 
Has potential to \\
assess analysis \\
and problem- \\
solving but often \\
used to assess \\
memorisation of \\
'facts'. \\
Quick to mark. \\
Can use software \\
to mark and set \\
question. Can \\
build up a question \\
bank. \\
Provides fast \\
feedback and \\
can be done \\
formatively online \\
with feedback. \\
\end{tabular} & $\begin{array}{l}\text { Difficult to write } \\
\text { good quality stems } \\
\text { and distractors. } \\
\text { Encourages } \\
\text { guessing. } \\
\text { Difficult to assess } \\
\text { complex learning. }\end{array}$ & $\begin{array}{l}\text { Medicine, } \\
\text { health, law } \\
\text { and the } \\
\text { sciences }\end{array}$ \\
\hline $\begin{array}{l}\text { Oral exam } \\
\text { (viva) }\end{array}$ & $\begin{array}{l}\text { Low unless } \\
\text { markers } \\
\text { engage in } \\
\text { calibration } \\
\text { activities } \\
\text { (see } \\
\text { Chapter 5) }\end{array}$ & \begin{tabular}{|l|} 
Good for checking \\
knowledge and \\
clinical reasoning. \\
Often used to deter \\
plagiarism. \\
Can be good \\
for synoptic \\
assessment, \\
connecting several \\
modules. \\
Can record \\
and review \\
to moderate \\
and check on \\
standards.
\end{tabular} & $\begin{array}{l}\text { Can be time } \\
\text { consuming } \\
\text { and difficult } \\
\text { to organize, } \\
\text { especially with } \\
\text { large classes. } \\
\text { Risk of hidden bias } \\
\text { (gender, race etc.). } \\
\text { Examiners need } \\
\text { professional } \\
\text { development; } \\
\text { often two } \\
\text { examiners } \\
\text { required. } \\
\text { Can be extremely } \\
\text { stressful for } \\
\text { learners. }\end{array}$ & All disciplines \\
\hline
\end{tabular}




\begin{tabular}{|c|c|c|c|c|}
\hline $\begin{array}{l}\begin{array}{l}\text { Assessment } \\
\text { type }\end{array} \\
\end{array}$ & \begin{tabular}{|l|}
$\begin{array}{l}\text { Marker } \\
\text { reliability }\end{array}$ \\
\end{tabular} & Advantages & Disadvantages & $\begin{array}{l}\text { Typically } \\
\text { used in }\end{array}$ \\
\hline Essay & \begin{tabular}{|l|} 
Low, unless \\
markers \\
engage in \\
calibration \\
activities \\
(see \\
Chapter 5)
\end{tabular} & $\begin{array}{l}\text { Depending on } \\
\text { type - explanation, } \\
\text { argument, } \\
\text { expository. } \\
\text { Good for testing } \\
\text { analysis, synthesis, } \\
\text { argument, } \\
\text { criticality. } \\
\text { Essay questions } \\
\text { can be quick to set. } \\
\text { Some students } \\
\text { may be familiar } \\
\text { with the genre. } \\
\end{array}$ & \begin{tabular}{|l|} 
'Essayist literacy' \\
(Lillis 2001) may \\
disadvantage \\
students from \\
marginalised \\
groups. \\
An essay is far \\
removed from \\
professional \\
practices - reports \\
may have more \\
validity.
\end{tabular} & $\begin{array}{l}\text { Arts, } \\
\text { humanities, } \\
\text { social } \\
\text { sciences, } \\
\text { some sciences }\end{array}$ \\
\hline Lab report & \begin{tabular}{|l|} 
Low, unless \\
markers \\
engage in \\
calibration \\
activities \\
(see \\
Chapter 5)
\end{tabular} & $\begin{array}{l}\text { Can provide } \\
\text { practice in } \\
\text { devising/ } \\
\text { understanding a } \\
\text { research question, } \\
\text { collecting } \\
\text { and analysing } \\
\text { data, writing a } \\
\text { discussion section. }\end{array}$ & $\begin{array}{l}\text { Can be difficult to } \\
\text { set up with large } \\
\text { groups. } \\
\text { Time in laboratory } \\
\text { is expensive. }\end{array}$ & $\begin{array}{l}\text { Engineering, } \\
\text { sciences }\end{array}$ \\
\hline $\begin{array}{l}\text { Observed } \\
\text { Structured } \\
\text { Clinical } \\
\text { Exam } \\
\text { (OSCE) }\end{array}$ & \begin{tabular}{|l|} 
Low unless \\
markers \\
engage in \\
calibration \\
activities \\
(see \\
Chapter 5)
\end{tabular} & $\begin{array}{l}\text { Examining } \\
\text { how learners } \\
\text { apply skills in } \\
\text { professional/ } \\
\text { clinical settings. } \\
\text { Good for observing } \\
\text { communication } \\
\text { skills. } \\
\text { Can be quick to } \\
\text { mark. }\end{array}$ & \begin{tabular}{|l|} 
Can be time \\
consuming and \\
expensive to set \\
up. \\
Requires several \\
examiners. \\
Can be stressful for \\
some learners.
\end{tabular} & $\begin{array}{l}\text { Professional } \\
\text { fields - } \\
\text { medicine, } \\
\text { legal practice, } \\
\text { social work, } \\
\text { psychology } \\
\text { and } \\
\text { management }\end{array}$ \\
\hline $\begin{array}{l}\text { Scenarios, } \\
\text { problem- } \\
\text { based } \\
\text { learning and } \\
\text { case studies }\end{array}$ & $\begin{array}{l}\text { Low unless } \\
\text { markers } \\
\text { engage in } \\
\text { calibration } \\
\text { activities } \\
\text { (see } \\
\text { Chapter 5) }\end{array}$ & $\begin{array}{l}\text { Allows learners to } \\
\text { show application } \\
\text { of knowledge, } \\
\text { teamworking and } \\
\text { problem-solving } \\
\text { skills. } \\
\text { Can be good } \\
\text { for synoptic } \\
\text { assessment, } \\
\text { connecting several } \\
\text { modules. }\end{array}$ & $\begin{array}{l}\text { Can be difficult } \\
\text { to design } \\
\text { authentically. } \\
\text { Learners need } \\
\text { support and } \\
\text { practice if the } \\
\text { genre is unfamiliar. } \\
\text { Can be complex } \\
\text { and time } \\
\text { consuming to set } \\
\text { up and run. Can } \\
\text { involve multiple } \\
\text { assessors so high } \\
\text { workload for staff } \\
\text { and potentially low } \\
\text { marking reliability. }\end{array}$ & $\begin{array}{l}\text { Engineering, } \\
\text { medicine, } \\
\text { education, } \\
\text { social work } \\
\text { - most } \\
\text { professional } \\
\text { fields }\end{array}$ \\
\hline
\end{tabular}




\begin{tabular}{|c|c|c|c|c|}
\hline $\begin{array}{l}\text { Assessment } \\
\text { type }\end{array}$ & \begin{tabular}{|l|}
$\begin{array}{l}\text { Marker } \\
\text { reliability }\end{array}$ \\
\end{tabular} & Advantages & Disadvantages & $\begin{array}{l}\text { Typically } \\
\text { used in }\end{array}$ \\
\hline Portfolios & $\begin{array}{l}\text { Low unless } \\
\text { markers } \\
\text { engage in } \\
\text { calibration } \\
\text { activities } \\
\text { (see } \\
\text { Chapter 5) }\end{array}$ & $\begin{array}{l}\text { Allows students } \\
\text { to collect and } \\
\text { curate learning } \\
\text { experiences. } \\
\text { Good for showing } \\
\text { attainment of } \\
\text { professional } \\
\text { and clinical } \\
\text { competencies. } \\
\text { Allows assessment } \\
\text { choice so good for } \\
\text { inclusivity. } \\
\text { Can be good } \\
\text { for synoptic } \\
\text { assessment, } \\
\text { connecting several } \\
\text { modules. }\end{array}$ & $\begin{array}{l}\text { Can be very time- } \\
\text { consuming for } \\
\text { both learner and } \\
\text { marker. } \\
\text { Can involve } \\
\text { learners in } \\
\text { a variety of } \\
\text { assessment tasks } \\
\text { - this may be } \\
\text { bewildering for } \\
\text { some learners who } \\
\text { will need support } \\
\text { with new genres. } \\
\text { Potential for } \\
\text { plagiarism but } \\
\text { can be combined } \\
\text { with an oral } \\
\text { examination. }\end{array}$ & $\begin{array}{l}\text { Used in most } \\
\text { professional } \\
\text { fields }\end{array}$ \\
\hline
\end{tabular}

\section{Preparing Students for Assessment}

When introducing new varieties of assessment, it is important to prepare students and provide them with practice in any new variety so that they have, as Gibbs and Simpson (2005) state, a chance to get good at a particular variety before they are summatively assessed. Think about where, in your programme, students will have opportunities to practise assessment tasks and written genres as an integral part of their learning. With the massification of higher education in many countries worldwide, and the increasing mobility of students, the higher education teacher cannot assume that their diverse student cohort has previous knowledge of any form of assessment, or any clear understanding of the academic standards on a course unit/module. Even if students have had experience of oral presentations or writing lab reports and essays at school, the format and expectations at higher education institutions may be completely different. So, the first stage is to prepare students, especially first year students, for assessment. For an example, see the description of the political analysis first year course unit/module earlier in this chapter.

Students need a good understanding of assessment processes, and especially of academic standards on the course, in order to evaluate and direct their learning. In Chapter 2, I discussed assessment literacy 
(and see also Chapter 7), in this section I want to focus on one aspect of assessment literacy: understanding academic standards. An effective way of helping students understand the standard of work they need to produce is through the analysis of exemplars (Hendry and Tomitsch 2014; Carter et al. 2018; Boud et al. 2018).

Teachers develop an understanding of academic standards in their discipline through seeing the range of work that students produce; Sadler $(1989,2009,2010)$ proposes that students need to be given similar experiences to develop their understanding of standards. When teachers see a range of work, they begin to develop an understanding of what students can produce and what good quality work looks like. Discussing student work with colleagues can help teachers to develop consensual understanding of what good quality work looks like (Sadler, 2010). Academic standards are held to be socially constructed, constructed and held by the disciplinary community (Sadler 2014). As discussion of a range of exemplars helps teachers understand the academic standard for their programme, it is proposed that exposing students to a similar process will help them develop an understanding of academic standards (Sadler 2010). But the use of exemplars is not standard practice on academic programmes. Model answers may be given to students, but exemplars of similar assignments from a previous year, showing a range of students' work (and the range is important) is less common. Some students report not seeing examples of their peers' work during their studies. In these cases, the student is in the dark about what good quality work looks like; explicit ways of conveying standards, such as explicit assessment criteria have been shown to be ineffective (see Chapter 5). Students need to see examples of a range of their peers' work, in order to gain an understanding of standards on their programme. In large, diverse classes, where students come from a range of backgrounds, some non-traditional, exemplars are especially useful in helping students understand academic standards. For example, health care professionals who return to education after a break of many years, may find academic tasks, such as short answer questions, report writing, oral presentations and literature reviews, unfamiliar and may be uncertain about the quality of work they need to produce. Similarly, students from non-traditional backgrounds, and mature students, may have experienced a limited range of assessment types - for example, multiple-choice questions - and may struggle with other forms of assessment, especially the essay (Lillis 2001). 
The essay has been extensively used in the arts, humanities and social sciences. Academic literacies researchers have criticised the prolific use of the essay in assessment in higher education as it disadvantages students entering universities from non-traditional backgrounds. Lillis and Tuck explain that 'academic literacies researchers have argued that the entrenched privileging of essayist literacy perpetuates inequalities in the academy, closing down diversity in knowledge-making, working against policy goals of widening access' $(2016,6)$.

\section{Diversity and Inclusion}

Widening participation has created greater diversity in student cohorts; many more students are the first in their families to participate in higher education. Dymond-Green (2018) reports on Henderson and Shure's tracking of entrants to higher education; their data suggests:

[...] that nearly 15 per cent of the English population born in 1990 are first in the family university graduates. This means that they comprise more than half of university graduates for this cohort (graduates who match their parents with a degree comprise nearly 12 per cent of the population). There is some suggestion from our early analyses that this is driven by increased participation by women and black and minority ethnic groups.

A greater variety of assessment types that link more with professional practice and better preparation of students for assessment is needed, to create more of a level playing field and allow students to demonstrate what they can do. However, there needs to be a balance as too much variety in assessment can bewilder students; they need practice in the selected range of assessments used on the programme.

\section{Reflective Writing (and Oral Reflection)}

In some disciplines, especially professional fields such as social and health care, the use of reflective statements has become widespread. Linked with the idea of reflective practice (Schön 1983; Moon 2004; Brookfield 2017), the reflective statement provides an opportunity for students to review their practice, often focusing on an incident and 
analysing what happened, how they responded to the incident, how they felt about their response and what they learnt. The analysis acts as a springboard to self-assessing development needs and planning future learning to meet those needs. Reflection and reflective writing are widely advocated in professional development courses. However, assessment of reflection is more contentious (Bolton, 2010; Boud, 1999; Rai, 2006; Ross, 2014); reflective writing is seen as performative, lacking in authenticity, confessional and emotionally problematic, as students write about themselves and their emotions. Assessing this writing as unsatisfactory can seem to imply criticism of the person. When reflective writing is compulsory and summatively assessed, students tend to be strategic in producing what they think the assessor wants, rather than authentic reflection. Reflective writing assignments can 'normalise surveillance of students' emotional and developmental expression and produce rituals of confession and compliance' (Ross 2011, 113).

\section{Validity}

In designing assessment, the teacher needs to have a clear idea of what they expect students to learn and what level of knowledge and skills students are expected to achieve. This needs to be matched with an appropriate assessment task that will enable students to demonstrate their learning. The task needs to have validity, connect with the aims of the course unit/module and be feasible within the time restraints and practicalities of the course (see Chapter 2 for a full discussion).

\section{Writing Clear Assessment Briefs}

To learn effectively from assessment, students need a thorough understanding of the assessment method(s). Developing a clear assessment brief, preferably with students, helps them to gain this understanding. An assessment brief details the task and gives students helpful guidance. It is important that the assessment method does not assume knowledge, skills and competencies that have not been covered in the syllabus; this would disadvantage some groups of students and give others an advantage. For example, do not assume that students have expertise in video production, oral presentations or writing genres such as reports or 
essays. If this expertise is important, then learning how to make a video or write an essay needs to be part of the course unit/module and students need practice to acquire these skills. Co-constructing assessment tasks with students is an excellent way to ensure they have a thorough understanding of the task (see Chapter 7 for more on co-construction of tasks and assessment criteria).

Setting the same task each year invites plagiarism (Carroll 2002). To design out plagiarism, teachers should devise authentic tasks which enable students to carry out similar tasks with different topics or give students, or groups of students, different scenarios or data sets to work with. For example, in the first year of a three-year undergraduate programme in biology, students worked in groups to discuss a key concept, namely, structure and function in biology. They began discussing the concept online, then in groups prepared a short presentation on structure and function of a group of organisms or single organelle (each group researched a different organism/organelle). This task involved literature searching and inclusion of a small number of references in the presentation. The group presentation was given in a seminar to the teacher and other group members. The presentation was not summatively assessed; the group received formative feedback from peers and the teacher. Following this, students were tasked with preparing a poster on structure and function in different organisms or an organelle. Posters were displayed and uploaded online; students peer reviewed and voted on the best poster. The next assessment task was to individually write a short essay on structure and function, choosing again a different group of organisms or organelle and including a short literature review. The draft essay was submitted for teacher feedback which was used to improve the final essay on structure and function. The final essay was assessed by the teacher as part of the summative assessment for the course unit/module (see STEM Wishees 2019 http://www.thinkingwriting.qmul.ac.uk/wishees/collections/ queenmary/biologyundergraduateposter/55580.html for sample posters and teacher commentary).

The group presentations, literature review, posters and draft essay prepared students for writing the final, summatively-assessed essay. They also provided practice in developing research skills, team working and exploring existing knowledge; students could draw on this learning to tackle more extensive research projects in subsequent course unit/ modules. Each group chose different groups of organisms or single organelle for each task. This demonstrates how different topics for each 
task and each group, as well as thorough preparation, can help reduce plagiarism (Carroll 2002).

\section{Assessment Briefs}

Clear instructions for assessments are provided in an assessment brief. An assessment brief needs to provide all the information that students require in order to successfully tackle the assignment. Typically, assessment briefs will provide information on (adapted from Bean 2011; University of Suffolk 2019; University of Plymouth 2019):

- workload and time allowance

- weighting of the assessment, i.e. percentage of course unit/ module assessment

- $\quad$ word count

- $\quad$ accessibility and inclusivity (access to resources; field trips etc.; adaptions for statements of reasonable adjustments (SoRas), e.g. if the student cannot do fieldwork what alternative method will be provided?)

- choice in assessment (can students choose to present their work in a presentation, video or essay? See Chapter 9)

- clear description of the tasks and modes of working (e.g. in teams), if applicable

- an explanation of how the task fits with the learning aim of the course unit/module, to establish validity

- $\quad$ an explanation of how the task will be assessed

- a link to work on exemplars to develop student understanding of assessment standards (see the description of guided marking in Chapter 7)

- $\quad$ assessment criteria (but see the discussion on the limitations of assessment criteria in Chapter 5)

- links between this assessment and others in this course unit/ module and subsequent course unit/modules across the programme of study

- information on resources - access to equipment (laboratories, video equipment etc.)

- bibliographies and access to set texts

- contact details of external facilitators (industry partners, nongovernmental organisation partners) 
- contact details for help and guidance - drop in help, online FAQs, technical support (e.g. video technicians or web design support)

- links to an online discussion forum for questions to peers and the teacher

- submission dates and arrangements for drafts and feedback

- submission date(s) when marks and feedback will be available

- date and location of follow-up feedback workshops.

\section{Reviewing an Assessment Brief}

The questionnaire in Table 3.2 highlights the areas you need to think about when designing assessments and writing an assessment brief for students. Use this questionnaire to design a new assessment or to review the existing assessment brief for your course unit/module.

Table 3.2: Assessment brief review questionnaire (sources: adapted from Bean 2011; University of Suffolk 2019; University of Plymouth 2019)

\begin{tabular}{|c|c|}
\hline \multicolumn{2}{|c|}{ Task design: validity } \\
\hline & Is the assessment valid? Does it link to the aims of the module? \\
\hline \multicolumn{2}{|c|}{ Comment: } \\
\hline \multicolumn{2}{|c|}{ Action required: } \\
\hline 2. & $\begin{array}{l}\text { Does the assessment task(s) enable students to demonstrate that they } \\
\text { have met these aims? }\end{array}$ \\
\hline \multicolumn{2}{|c|}{ Comment: } \\
\hline \multicolumn{2}{|c|}{ Action required: } \\
\hline 3. & $\begin{array}{l}\text { Is the assessment task clearly explained? What opportunity is there for } \\
\text { students to check their understandings of the task (e.g. virtual learning } \\
\text { environment forum discussion, FAQs, exemplars of student work for } \\
\text { similar tasks)? }\end{array}$ \\
\hline \multicolumn{2}{|c|}{ Comment: } \\
\hline \multicolumn{2}{|c|}{ Action required: } \\
\hline \multicolumn{2}{|c|}{ Academic standards } \\
\hline & $\begin{array}{l}\text { Do students understand assessment standards on the module? How do } \\
\text { you know? Have you discussed exemplars of previous students' work or } \\
\text { organised guided marking (see Chapter 7)? }\end{array}$ \\
\hline
\end{tabular}


Comment:

Action required:

5. Are academic standards on the module in line with 'sector recognised standards' (Quality Assurance Agency 2019)? Have you checked appropriate national documentation (e.g. the Framework for Higher Education Qualifications, QAA 2014, and Subject Benchmark Statements, see QAA 2019a)?

Comment:

Action required:

6. Do students understand the assessment criteria? Is their understanding the same as yours? How do you know? (See Chapter 6.)

Comment:

Action required:

7. Are students involved in designing the assessment or grading and giving feedback? Are they competent to take on these tasks? How do you know? (See Chapter 7.)

Comment:

Action required:

Preparation

8. Have the knowledge and skills required for this assessment been practised in formative tasks?

Comment:

Action required:

9. Is there any aspect of the assessment that requires knowledge and skills that haven't been covered in the curriculum (either in this module or a previous one)? If yes, what are they, e.g. results need to be presented in Excel $^{\circledR}$ ? Can this aspect be removed from the task or can students be given an alternative way of presenting data or can additional classes (e.g. Excel ${ }^{\circledR}$ classes) be included in preparation activities? 
Comment:

Action required:

10. How does this assessment link to assessments in previous and future modules? What skills and knowledge from previous modules can students use to tackle this assignment?

Comment:

Action required:

\section{Inclusivity}

11. Does the assessment brief explain what support is available to students (e.g. office hours, virtual learning environment forum, student mentors, writing support etc.)?

Comment:

Action required:

12. Does any element of the assessment exclude groups of learners, e.g. are field trips accessible? Do scheduling arrangements respect religious observances?

Comment:

Action required:

13. Does the assessment brief explain what choice is available (e.g. choice of assessment tasks such as an essay or presentation, see Chapter 9)?

Comment:

Action required:

14. Does the assessment brief explain any necessary alternative arrangements for students with SoRAs? [N.B. it is better to design assessment in an inclusive way so that no alternative arrangements are necessary. See Chapter 9 for a full discussion.]

Comment:

Action required: 


\section{Assessment genre}

15. Does the assessment brief explain the audience for the task, e.g. public information leaflet, briefing report for local charity managers? Have students had practice in communicating with this audience? (See Chapter 5.)

Comment:

Action required:

16. Have students had experience in your module or a previous module of the assessment genre, e.g. writing an essay, giving an oral presentation, presenting a case or mooting? If not, how can they get this experience? How can they get good at communicating in this genre before they are assessed (e.g. writing-to-learn tasks, see Chapter 2)?

Comment:

Action required:

\section{Mechanics}

17. Are the mechanics of the assessment clearly stated, e.g. submission date, word/page count (if appropriate), font size, presentation guidelines (if appropriate)?

Comment:

Action required:

18. Do students have time to do the assignment? Are assessments 'bunched' or evenly distributed across the module and programme?

Comment:

Action required:

19. Is plagiarism designed out of the assessment? Are tasks changed regularly? Are students prepared for tasks? Are they over-assessed, leading to stress and the impulse to plagiarise?

Comment:

Action required:

20. When will students receive grades and feedback? Will they have time to act on this feedback to improve their next assignment? 


\begin{tabular}{l} 
Comment: \\
Action required: \\
\hline 21 . What kind of feedback will students receive (see Chapter 8)? \\
\hline Comment: \\
Action required: \\
\hline $\begin{array}{l}\text { For teachers: reliability } \\
\text { comments) are fair and consistent with the academic standards on the module } \\
\text { (see Chapter 6)? }\end{array}$ \\
\hline Comment: \\
Action required:
\end{tabular}

\section{Follow-Up}

Reading

The University of Suffolk have produced useful guidance on assessment briefs and moderation of marking:

https://www.uos.ac.uk/sites/default/files/assessment-overview. pdf

The University of Plymouth has excellent resources on inclusivity, including guides and videos on inclusive assessment (and see Chapter 9 in this guide for a detailed consideration of inclusive assessment):

https://www.plymouth.ac.uk/about-us/teaching-and-learning/ inclusivity/inclusive-assessment

Investigating Your Practice

Work with a colleague(s) to review your course unit/module assessment guidance. Use the assessment review questionnaire to review the assessment brief and identify changes you would like to make. 
Alternatively, work with some students to review the course unit/ module assessment guidance. These could be final year students who have an understanding of the structure of the course unit/module and/ or first year students (entry year students) who are new to the course unit/module and can give feedback on what they need clarified. Check their understanding is the same as yours by asking them to paraphrase key instructions in the brief. 


\section{Chapter 4 \\ Designing Assessment Across a Programme}

\section{A Programme-Wide Perspective}

This chapter covers the challenge of designing assessment across a programme. It focuses, to a large extent, on modularised degree programmes. Modularisation is widely used in higher education; for example, in Europe, the UK, Australia, New Zealand and the USA, and involves the design of separate, often standalone, units of study. These units of study, or modules, can be of varying sizes, can be core modules in a degree programme or can be shared between many programmes. You may be working in a degree programme structure that is not modularised; this chapter provides a useful introduction to modularisation, the benefits and pitfalls.

Modularisation has led to, in some cases, more disparate, less cohesive programmes of study. It has also had an impact on assessment design, as students can experience a range of diverse assessments and have difficulty taking learning from one assignment to the next. The Transforming the Experience of Students through Assessment (TESTA) project has highlighted these issues. Students need a sense of progression in their studies; this chapter offers practical ways to create more cohesive programmes.

The chapter focuses on creating cohesive assessment across a programme (and links with Chapter 3, on module design). In particular, it will cover: 
- advantages and disadvantages of modularisation

- connecting assessments, ensuring that the sequencing of assessments allow students to build knowledge, competencies and skills

- reviewing assessment across a programme.

\section{The Dilemma of Modularisation}

Since the 1990s, higher education institutions in the UK, and other countries have adopted modularisation of degree programmes. Modularisation entails designing programmes of study in discrete units, or modules. In theory, this hugely increases choice for students who can select a range of modules and customise their learning. Some disciplines, however, have adhered to very tight programmes with a limited choice of modules. In some professional programmes, most modules are compulsory, so students follow the same programme; for example, in law. In other disciplines, core modules provide continuity in the programme and a through-line of learning so that each core module builds on learning from the previous module; outside of the core modules, students have relative freedom to choose from a range of option modules. In large interdisciplinary programmes, there may be few core modules and an extensive menu of choice.

The move to modularisation was seen to offer institutions and students many advantages, as described in the following (adapted from French 2015; Brown and Saunders 1995).

- Increased choice and flexibility for learners to create their own programmes and follow their own interests.

- Increased opportunities for interdisciplinary programmes, with sharing of modules between programmes, thus reducing costs. The move to modularisation may have an economic driver as modules can be shared across programmes with savings due to economies of scale.

- Greater flexibility for part-time students who do not need to follow a set sequence of modules.

- Marketability of standalone modules; this is of particular interest to institutions that want to gain income from providing continuing professional development (CPD) courses. 
- Transfer of credits within the institution and across institutions, which again provides students with greater choice and flexibility.

However, the disadvantages of modularisation are becoming increasingly apparent. These are described in the following (adapted from French 2015; Brown and Saunders 1995).

- Organisational issues and keeping track of student learning, making sure someone knows about their progress.

- Choice can be problematic, especially if there is a bewildering range of modules to choose from; students may not make the best choices and may not understand which modules to pick for particular careers, so there is a need for guidance.

- Mixed levels teaching - teaching students who have no previous learning in a subject with those who have. To ensure students have the relevant level of knowledge for a module they may be required to successfully complete a preparatory module (prerequisite).

- Exponential increases in assessment have been attributed to modularisation as each module may require two or more assessments (Harland et al. 2015; Jessop and Hughes 2018).

- Academic 'fragmentation' (Brecher 2005) as students don't get a scaffolded understanding of the discipline; this is more important in some disciplines, e.g. physics.

Some degree programmes, particularly in professional fields where learning may be regulated by professional bodies, permit very little choice of module. These programmes are designed along a more traditional linear model with core modules and very few option modules. In these programmes, connected through-lines are easier to design, and larger modules and synoptic assessments can help to contain the volume of assessment (see De Vita 2004 for an evaluation of a synoptic module).

\section{Modularisation and Assessment}

In a modularised programme, it is important to ensure that assessment is connected throughout the programme and that students have an opportunity to build on previous learning and develop understanding. This can be problematic as some modules may be seen as standalone units of learning or may be shared with other disciplinary programmes 
and be based on very different epistemological beliefs. In these cases, the programme leader needs to ensure that students receive adequate preparation for all assessment tasks.

Overassessment in modular programmes has been highlighted by Harland et al. (2015). For small, 15 credit modules (in England, Wales and Northern Ireland, QAA, 2014) typically two or more pieces of assessment are set. Fifteen credits are equivalent to 150 notional hours of learning (this includes taught sessions, self-study time and time spent on assessments), and to 7.5 European Credit Transfer and Accumulation System (ECTS); a bachelor's degree with honours is typically equivalent to 360 credits or 180 ECTS.

Harland et al. (2015) describe this overassessment as a 'pedagogy of control' (see also Jessop and Hughes 2018), using assessment to motivate and ensure students cover module content. However, an increased assessment load can have the opposite effect and result in more strategic study practices, with students focusing on the assessment tasks with no time for wider reading (Harland et al. 2015). As more summative assessment is added to the programme, there is less space for formative assessment, so students do not get a chance to practise and develop. They may also ignore formative assessments entirely, making a strategic decision to focus their efforts on summative assessments. As a result, they do not engage in valuable practice activities, which can disadvantage marginalised groups.

\section{Synoptic Assessment}

Possible remedies to the problem of overassessment include synoptic assessment (De Vita 2004), where several modules are assessed through one assignment. Synoptic assessment combines knowledge and skills from two or more modules and allows students to demonstrate their understanding of a topic. Synoptic assessments span several modules in a programme and require students to synthesise learning from these modules, to recognise links between modules and to apply learning to real world problems.

Students can be prepared for synoptic assessments through small formative tasks which help them make links between modules and synthesise learning. Larger modules can also help to reduce assessment. Small 15 credit modules can dramatically push up the volume of assessment on a programme, especially if each small module requires at least two assessments. Small modules can be replaced with one 
large 60 credit synthesising module; formative tasks can then prepare students for a larger, summative assessment and so decrease the number of individual summative assessments. With fewer summative assessment tasks, students have more time to tackle formative tasks and more time to think and read around the topic. Another benefit is that the teachers' assessment workload is decreased, as formative tasks can be carried out in groups and generic feedback can be given on the task. To give generic feedback, scan the formative tasks looking for strengths and common weaknesses. Provide students with an oral or written summary (either online or in class) of what you expected students to achieve, highlight some strengths and indicate weaknesses with suggestions for further work.

\section{Transforming the Experience of Students through Assessment (TESTA)}

TESTA is a useful tool for exploring assessment practices across a programme and identifying areas for development. TESTA was initiated by Graham Gibbs, Tansy Jessop and Yassein El Hakim, who designed a methodology for collecting data on assessment and feedback in a programme. They wanted to address problems of modularisation and promote programme assessment practices that enable students to understand academic standards on the programme and what they need to focus on to achieve programme level aims. The TESTA initiative shares concerns about the documentation of standards (Sadler 2014); academic standards do not exist in programme documentation, such as in learning outcomes and assessment criteria. Students come to know these standards through engaging in formative and summative assessment tasks and dialogic feedback.

The TESTA methodology consists of a programme audit, collecting data on 'volumes of summative and formative assessment, varieties of assessment, proportions of exams, and the volume of written and oral feedback' (Jessop et al. 2014a, 21). A questionnaire is distributed to all final year students on the programme; the 'Assessment Experience Questionnaire (AEQ), is a 28 question survey based on assessment principles distilled by Graham Gibbs' (Gibbs and Simpson, 2005). Finally, a focus group is carried out with a selected group of final year students. The mix of quantitative and qualitative data provides a good profile of assessment on the programme. In the analysis of the data, qualitative data is drawn on to illuminate quantitative data and helps to tease out 
issues such as overassessment, lack of alignment of assessments and the quantity and usefulness of feedback.

In a comparison of data from 23 TESTAs, Jessop et al. (2014b) found that some programmes had six times as much assessment as others and that final year students were still vague about academic standards on their programmes: 'In spite of well-documented modules and programmes, outlining aims, learning outcomes and assessment tasks, final-year students were not clear about goals and standards ...' (Jessop et al. 2014b, 82)

\section{Putting this into Practice: Reviewing an Existing Programme}

Degree programmes developed over a period of time may lose focus as new content is added and assessments changed. Some large programmes can have labyrinthine structures, making links between modules and a sense of progression problematic.

If you are working on an existing programme, start by analysing your programme. You can either initiate this as a member of the programme team or as a team leader. Use the review questionnaire shown in Table 4.1 and work with colleagues and students to review assessment across the programme, identify connections between assessment tasks and through-lines of activities that enable students to practise and perfect performance.

If you are using this questionnaire to plan a new programme start by deciding what you want students to learn across the programme and understand how each module contributes to that learning (see Chapter 3 for an explanation of backward design). Think about the complex learning that students need to engage in and how the programme will introduce and give practice in critical thinking, exposition, synthesis etc.

Check that the learning on the programme is at a suitable level. If comparable national standards are expected, check the appropriate documentation, for example, The Framework for Higher Education Qualifications (FHEQ) and subject benchmark statements or similar national documents (QAA 2014, QAA 2019a). Bear in mind the limitations of language in documenting standards (see Chapter 6 for a full discussion) and consider whether you are able to judge if the programme modules are set at an appropriate level. 
Table 4.1: Reviewing an existing programme (sources: adapted from Bean 2011; University of Suffolk 2019; University of Plymouth 2019)

\begin{tabular}{|c|c|}
\hline & lantity of assessment \\
\hline & $\begin{array}{l}\text { Is there any evidence of overassessment? Modularisation may mean that } \\
\text { there are several assessments for each module, leading to overassessment } \\
\text { and that the same knowledge/skill is repeatedly assessed while others are } \\
\text { not. You may want to use a tool such as the Transforming the Experience of } \\
\text { Students through Assessment (TESTA http://testa.ac.uk) research toolkit } \\
\text { or similar to identify the amount of assessment on the programme, the } \\
\text { number of varieties and links between assessments. }\end{array}$ \\
\hline & mment: \\
\hline & inned development: \\
\hline & $\begin{array}{l}\text { Are there opportunities to introduce synoptic assessment? Synoptic } \\
\text { assessments can be more meaningful for learners as they enable students } \\
\text { to make links between modules. Overall summative assessment is reduced, } \\
\text { so learners have more time to spend on fewer, synoptic assessments. }\end{array}$ \\
\hline & mment: \\
\hline & Inned development: \\
\hline & rough-lines and connections \\
\hline & $\begin{array}{l}\text { Are there through-lines of assessment? Are there key modules where } \\
\text { disciplinary understandings/knowledge/skills will be developed? }\end{array}$ \\
\hline & mment: \\
\hline & Inned development: \\
\hline & $\begin{array}{l}\text { How do subsequent modules build on this knowledge/these skills? Where } \\
\text { are the gaps? }\end{array}$ \\
\hline & mment: \\
\hline & inned development: \\
\hline & $\begin{array}{l}\text { How are students prepared for assessments; where do they get practice for } \\
\text { subsequent assessments? }\end{array}$ \\
\hline & mment: \\
\hline & ed development: \\
\hline
\end{tabular}


- How are students involved in assessment design? (e.g. co-construction of assessment tasks, assessment criteria, peer review etc. See Chapter 7.)

Comment:

Planned development:

\section{Timing of assessments}

- Are assessments bunched together? This typically happens when assessments occur at the end of a module. Change deadlines or reduce assessment to avoid bunching, and where bunching can't be avoided, come up with strategies to ease student and staff workload (e.g. preparation time for students before exams, marking period afterwards for teachers with no other deadlines).

Comment:

Planned development:

- How many varieties of assessment are there in the programme? (e.g. lab reports, case studies, MCQs/SBA, OSCEs etc. (see Table 3.1 in Chapter 3). Diversity in assessment is good, because it helps develop students' communication skills, enabling communication with different audiences using different modes of communication (blogs, presentations, formal reports, etc.). But students need to be prepared and have an opportunity to practise each new type of assessment; this can be done through formative assessment tasks, which help prepare students for summative assessments. Formative and summative tasks need to be closely linked so students can see the value of completing them. Assessment tasks need to be linked into the overall structure of the programme.

Comment:

Planned development:

\section{Inclusive assessment}

- Is assessment planned to support a diverse student cohort? (Does the curriculum reflect that diverse cohort, e.g. tasks that give students the opportunity to explore their neighbourhoods and indigenous knowledge?)

Comment:

Planned development: 
- Are students given a choice of tasks so that they can choose types that allow them to show attainment (see University of Plymouth 2019, and Chapter 9)?

Comment:

Planned development:

\section{Academic standards}

- How are students helped to understand assessment standards? (See Chapter 7 and discussion of designing activities for preparation, practice and partnership.) How will they be able to recognise good quality work? What activities will help them gain this understanding? (See Chapter 7.)

Comment:

Planned development:

- How is student progress monitored and supported? And how are they supported to monitor and direct their own development? See section on ipsative assessment in Chapter 8.

Comment:

Planned development:

- How will students learn about ways of thinking within the discipline and how will they be helped to express their thinking in appropriate disciplinary discourse (in oral, written, multimedia assignments)? Are writing-to-learn (WTL) tasks embedded in lectures, seminars, online activities, fieldwork and tutorials? (See Chapter 2 on writing in higher education.)

Comment:

Planned development:

- How will students learn from assessment tasks and show their learning? Validity is important here (see Chapter 3). Do the assignments allow students to develop and learn across the programme? Are there synoptic assessments, providing opportunities to synthesise learning across modules?

Comment:

Planned development: 
Think about how learning for the whole programme (knowledge, skills etc.) can best be expressed. Analyse the validity of the assessment tasks and ensure they provide opportunities for students to learn and demonstrate their learning and are connected to the programme aims. It can be helpful to work from exemplars of students' work on your programme (or similar programmes) and identify knowledge and skills needed to perform well in assessment tasks.

Think about how each module in the programme contributes to the whole and helps students to achieve the academic standards of the programme. Find a way to make this linking apparent to students. Help students to produce a map that guides them through the programme, shows their learning journey, shows how learning is linked and how the skills and knowledge and competencies learnt in one module will be developed in subsequent modules. Students need to conceptualise this and understand how their module choices connect and how one assessment prepares them for a subsequent assessment.

There may be an obvious structure for the modules, and this structure may be disciplinary specific. For example, one teacher comments: 'In my own field of physics, the learning structure is naturally hierarchical - there's no point in teaching students Relativity if they don't understand Newton! These hierarchies place definite constraints on when you teach what subject' (James Fryar, 2012).

\section{Follow-Up}

\section{Reading}

Read more about overassessment in higher education:

Harland, Tony, Angela McLean, Rob Wass, Ellen Miller and Kwong Nui Sim. 'An Assessment Arms Race and Its Fallout: High-Stakes Grading and the Case for Slow Scholarship', Assessment and Evaluation in Higher Education 40, no. 4 (2015): 528-41.

\section{Investigating Your Practice}

Work with colleagues and students to create a diagram for your programme showing connected through-lines of assessment activity. Indicate how learning from one assignment can be used in subsequent 
assignments. Share the diagram with students (e.g. in module handbooks) and explain the connections.

Have discussions with students and colleagues about ways to reduce summative assessment on your programme; for example, combining modules and developing synoptic assessments, moving or splitting assessments to alleviate bunching. If the module assessment is six lab reports or six essays, considering changing this to four lab reports but with an option for students to submit drafts on the first two reports. Student workload is then reduced, they have more time to develop the first two reports and they receive feedback on their drafts with suggestions on how to develop them. 


\section{Chapter 5 \\ Reaching Out: Making Links With Communities}

Well-designed research-based assessments can help students to engage with the world beyond higher education and contribute critically to policy decisions. Higher education institutions are part of the wider community and are often funded by and accountable to that community and its representatives, for example, political bodies. Higher education institutions often include in their 'mission statements' an aim of reaching out and working in partnership with local communities. Links can be created and strengthened through assessments involving students working with community organisations, such as non-governmental organisations (NGOs) and community groups, government departments, and local and international employers. Community linked assessments can also give students experience of using research to contribute to knowledge building within their community and experience of presenting to and writing for external audiences. This chapter explores the practicalities of setting up assessments which have an external element, liaising with external bodies and designing these assessments. Beginning with a consideration of the idea of authentic assessment, the chapter explores types of inquiry-based learning (IBL) and ways of linking academic research with community involvement through imaginative assessment tasks which aim to develop students as independent researchers. 


\section{Communicating with Audiences}

Authentic assessment, that is assessment that mirrors practices in work and the community is increasingly used in higher education; for example, scenario-based assessments which require students to respond to professional issues. Scenarios can be designed to mirror professional tasks, requiring groups of students to collaborate to solve an ill-structured problem (Voss and Post 1988), that is, a problem with no correct answer. In solving the task, students combine theoretical knowledge of the subject, understandings of how knowledge is created and communicated within a discipline (Barradell et al. 2018, McCune and Hounsell 2005) with professional skills and so gain a better understanding of the application of theory. As problems to be investigated are ill-structured, student responses can be divergent. Students have an opportunity to explore creative responses to the problem. In some cases, this may lead to creation of new knowledge in the field or profession (e.g. Chang 2005; Chang and Jackson 2007).

One step further to is develop assessment in partnership with external bodies, ensuring that the assessment task will have diverse audiences. This approach to assessment requires careful planning; many practical and quality assurance issues need to be thought through. Traditionally in higher education, the teacher is the audience for students' assessed work, whether it is a lab report, mathematical calculation, essay or presentation. Involving external bodies can be a motivating factor for students as they can connect their work in higher education with industry, employment and with issues in their own community.

The assessment for this type of task can take a non-traditional form, so rather than essays or lab reports, students may give presentations, write blogs, design multi-media training resources, make videos and write public information leaflets. Students learn to communicate with different audiences. The experience gained from these assessments can be valuable when they leave higher education and apply knowledge to the world beyond (Boud 2000). Boud and Soler define sustainable assessment 'as a way of rethinking outcomes, curriculum and pedagogy away from a focus on disciplinary knowledge to what students can do in the world' $(2016,401)$. Sustainable assessment, and the notion of assessment for learning, position assessment as an integral part of the learning experience, rather than assessment of learning. Sustainable assessment tasks go beyond memorisation and regurgitation of facts, and engage students in complex learning, requiring the application 
of theoretical knowledge to formulating and solving professional or community authentic problems. Learners apply knowledge to community or work issues, but this is not about creating 'worker identities' (Tennant et al. 2010, 107) or producing students ready for employment. Sustainable assessment has the wider aim of developing students and enabling them to join and better understand their communities, providing them with the knowledge and skills to contribute through active citizenship. The non-governmental organisation Citizens UK (2019), works with the academic community to investigate issues in the local community and campaign for action. Academics work in partnership with Citizens UK and contribute to their campaigns. Students engage with these campaigns and gain a better understanding of their local community and democratic processes through carrying out research work.

Authentic assessment is not unproblematic. Issues can arise when scenarios and problem-based learning (PBL) are set up so that there is a right answer. This can be reassuring for teachers, who are provided with crib sheets and are confident that they have the best possible answer, but can create an inauthentic feel. Lack of external involvement can also lead to inauthenticity. If there is no external involvement in the scenario, e.g. community groups or industry contacts, the assessment can become just another exercise communicating with the teacher. Other issues arise when enthusiastic teachers design a variety of unfamiliar assessment tasks for students; for example, blogs, vlogs, public information leaflets, posters and hyperlinked articles. These can be valid tasks but the sheer variety and lack of familiarity with these genres can create problems. Students may have had no previous experience of making videos or writing for the public. A change in the genre of assessment needs careful preparation; students need practice in the new genre so that they can achieve mastery before being assessed and before their performance is summatively judged. Similarly, teacher assessments of these innovative tasks may be unreliable, because teachers may not have experience of assessing innovative tasks and may not have discussed with colleagues how to assess these tasks or agreed academic standards (see Chapter 6).

\section{Research-Based Learning}

Citizenship in our 'supercomplex' world (Barnett 2000) involves being able to critique and understand complex issues, recognising the limitations of research findings, understanding to what extent research 
can help towards finding solutions and how best to implement and critically evaluate those solutions.

In higher education, many students are studying for entrance to professions such as medicine, law and engineering (Brew 2006); their aim is not to become academics. However, the impact and influence of academic research and ways of thinking and practising (WTP) in the disciplines reaches into all aspects of our professional and personal lives. McCune and Hounsell (2005) argue that WTP describe the breadth of learning that a student might engage in and that might give students insight into the way professionals think and express themselves. For students to effectively influence their professions and communities, they need to be cognizant of established ways of knowing and of ways of creating knowledge within their discipline(s) so that they can engage in knowledge building. In developing this awareness, they are also able to critically evaluate the established ways of knowing and, through critical appraisal, identify shortcomings and dispute current orthodoxy. Students may also understand how to use research findings to explore and resolve complex challenges, which may be professional, personal or societal. This then is the rationale for engaging students in authentic research experiences; to provide opportunities for them to develop the knowledge and skills they need to function effectively in a supercomplex world.

\section{Views of Research-Based Learning}

Research-based learning epitomises a shift in ways of thinking about learning; research-based learning places the student at the centre of learning. One of the teacher's roles entails designing 'scaffolding' activities (Bean 2011) to help students acquire the skills and knowledge needed to plan and conduct research.

Research-based learning embraces a wide range of practices, e.g. inquiry-based learning, object-based learning, case studies or scenario based-learning and problem-based learning. Issues raised in the literature are the:

- $\quad$ power relations between students and teacher

- degree of support/scaffolding required

- $\quad$ openness of the task set

- connection to professional practice

- authenticity of the task

- $\quad$ range of genres and audience for the final product(s) 
- focus on knowledge building or building generic research skills.

(Visser-Wijnveen et al. 2016; Smyth et al. 2016; Aditomo et al. 2013; Levy and Petrulis 2012; Brew 2006)

Brew views research-based learning as a 'shared encounter between individual human beings' $(2006,14)$. She discusses the power dynamic between student and teacher and the danger of the teacher imposing their views and opinions on the less experienced 'submissive' student. A key principle for Brew is that teacher and student should engage in researchbased learning as equal partners. Chang's (2005) work illustrates how this can be done. His students engage in research in an area that he is not expert in and, through the use of an 'inheritance mechanism' - a way of handing on research data and analysis to the next student cohort, they soon become expert. His role is to act as a guide and facilitator, enabling students to progress in their research. Chang explains, 'In the exam I include references to other students' work. So they come to appreciate each other as experts' (Brew 2006, 176).

Brew's model of the relationship between research and teaching is dynamic and focused on teachers and students interacting as learners and 'knowledge builders' (Brew 2006, 31), which she terms 'inclusive scholarly knowledge building communities'. Participants are allowed to be involved in research activity and there is an equal partnership between participants. This can be difficult to achieve as teachers have more 'academic capital' than students, so it is important to strive towards equality. Brew explains that 'inclusive' means 'democracy in the sense in which Dewey used the term, where education is about nurturing human growth and development' (Brew 2006, 34).

\section{Inquiry-Based Learning}

Levy and Petrulis's (2012) view of 'inquiry-based learning' draws on Brew's work. In a small-scale, qualitative study of first year students' experiences of inquiry-based learning, they identified different dimensions of experiences from 'identifying' at an early stage in the programme, where students work on investigations framed by the teacher and explore existing knowledge, to 'authoring' where students generate their questions and can be involved in original research and knowledge building. They argue there is evidence for providing more guided forms of inquiry-based learning at the start of a programme, while more open 
'authoring' tasks that empower students to develop their own research agendas can be used later (Levy and Petrulis 2012, 98). Their model can be used for designing research tasks, helping teachers to identify levels of support to provide.

Aditomo et al. (2013) investigated the design of inquiry-based learning tasks. They collected data from 224 academics in three Australian universities, one from each "type [...] "Sandstones" (most research intensive), "Gumtrees" and "Unitechs" (least research intensive)' (Aditomo et al. 2013, 1244). They asked the teachers at these universities to send examples of their tasks and objectives. They investigated whether academic discipline or other contextual factors influenced tasks types and objectives (Aditomo et al. 2013, 1243).

They identified a range of task types and distinguished between a focus on content and a focus on practice, that is, the kinds of skills students need to develop. 'Use-oriented' tasks have practical applications and aim to develop professional knowledge and skills. They identified four types of use-oriented task, namely:

- $\quad$ roleplaying (2.3 per cent)

- enactment of practice (28.8 per cent) - provide service to clients, e.g. in medicine (clinical consultations), education, accounting etc.

- applied research similar to simplified research but with a practical application (9.3 per cent)

- $\quad$ simulated applied research (8.8 per cent).

(N.B.: figures in brackets relate to the percentage of tasks.)

The remaining tasks were categorised as non use-oriented. Non useoriented tasks were designed to develop knowledge of content and categorised as:

- discussion-based inquiry involving online or face-to-face discussion (5.6 per cent)

- literature-based inquiry (6 per cent) involving a review of the literature with no data collection

- $\quad$ simplified research with pre-specified research questions and methods/analysis provided (27.4 per cent)

- scholarly research (10.7 per cent), requiring formulation of questions and collection and analysis of data. 
Applied research, simulated applied research and simplified research tasks focused on 'the use and acquisition of disciplinary concepts' and guided students to use particular theories (Aditomo et al. 2013, 1250). Scholarly research typically required students to communicate findings to external audiences, at least external to the class.

\section{Examples of Inquiry-Based Learning Tasks}

Here are examples of some inquiry-based learning task types (all from Aditomo et al. 2013); no difference was found between types of university and type of task set.

\section{Scholarly Research}

The students are to obtain a data set, ask some statistically based questions (their choice) about the data and use statistical methods to answer their questions. The students are to summarise their work in a short report. Students may work in teams of up to three students. (Undergraduate, statistics, 210 students) (Aditomo et al. 2013, 1246)

\section{Simplified Research}

Students are given three sets of DNA sequences and need to use the computational tools and databases they have learnt about to discover the respective functions of the proteins. They are not told which tools to use, and the third of the sequences requires some detective work (I do give a hint). (Undergraduate, biomedicine) (Aditomo et al. 2013, 1246)

\section{Literature-Based Inquiry}

'Asked to undertake a systematic review on a question of their choice.' (Undergraduate, psychology, 39 students) (Aditomo et al. 2013, 1246)

\section{Applied Research}

[Students] had to research the issues surrounding transport, energy, food and waste in residential dwellings in NSW and then work out how they could deliver a 'car free household', a 'zero waste 
household' or a 'food producing household'. They worked in teams following a process of research, synthesis and communication. When they had come up with a range of design solutions, they had to pitch these ideas as if to a funding body, seeking start-up funding for further development. (Undergraduate, engineering, 580 students) (Aditomo et al. 2013, 1247)

\section{Simulated Applied Research}

Students are given several case scenarios related to professional practice, ethical behaviour and clinical reasoning during practicums. Students discuss these case scenarios in small groups and use a problem solving framework to plan appropriate action or intervention related to the given scenario. Students feedback and discuss their findings and plans for intervention with the large group. (Undergraduate, occupational therapy, 75 students) (Aditomo et al. 2013, 1248)

\section{Role Playing}

After the two hour lecture we held a workshop for an hour where the class of 35 was divided into groups of three and each group was given six scenarios to work through. The scenarios were worked through one at a time with one student being the patient presenting a prescription, another being the pharmacist dispensing the prescription and the third student observing. Then the next student would have the opportunity of being the 'pharmacist' and so on until they had each been the pharmacist twice, the patient twice and observed twice. (Postgraduate, pharmacy, 35 students) (Aditomo et al. 2013, 1248)

From this data, Aditomo et al. (2013), developed a typology of IBL tasks. Many of the inquiry-based learning tasks collected in this study fell into Levy and Petrulis' (2012) category of identifying, that is, exploring existing knowledge. Scholarly research tasks, which account for 10.7 per cent of the tasks, were the closest to authoring tasks, involving knowledge building. The authors point out that concerns about inquirybased learning activities lacking authenticity seem valid, particularly when the task is not open-ended but has a right answer. 


\section{Object-Based Learning (OBL)}

One type of inquiry-based learning task that requires special mention is object-based learning, pioneered by university museums and collections (Chatterjee and Hannan 2016; Hannan et al. 2013; Duhs 2010; Kador et al. 2018; Morgan 2018). Object-based learning can offer the opportunity for knowledge building and scholarly research. It is not a new pedagogy; objects in museum collections were extensively used in teaching before the twentieth century (Kador et al. 2018, 159). Objects can be from curated collections or from elsewhere and can be used to enhance learning in any discipline. It is 'a pedagogy that prioritises facilitated interaction with "material culture" to enhance critical thinking and key skills' (Kador et al. 2018, 158). 'Material culture' is a broad term that includes everyday objects.

Chatterjee and Hannan (2016) emphasise the importance of using the senses, especially touch to make sense of an object. Looking closely at objects and touching them can bring to life theoretical concepts and increase student understanding (Kador et al. 2018). The mystery specimen activity (see below) engages students with a mystery object. They use all their senses, especially touch, sight and smell, to explore the origin and use of the object. Object-based learning can be an opportunity for both identifying inquiry-based learning and, in the case of more complex investigations, authoring inquiry-based learning as students are involved in knowledge building and constructing the histories of unknown objects.

\section{Case Study: Mystery Specimen}

Level - third and fourth year undergraduate (but also used in master's programmes and in a range of modules)

Discipline - biology and zoology, but could be adapted to many disciplines (see below)

Module - used in a range of modules, e.g. Vertebrate Life and Evolution in the Department of Genetics Evolution and Environment, UCL

Cohort - a wide range, most from biological sciences but also some from geography, anthropology or human sciences. Both home and international students

Learning approach - object-based learning, active learning 
The 'mystery specimen' involves students in activities that develop disciplinary thinking and mirror disciplinary research. Students work in the Grant Museum of Zoology, interacting with museum staff who facilitate parts of the module. They are each given an unidentified vertebrate specimen and, over a term (a three-month period), they are required to identify the specimen.

The specimens all have museum labels, descriptions and classifications removed and can be anything from bone to skin. The student's task is to identify which part of the animal the specimen comes from. They must identify the 'correct class, order, family, genus or species' (Kador et al. 2018, 163). Most students manage to identify which group of vertebrate the specimen comes from (e.g. bird, fish etc.). Their research helps them identify:

- the material of the specimen

- whether the specimen is complete or partial

- what part of the animal the specimen comes from.

It can be more difficult for students to identify:

- whether the specimen is from a male or female animal

- the age of the animal (adult or juvenile)

- whether any part of the specimen has been altered

- any sign of pathology in the specimen.

Students are required to engage with disciplinary literature and to develop disciplinary thinking and research skills. It is not possible to identify the specimen from internet searches. Students are supported in their learning by a series of teaching sessions. They learn about ways of looking at specimens; this involves detailed anatomical observations and consulting drawings and photographs. They interact with museum staff, for example, they can ask for additional comparable material to help them identify their specimen. They can explore other museums and consult relevant literature. In this way, they are developing the research skills required for specimen-based research.

Assessment of the module draws on the research skills that students have acquired and involves writing an article for the scientific journal, Trends in Ecology and Evolution, following the journal's author guidelines. The assessment gives students practice in communicating with an external audience using appropriate conventions. In the article, students are expected to propose further research work that would need 
to be carried out to confirm their identification and reflect on which scientific techniques would give a more accurate identification, for example DNA sampling or micro-CT scanning. The articles are assessed on the quality of the research work, not on whether the identification of the vertebrate is correct.

This work also benefits the Grant Museum as student identifications are compared with descriptions in the Museum's catalogue and, in some instances, this has led to discoveries that specimens have been misidentified. These misidentified specimens are now on display in the museum, celebrating the students' detective work.

Students' perceptions of object-based learning was investigated in a survey of 154 students from a range of disciplines; the authors reported that 61 per cent of students agreed that object-based learning is more effective than listening to a lecture and valued object-based learning because it is visual, exciting, has practical application, and is good for developing teamwork, communication and observation skills (Hannan et al. 2013).

\section{Preparation}

This activity is an example of an authoring activity and, as such, assumes considerable knowledge of research skills and academic writing. Students will need to have completed activities previously in order to be familiar with the research skills and knowledge needed for this kind of object-based learning. Identifying activities such as 'Meet the Researcher' (see Chapter 2) will introduce them to research areas and literature. In addition to knowledge and research skills, they will need practice in journal article writing; this is a high-level skill which will need to be developed throughout the programme of study. (See Chapter 4 for a discussion on planning assessment across a programme.)

\section{Adaptation: Use in Other Disciplines/at Other Levels}

The activity could be simplified for first year students by asking students to work in groups and blog about their mystery specimen. Other objects such as artwork and historical artefacts can be used for object-based learning in a range of disciplines. 
For a more detailed explanation of the mystery specimen, and more case studies of object-based learning, see the two titles below.

Kador, Thomas, Leonie Hannan, Julianne Nyhan, Melissa Terras, Helen J. Chatterjee and Mark Carnall. 'Object-Based Learning and Research-Based Education: Case Studies from the UCL Curricula'. In Teaching and Learning in Higher Education: Perspectives from UCL, edited by Jason P. Davies and Norbert Pachler, 157-76. London: UCL Institute of Education Press, 2018.

Hannan, Leonie, Rosalind Duhs and Helen Chatterjee. 'ObjectBased Learning: A Powerful Pedagogy for Higher Education'. In Museums and Higher Education Working Together: Challenges and Opportunities, edited by Anne Boddington, Jos Boys and Catherine Speight, 159-68. Farnham: Ashgate Publishing, 2013.

\section{Disciplinary Knowledge}

Ashwin et al.'s (2017) study of undergraduate dissertations, highlights what students gain from assessments that focus on disciplinary knowledge (producing and authoring in Levy and Petrulis' 2012 terms) rather than generic research skills. They conclude:

... it seems that students' engagement with disciplinary knowledge through research is a key mechanism for the subject-based benefits that are provided through research-based learning. The implications of this are that these benefits are not likely to be derived from students doing any form of research. Unless they see their disciplinary ways of thinking and practising (McCune and Entwistle 2011; McCune and Hounsell 2005) as providing a way of answering their questions, engagement in inquiry-based learning is unlikely to lead to changes in students' understanding of academic knowledge. (Ashwin et al. 2017, 528)

\section{Advantages of Non-Traditional Assessments for Students}

Traditional forms of assessments in higher education, such as essays and multiple-choice questions, which do not involve students in researchbased learning or link to an external context are limited. The advantages 
of the non-traditional assessments described in this chapter are described here (adapted from UNSW 2019).

- Learning is linked to a context beyond the higher education institution. In this context, students have the opportunity to apply knowledge and skills or develop new knowledge or skills.

- Assessment can be more holistic and can help students bring together learning from a range of modules and link theoretical knowledge and professional knowledge.

- Assessments can align more with the kind of activity students would do outside of the higher education institution, either as employees or citizens. Students can see the benefit of the assessment; it appears more valid.

- Research-based learning that focuses on knowledge building can shift the power balance in learning and assessment (Brew 2006). Students may explore areas that are unfamiliar to teachers. Students can become 'experts' in those areas (see Chang 2005).

- Research-based learning can enhance employability; employers like to know that students can apply knowledge, work in teams and communicate with the public.

\section{Advantages of Research-Based Learning for Teachers}

Teachers can benefit from research-based learning in the following ways (adapted from UNSW 2019).

- Teachers often comment that students do not make links between modules. Research-based learning assessments can help students make links between modules so that they develop a more holistic view of their programme.

- Research-based learning can keep teachers up-to-date with industry, professional and community developments and practices. Students may explore new areas and add to areas studied, helping teachers to expand their knowledge; in Levy and Petrulis' terms (2012) students are engaged in 'authoring' activities. Teachers may come to see students as experts and facilitate publication of their work (Chang 2005).

- Research-based learning can help students develop as independent learners. 


\section{Disadvantages and Challenges of Research-Based Learning}

The disadvantages of research-based learning (adapted from UNSW 2019) are as follows.

- Unfamiliar genres and tasks. Some students may be disadvantaged if research-based learning assessments require unfamiliar genres, e.g. a video, case study report, maths lesson plan and resources, public information leaflet or academic article/book chapter. If students are not prepared, they can flounder with new ways of studying and unfamiliar genres. It is important to plan preparation activities and give students time to practise new genres. Build in lots of identifying activities (Levy and Petrulis 2012) at the start of the programme.

- Time commitment. Research-based learning can take much longer than traditional assessments and there is a limit to what can be explored in a short module or even one year. Chang's (2005) inheritance mechanism (see case study below) enables handover of work to the next cohort, so that students can quickly pick up and develop their peers' work.

- Accessibility. If students are required to visit external sites, these need to be fully accessible and safe environments. Timing of visits should respect religious holidays (see Chapter 9 for more on inclusive assessments).

With these considerations in mind, teachers need to think about the increased time commitment needed to develop and plan links with community groups or health care providers or industry. Wills (2014) suggests that the higher education institution should have pre-existing links with community organisations and should be contributing to work in their communities, 'developing long lasting, reciprocal relationships'. She comments on the value of fieldwork for geography students: 'In our experience at Queen Mary, geographical field study is a vehicle for learning about the ways in which local institutions and their people work together, the power of relationships to effect political change and the dynamics of running campaigns' (Wills 2014, 281).

The value of fieldwork in the community is that students learn a wider range of skills. Wills (2014) worked with Citizens UK (formerly known as London Citizens). Her students carried out research in a multicultural inner-city area with an non-governmental organisation that is 
working 'across divisions of faith, ethnicity, gender and age through a focus on working together for the common good of the city' (Wills 2014, 281). Students developed a shared project with Citizens UK members and learnt, '... a variety of other skills such as, in our case, research design, planning and methodology, team working, time management, presentation and professionalism' (Wills 2014, 281). Moreover, as some home students lived in the multicultural inner city, they could bring their knowledge and understanding of community issues to their research. Interestingly, this local knowledge can shift the power dynamic between students and teacher; teachers may have more 'academic capital' (Brew 2006, 31) than students, but students may be more cognisant of local issues and can use this knowledge in interpreting research data.

In creating and maintaining links with external partners, it is important to delineate a clear role for them. The role of the external partner in the assessment process needs to be specified and in line with institutional policies and regulations. Other considerations, discussed in subsequent chapters, are grading of new forms of assessment; for example, video assignments and assignments that include web design. Teachers need to think through what degree of expertise in video etc. is expected. If students are involved in designing assessments or involved in peer assessment, they need to be competent to carry out these roles. Chapter 7 discusses ways of preparing students for peer and collaborative assessments.

\section{Overcoming Challenges}

The challenges listed above can be overcome through careful preparation of both students and external partners. The roles of all parties need to be clearly defined. In research-based learning, the teacher's role changes, and s/he becomes a mentor, guiding students in their discovery, advising on time scales and research methodology. The teacher ensures groups do not take on too much and are realistic about what they can achieve. The teacher also ensures that external partners have realistic expectations of student outputs. As with all assessments, it is important to plan researchbased learning activities across the programme (see Chapter 4 on programme design). The assessment may be synoptic, requiring students to draw on learning from several modules and address concepts central to the discipline(s); for example, a final year dissertation project.

Teachers should ensure that students have practice in 'bite size' bits of the research-based learning assessment; for example if the assessment involves collecting data and writing a briefing report for an external 
audience, ensure that students have a task in the first term of the first year that involves data collection in groups, and in the second term, build on this with a task that requires more data collection and analysis. Students should be required to write a short version of a briefing report and present to an external audience, so that they have practice in the genre and content before they tackle a summatively assessed briefing report. When research-based learning assessments are set, opportunities for discussion of early plans (e.g. group presentations) and feedback on drafts should be provided.

External partners can be an invaluable source of information. Involving them in the design of the assessment can help ensure authenticity, for example by developing a task that mirrors professional practices. Having an external audience, someone who is steeped in the professional community of practice, can add an extra dimension to student learning and help focus the task. For students, additional learning may occur as they interact with members of the external community. For the teacher, much time may be spent in making contact, designing a valid assessment task and negotiating external involvement in line with institutional assessment policies; check the quality assurance guidelines for your institution.

\section{Case Study: Authoring in the Physical Sciences}

Module title - topics in the history of the physical sciences

Level - undergraduate

Cohort - home and international students

Learning approach - research-based learning, 'directed community model' (Chang 2005, 389)

What's of interest - students develop as experts and cite each other's work, pass work on to incoming students through an inheritance mechanism' (Chang 2005, 391) and publish collaborative work.

Chang's way of working with students is fascinating. He has created a 'directed community' of student researchers, engaged in knowledge building and creating original work that has been published in a collected book. Student assessment has become a learning opportunity for Chang himself, as his students research areas in which he is not an expert. His role is to guide and facilitate student research.

Chang felt frustrated that the excellent quality of work his students were producing could not be published and thus reach a wider audience. A single module did not allow students enough time to create publishable 
work that could be seen as contributing to research and building knowledge. Student research projects needed to be developed over a longer period of time, so he created the idea of a 'directed community' of students working together and sharing work through an 'inheritance mechanism' (Chang 2005, 391).

Students work on a theme that is flexible enough to accommodate groups of students over a period of years; the chosen theme was 'history of the chemical element chlorine' (Chang 2005, 388). Each student has an individual project but all projects are connected to the common theme of the history of chlorine. Students carefully document their work, creating records that are passed on to student cohorts in subsequent years. Over a period of four years, the data collected and work done by students contributes to knowledge building in the field.

Chang describes his approach as a 'directed community model' of research where students are involved in working independently on their own research projects, supported by the teacher and their peers. The teacher introduces them to ways of thinking and practising in the discipline (Entwistle 2005), and students are guided to make contact with experts in their topics. Use of their predecessors' work quickly introduces them to ways of working and they learn to cite each other's work and refine and develop their predecessors' work. This 'inheritance mechanism' (Chang 2005, 391), inheriting work from previous students, allows students to make further progress with the research and reach a publishable standard. Students choose whether to make their work available to the next cohort; only one student had opted not to do this. In the published book (Chang and Jackson 2007), all students who have contributed to the work are listed as authors.

\section{Assessment}

The module is assessed through an essay and exam. Students submit with their essay all their research records, e.g. annotated bibliography, reading notes, literature searches, photocopies of materials, drafts, work plans and correspondence (Chang 2005, 391). Inheriting this wealth of material enables students to build on previous work and also to learn how to carry out research. In addition to the essay, students take an exam answering questions on their peers' work and writing an essay about the research process. Chang (2005) points out that students in this module achieve higher grades compared to the other modules they take on the programme. He has received enthusiastic reviews from students about their experiences of learning on this module. 
Chang, Hasok. 'Turning an Undergraduate Class into a Professional Research Community', Teaching in Higher Education 10, no. 3 (2005): 387-94.

Chang, Hasok and Catherine Jackson, eds. An Element of Controversy: The life of chlorine in science, medicine, technology and war. London: British Society for the History of Science, 2007.

\section{Follow-Up}

\section{Reading}

For an introduction to research-based learning, issues and challenges, read Angela Brew's Research and Teaching: Beyond the Divide. Basingstoke: Palgrave Macmillan, 2006.

For an engaging account of one teacher's experience of introducing research-based learning, read Hasok Chang's 'Turning an Undergraduate Class into a Professional Research Community', Teaching in Higher Education 10, no. 3 (2005): 387-94.

\section{Investigating Your Practice}

Use the advice in the UNSW (2019) website to design a new researchbased learning activity for your programme or to review an existing activity. Work with students and colleagues to identify issues and areas for change. If there is no 'inheritance mechanism' (Chang 2005) consider whether it would be beneficial to introduce one. An inheritance mechanism can ensure that students are involved in knowledge building in the discipline and work as a community to develop an area of research over a period of years.

Consider ways of introducing students to local democracy within the research-based learning activity, working on shared research with community groups. This can introduce students to democratic politics, a much wider demographic and to local activism, teaching them skills for citizenship (see Wills 2014). 



\section{Part 2 MAKING JUDGEMENTS}





\section{Chapter 6}

\section{Marker Reliability}

Marker reliability in higher education is the elephant in the room. Academic staff experience considerable anxiety around marking and frequently experience disagreements and inconsistencies when marking with colleagues. A large number of studies have found that marker judgements in controlled conditions are unreliable. This chapter explores academic standards, drawing on a project aimed at developing comparable, national academic standards. I will explore the complexity of assessment judgements in higher education, dig further into the limitations of practices that claim to develop more reliable marking (e.g. assessment criteria, harmonisation) and propose practical solutions to enable more reliable assessment judgements.

Assessment is highly regulated, both within institutions and externally. In the UK, the Quality Assurance Agency (QAA 2019b) offers guidance on quality assurance through, for example, the Quality Code which covers threshold levels, academic standards and academic quality. Institutions are expected to provide details of assessment standards; for example, module and programme assessment criteria, rubrics and level descriptors. Despite these explicit descriptions of standards, marking in higher education is found to be unreliable (Bloxham et al. 2016). Students recognise that teachers' judgements of the quality of their assignments vary. Typically, they describe markers as 'hard' or 'soft' markers (O’Donovan 2019). 


\section{Why are Marking Judgements Unreliable?}

The unreliability of marker judgements has been a feature of many studies on marking in higher education (e.g. Williams and Kemp 2019; Bloxham et al. 2016; Bloxham et al. 2015; Tisi et al. 2013). Notwithstanding this research, markers will often claim that they mark similarly to colleagues in their programme, but there may be reasons for this.

- $\quad$ Teacher knowledge of the student cohort and expected grade; there may be an expectation that most students will get a good degree, so markers use a very narrow band.

- Power relations; teachers follow the lead of the marker with the highest status within the department, e.g. a senior professor.

In addition, the assessment load on teachers, when they mark and where they mark can all have an impact on markers' judgements. In the research literature, suggested reasons for variation in marker judgements are as follows.

- $\quad$ Seeing another marker's mark. If second marking is not 'blind' then the second marker will be influenced by the first marker's grades.

- The type of assessment task - ill-structured tasks (Voss and Post 1988) produce more variation because there is no agreed correct answer. In higher education most tasks that aim to assess complex learning are open-ended with no one correct answer. There is considerable subjectivity in judging the quality of students' work, especially judgements on creativity, quality of argument and criticality.

- $\quad$ The design of the assessment task may also produce variation. Innovative assessments such as blogs, vlogs, video and web-based assessment may be judged differently as assessors may, irrespective of assessment criteria, be influenced by the form the assessment is presented in, rather than the content, e.g. quality of video production.

- Lack of harmonisation (also called pre-moderation or parity meetings) of assessment standards. Markers do not meet before grading to discuss exemplars of students' work and agree standards through discussion, especially focusing on levels. In a harmonisation discussion, markers can consider what they 
value in the exemplars and what constitutes different levels of work, e.g. good quality work, a borderline pass etc.

- Marker backgrounds may cause variation. Markers may have different disciplinary backgrounds and different epistemological understandings (Lea and Street 1998). Tacit knowledge (Polanyi 2009) influences marker's judgement (Sadler 2014; Hunter and Docherty 2011) and individuals have different influences on their tacit knowledge.

- Assessment criteria is not comprehensive. The range of influences which markers draw on in making a judgement cannot be represented in one small list of pre-set criteria (Sadler 2014). Typically, markers add other criteria, ignore some criteria or have different interpretations of criteria (Bloxham et al. 2016).

- Assessment criteria and other documents that try to 'describe' standards are limited, e.g. Framework for Higher Education Qualifications (QAA 2014) and Subject Benchmark Statements (QAA 2019a). The language used in documentation is open to a range of interpretation.

Other factors that can affect markers' judgements are:

- the time of day

- marking a good assignment after a weak one

- student trajectory - if marking is not anonymised, markers can be influenced by their knowledge of the student and whether the current assignment is better/worse than the last one.

\section{Reducing Variation Through Documentation of Standards}

Attempts to reduce variation in marking judgements centre around descriptions of standards in written documents, such as level descriptors and assessment criteria, which aim to describe academic standards in a specific context (e.g. in a module, programme, discipline, professional qualification). Examples of such documents are the Framework for Higher Education Qualifications (QAA 2014), Subject Benchmark Statements (QAA 2019a) and professional and regulatory bodies' standards, e.g. the General Dental Council (2019). Making standards explicit involves describing the standard in language; the assumption is that this will 
enable assessors to make comparable and reliable judgements about the quality of student assignments.

These reliable judgements would then be consistent across time and, in countries where national standards are required, across programmes and institutions. In these countries, there is an expectation that higher education institutions' degree awards conform to a shared disciplinary standard and that there is an understanding across disciplines of academic standards, so for example the UK Quality Code states that:

The value of qualifications awarded to students at the point of qualification and over time is in line with sector-recognised standards. [...]

Higher education providers are expected to ensure that their standards are consistent with documented standards [...]

The academic standards of courses meet the requirements of the relevant national qualifications framework. [...]

And there is an expectation that assessment of student performance will be "reliable" $[\ldots]$

Courses are well-designed, provide a high-quality academic experience for all students and enable a student's achievement to be reliably assessed. (QAA, Quality Code 2014)

The assumption in the Quality Code in the UK is that there are 'sectorrecognised standards', that these standards will remain the same 'over time' and that an institution's standards are 'consistent with the relevant national qualifications frameworks'. The mechanism for ensuring sector-wide comparable standards is a reference to national frameworks and 'external expertise' so that: 'Degree-awarding bodies engage independent external examiners to comment impartially and informatively on academic standards, student achievement and assessment processes for all provision that leads to the award of credit or a qualification' (QAA 2019c).

In other countries, institutions may be autonomous, and so may expect only that marking within a programme in the institution should be consistent. They may expect that the programme team should have a shared understanding of good quality work at undergraduate and postgraduate levels and that they apply this standard across time, so that the current degree standard is the same as past awards.

In Australia, there has been a shift to establishing national standards. For example, Watty et al. report that: 
In accounting education in Australia, these standards are now determined at the national level and are disciplinary focused, rather than at a local/university level which has been the practice in the past. Higher education institutions are still free to expand and build on these minimum standards to differentiate their programmes (courses of study). (2014, 461-2)

The mechanisms for ensuring national qualification standards in Australia have not been specified:

The emergence of these standards has, in turn, given rise to a question as to how higher education institutions are to provide evidence that their students have achieved the standards on graduation. At the time of writing, no formal process has been nationally accepted in Australia for providing this evidence. (Watty et al. 2014, 462)

In the UK, degree standards are assumed to be upheld through external peer review. However, the process of external examining has come under scrutiny (Bloxham and Price 2015; Medland 2015). An external examiner is a subject specialist appointed by an institution to peer review the module(s) and to monitor assessment design and assessment processes with the aim of assuring quality and comparability of academic standards. Universities UK explains the British system of external examiners:

All UK universities have long made use of a network of independent and impartial academic advisers, called external examiners. These are drawn from other institutions, or from areas of relevant professional practice. External examiners report to the ViceChancellor of the university on whether the standards set are appropriate, by referring both to their experience of standards in other universities, and to the Academic Infrastructure established by the Quality Assurance Agency (the Code of Practice, Subject Benchmark Statements, the Frameworks for Higher Education Qualifications, and institutional Programme Specifications). The aim is to ensure that the threshold standards of student performance are comparable with those of students following similar courses in other UK universities. External examiners provide authoritative advice on the extent to which the processes for assessment, examination and the determination of awards are 
sound and have been applied fairly. External examiner reports have significant status within the university. They are directed to the Vice-Chancellor and are considered at, and used by, the department and university in internal quality assurance committees. $(2008,5)$

The role of external examiner is independent of the institution; the external examiner is expected to follow the institution's policies and procedures and is paid by the institution. The examiner's role however is to offer a critical, peer review of the module, including the syllabus and assessment arrangements. S/he is expected to be autonomous and objective. Other countries have used an external examining system, e.g. Denmark, Ireland, New Zealand, Malaysia, Brunei, India.

Research on the assessment literacy of external examiners has raised concerns about whether external examiners, appointed as subject experts have the necessary assessment literacy to make robust decisions about comparable academic standards (Medland 2015; Bloxham and Price 2015; Bloxham et al. 2015). Following a critical review of external examining in the UK and concerns about the robustness of degree standards, a government-funded project has been designed to explore degree standards in the UK. The purpose of this five-year project is to:

- design, pilot and deliver different approaches to the professional development of external examiners

- propose evidence-based and cost-effective longer-term approaches to the professional development of external examiners operating across the higher education system in England, Northern Ireland and Wales

- explore approaches to the calibration of standards, presenting recommendations for future work in this area. (quoted from Advance HE 2019b)

Professional development of external examiners is important because external examiners may be the only external process to comment on academic standards.

\section{Critique of Codifications}

Written documentation of standards, such as the Framework of Higher Education Qualifications and subject benchmark statements aim to promote and maintain consistent standards across a discipline or a sector. 
However, written descriptions of standards are notoriously difficult to interpret; the language used in criteria such as 'argument', 'structure' and 'criticality' can be interpreted differently by different markers.

Sadler (2014) defines 'standards' as 'fixed reference levels of attainment' $(2014,193)$, as 'the recognised measure of what is adequate for some purpose, so established by authority, custom, or consensus' (2014, 189). Sadler terms all explicit descriptions of assessment standards (e.g. assessment criteria, grade descriptors, marking rubrics, intended learning outcomes, subject benchmark statements and graduate attributes) as 'codifications' - 'Codification is the act of developing explicit descriptions of standards...' (Sadler 2014, 275). The aim of codifications is to describe standards so that assessors can make similar judgements about the quality of student work. However, the descriptions of these levels of attainment in written documentation cannot fix standards. Research studies suggest that assessors' interpretations of codifications vary (Bloxham et al. 2011). One reason suggested for this variation is that the language of codifications is open to interpretation and because markers will draw on tacit knowledge to interpret, they will inevitably come to different understandings. Moreover, codifications, such as assessment criteria, cannot encapsulate the vast range of tacit knowledge that assessors draw on when making a judgement (Sadler 2014).

Sadler (2014) offers a detailed analysis of the limitations of assessment criteria, arguing that:

- there is often overlapping criteria $(2014,276)$

- some criteria are included, others not $(2014,277)$

- there is extensive use of hedge words, e.g. 'excellent', 'adequate', 'mostly' $(2014,279)$ which are open to interpretation by markers

- more detailed descriptions of criteria do not clarify; they are also open to interpretation $(2014,279)$.

The 'fuzziness and elasticity of specifiers' (Sadler 2014, 286) in assessment in higher education results in fuzzy standards. But it is impossible to precisely describe these standards; more and more description is not going to lead to more exact standards. One reason for this is the nature of learning in higher education. The goal of some degrees, particularly at postgraduate level, may be to lead learners to construct new knowledge (see Chapter 5 for examples of student involvement in knowledge building). Criticality, knowledge construction 
and creativity may be highly valued by teachers but are difficult to pin down in codifications (Sadler 2014, 278).

\section{Ways Forward: How Disciplinary Communities Establish Standards}

If standards cannot be reliably described in written documentation, how can they be fixed? Butler Shay's (2004) interesting work on the nature of academic standards suggests that standards are held within disciplinary communities and are socially constructed within the community. Socially constructed academic standards imply that within each discipline, teachers can reach agreement on the appropriate standard of work at each level of study. Through discussion, standards come to be socially constructed within the community; the community determines and maintains the standards. In Chapter 2, I discussed the idea of learning within a community of practice (Wenger 1999) and the way in which knowledge is constructed and held within the community. Sadler argues for standards as 'fixed reference levels' $(2014,283)$ and 'comparability across both contexts and time requires that standards are not only held in common, but also kept secure...' (2014, 284). He also states that 'if standards could be fixed over time, students' achievement could be graded with integrity' (Sadler 2014, 283). If we accept Sadler's argument, then there is a need to establish a process whereby disciplinary communities can discuss and agree standards. In some countries, the commentator on standards is the external examiner but, as discussed above, studies have shown external examiners are not necessarily experts in assessment or national standards so, currently, external examining is not a robust process for ensuring standards. An alternative process for ensuring comparability of academic standards has been trialled in Australia. The use of calibration as a means of establishing disciplinary standards has been introduced, and calibration trials have also been conducted in the UK as part of the Degree Standards Project (Advance HE 2019b).

\section{What is Calibration?}

Calibration is a process whereby a community of teachers and practitioners discuss and compare exemplars of students' work in order to reach consensus and agreement on a standard. Calibration has been used to agree degree standards, especially borderline classifications, 
and understandings of key assessment criteria. Research in this area is recent, so there is no body of evidence to draw on to make claims about the effectiveness of calibration, but there are studies that suggest that calibration activities can lead to more consistent assessment judgements (Watty et al. 2014; O'Connell et al. 2016).

The following case study describes how calibration works.

\section{Case Study: Calibration of Threshold Standard for Bachelor Graduates in Accounting}

Type of programme - bachelor's degree in accounting

Level - undergraduate

What's of interest - implementation and evaluation of calibration meetings as a means to ensure comparable national standards

This initiative to ensure comparable national standards in accountancy in Australia, engaged with 30 participants from 10 of 40 Australian universities representing a broad cross-section of business schools.

Participants were senior accounting academics (two participants from each university) and practitioners. Three iterations of the calibration activity were carried out in Darwin, Melbourne and Adelaide. They aimed to calibrate a threshold standard, namely, bachelor graduates will be able to:

Justify and communicate accounting advice and ideas in straightforward collaborative contexts involving both accountants and non-accountants. (Watty et al. 2014)

The participating universities provided anonymised samples of final year students' written work. The calibration exercise involved three stages. Before the workshop, participants viewed samples online and rated the samples as to whether the threshold standard was met or not met; the project leaders felt having to decide between two grading categories would produce more agreement. Grades were submitted using an anonymised online system along with reasons for the grading decisions. After submitting grades and reasons, participants could then view other participants' grades and comments, which were anonymised. Anonymity was important for participation. Viewing grades and comments helped assessors reflect on their own judgements and prepared them for the follow-up face-to-face workshops. 
The second stage was face-to-face workshops, attended by all participants. The workshops lasted three to six hours and consisted of dialogue around the samples and pre-workshop gradings. All reviews remained anonymous. Initially participants broke into small groups for a detailed discussion of the samples and threshold concept. This discussion helped develop a 'shared understanding' of the threshold standard and participants decided whether the sample met that standard. Finally, there was a plenary discussion with the aim of reaching a group consensus on which samples met the threshold and why. The third and final stage was a remarking of the samples, following the workshop discussion and within two weeks.

The project team carried out an evaluation of the calibration process, collecting self-reported comments on the efficacy of the discussions. Participants felt that the process helped reduce variation and achieve more consistent assessment judgements:

I think that the peer review process including the workshops themselves doe[s] help build a shared understanding of the standard recognizing that assessment of it is still a judgement call for all of us. Variation in assessments will definitely decline following the workshop in my view. (Watty et al. 2014, 472)

Participants became more confident in their ability to judge national threshold standards after the second iteration:

The Darwin workshop and, specifically, the social aspect of the moderation process appeared to foster this confidence. (Watty et al. 2014, 473)

However, after the third iteration, participants gained an increased understanding of the complexities of assessment judgements and gaps in their own knowledge:

However, and quite significantly, this confidence was not as prominent a theme as it was in the Melbourne pre-workshop data. There were also quite a few assessors who revealed scepticism about achieving consistency across multiple markers. (Watty et al. 2014, 474)

The aim of the calibration was not to achieve 'perfect agreement'. The project team recognised that there are many reasons for variation in 
assessor judgements (as discussed in this chapter). Their aim was to 'to facilitate consistency and thus reliability and validity in marking' (Watty et al. 2014, 472).

\section{Further Reoding}

For further information about this case study see:

Watty, Kim, Mark Freeman, Bryan Howieson, Phil Hancock, Brendan O'Connell, Paul de Lange and Anne Abraham. 'Social Moderation, Assessment and Assuring Standards for Accounting Graduates', Assessment and Evaluation in Higher Education 39, no. 4 (2014): 461-78.

See also a description of calibration activities in the Degree Standards project: Advance HE. 'The Degree Standards Project', (2019b). Accessed 10 November 2019. www.heacademy.ac.uk/ degree-standards.

\section{Implications for Practice: Ways of Developing Markers}

The considerable body of research into marking in higher education supports the claim that marking in the sector is unreliable. Lack of reliability stems from the role of tacit knowledge in assessor judgements, the impossibility of producing accurate written standards of complex student work, the 'ill-structured' (Voss and Post 1988) nature of assignments which aim to assess complex learning and the lack of opportunities for calibration of standards. Calibration as a way of improving reliability of marking judgements, across a programme and across a discipline has potential (Watty et al. 2014); calibration activities are being actively researched (O'Connell et al. 2016; Beutel et al. 2017). In the UK, calibration activities have been organised in a range of disciplines, e.g. geography and law, as part of the work of the Degree Standards Project (Advance HE 2019b). Workshops, calibration toolkits and case studies have been developed to provide guidance on how to do calibration (see Advance HE https://www.heacademy.ac.uk/ project-section/calibration-in-practice).

Calibration can be used at programme team level, across a department, and across a discipline (at national level). Through sharing standards in a programme, team or across a department, marker judgements may be made more consistent and reliable, though variation 
in judgement would still be expected given the complex assessment tasks that students undertake. In calibration activities, teams spend time discussing and agreeing standards before marking, so an ideal time to start this work is towards the end of the academic year. Team leaders can start by creating resources for sharing standards with teachers and students; for example, collecting and anonymising a range of student assignments that illustrate a standard or criterion.

To organise calibration sessions, collect exemplars of students' assignments, particularly around grade boundaries or work that illuminates a particular assessment criterion. Distribute to the teaching team and ask them to read and make a judgement about the assignments and give a rationale for that judgement (without using assessment criteria or rubrics); record these anonymously in a virtual learning environment. Either online or in a face-to-face meeting, discuss exemplars in groups and through discussion, try to tease out a list of characteristics used by the group to make a judgement about the standard of the exemplar. If agreement is reached, document this, recording the agreed characteristics.

If agreement cannot be reached, try to identify the issues that prevented agreement, e.g. did the requirements of the assignment divide opinion? This can happen when students are required to make videos, write blogs and undertake other non-traditional forms of assessment. Assessors may disagree on the relative weighting to assign to the form (e.g. essay, video, web page) and the content of the assignment.

Were there disciplinary differences? Did assessors have fundamental, epistemological disagreements? This can happen in interdisciplinary programmes or in subjects that attract scholars from a variety of disciplines; for example, engineering may have teaching teams drawn from computer sciences, biomedical fields, mathematics and physics. In politics, teachers may come from history or the social sciences, and some may take a predominantly quantitative view of research, while others may adhere to qualitative paradigms with a constructivist underpinning, such as naturalistic inquiry (Lincoln and Guba 1985).

Agreeing standards before marking, is more effective than relying on post-marking moderation (Bloxham 2009). However, calibration takes time and needs to be factored into workloads and planned within the programme schedule. There will always be variation in marking standards; there is no one correct grade for complex student work and variation in judgements is to be expected. However, as the studies cited above indicate, calibration has potential to establish more robust academic standards. 


\section{Follow-Up}

Reading

For more on how markers use assessment criteria read:

Bloxham, Sue, Peter Boyd and Susan Orr. 'Mark My Words: The Role of Assessment Criteria in UK Higher Education Grading Practices', Studies in Higher Education 36, no. 6 (2011): 655-70.

For a detailed exploration of codifications of academic standards read:

Sadler, D. Royce. 'The Futility of Attempting to Codify Academic Achievement Standards', Higher Education 67, no. 3 (2014): 273-88.

For a description and evaluation of calibration activity in Australia read:

Watty, Kim, Mark Freeman, Bryan Howieson, Phil Hancock, Brendan O'Connell, Paul de Lange and Anne Abraham. 'Social Moderation, Assessment and Assuring Standards for Accounting Graduates', Assessment and Evaluation in Higher Education 39, no. 4 (2014): 461-78.

\section{Investigating Your Practice}

Try calibration in your disciplinary team or link up with a disciplinary team from another institution to calibrate across teams. Begin by setting up a collaborative virtual learning environment, e.g. a Moodle or Blackboard, to collate marks and feedback on exemplar assignments and share with other teams. Follow the guidelines in this chapter for organising calibration and use the toolkits on the Degree Standards webpage (Advance HE 2019b). Evaluate the impact of calibration both on markers' confidence levels and on variation of marking judgements. You should follow-up the calibration activity with an investigation of impact. Using interviews, a survey or reflective journals, you could investigate whether teachers feel more confident about their marking judgements. Or you could investigate whether the calibration activity brought about any changes in marking consistency in the department by examining first and second markers' grades. Is there more agreement? Remember, however, that there may be many reasons for greater 
agreement of grades (see the discussion in this chapter on factors that affect markers' grades).

\section{Exploring Teacher judgement}

Capture teachers' judgements and what they value in student assignments. Begin by deciding what to calibrate, e.g. an assessment criterion or a borderline degree classification. Collect at least three exemplars of students' work (ensuring that students give permission). Make sure you have a range. Anonymise the exemplars and ask colleagues to, without using assessment criteria or rubrics, explain what they value in the assignments, giving reasons for their assessment judgements; see the Stem Wishees website for examples of self-recordings from academics discussing what they value in students' assignments (http://www.thinkingwriting.qmul.ac.uk/wishees ).

Ask colleagues to record their reasons in writing and upload to a virtual learning environment. They may want to think about the below questions.

- What they wanted students to do.

- What they valued in each exemplar.

Analyse the reasons given and what markers say they value. Are there common characteristics that all markers draw on? Do markers make similar judgements about the quality of students' work but give very different reasons? What other issues can you identify? Share the teachers' judgements with your colleagues and use to discuss the consistency of marker judgement in your team. 


\section{Chapter 7}

\section{Peer and Collaborative Assessment}

This chapter explores the advantages and pitfalls of involving students in the assessment process. The importance of developing trust through developing students' competency and integrity is highlighted (Carless 2009) and there are examples of practical activities that aim to develop trust.

In Chapter 6, I discussed academic standards, arguing that standards are constructed within the teachers' community of practice (Sadler 2014; Butler Shay 2004). Teachers benefit from discussing and sharing their understandings of standards between each other, as well as sharing these understandings with students. Students need a good understanding of academic standards to direct their learning. In this chapter, I describe how students can become fully involved in the assessment process, co-designing assessment tasks and making judgements about the quality of their own and their peers' work. This involvement, and preparation for assessment design and marking, ensures that students have a good understanding of assessment processes and standards, are able to make judgements about their own and their peers' work, can direct their own learning and plan strategies to develop their work.

\section{Why Involve Students in Assessment?}

When students are involved in the assessment process, they gain an understanding of the standards they are expected to achieve. In influential papers, Sadler (1989, 2009 and 2010) argues that students need to develop their understanding of assessment standards through 
involvement in activities that replicate the experiences of markers (see also the discussion in Chapters 2 and 8 on evaluative judgement).

Teachers develop their understanding of academic standards through their assessment experiences and interactions with peers (Bloxham and Price 2015; Sadler 2014; Butler Shay 2004). When teachers set an assessment task, they may not know initially what students are able to produce in response to the task, particularly a new assessment task. It is through seeing many student responses to assignments, seeing the range of work that students can produce, making judgements about that work and discussing these with peers that they develop a sense of standards on the programme (Sadler 2010). In co-constructing academic standards, programme teams articulate what counts as good quality student work (see Chapter 6 for a discussion on calibration). Sadler (2010) argues, that students need to experience a similar process; they need to see a range of work in order to develop an understanding of quality; by showing students a range of work, we expose them to the kind of experiences markers have. Through group discussion on the quality of this work, students are helped to develop an understanding of standards and an interpretation of assessment criteria.

The overt aim is to shift the focus away from telling students about the quality of their work (disclosure) and towards having them see and understand the reasons for quality (visibility), and in the process develop personal capability in making complex judgements [...] educating students in the art of making substantive and comprehensive appraisals in ways similar to those characteristically used by expert assessors. (Sadler 2010, 546-7)

If students have the opportunity to create constructions of academic standards and understand the standard they need to reach, they are less dependent on teachers telling (transmissive) them what to do (Sadler 2010). This frees students from the need to check constantly with teachers or to be dependent on teachers for feedback on their work. Students can avoid 'learned dependence' (Yorke 2003, 489) on a teacher and become more autonomous learners. Through these experiences they develop assessment literacy which Price et al. (2012) define as a range of knowledge and skills, namely: 
- an appreciation of assessment's relationship to learning

- a conceptual understanding of assessment

- understanding of the nature, meaning and level of assessment criteria and standards

- skills in self- and peer assessment

- familiarity with technical approaches to assessment (e.g. familiarity with pertinent assessment and feedback skills [...]

- possession of the intellectual ability to select and apply appropriate approaches and techniques to assessed tasks. (quoted from Price et al. 2012, 10)

Teaching idea - Paraphrasing assessment criteria (Carless 2016)

Assessment criteria is written in a professional discourse which is difficult for students to interpret (see Chapter 6). Check student understanding of assessment criteria by asking them to paraphrase the criteria in their own words. This can be done online or at the start of a seminar. Give students an exemplar of an assignment and the assessment criteria for the assignment. Ask students in pairs or small groups to take one criterion and rewrite the criterion in their own words. Share and comment on the rewritten criterion. This helps to demystify criteria and creates shared understandings of criteria.

Collect and compare paraphrasing and discuss online or face-toface. Does this activity reveal misunderstandings of the criteria? What are they?

(See Carless 2016: https://tinyurl.com/tfr8k8j.)

You could follow up this activity by looking at exemplars and identifying aspects of the criterion in students' work, e.g. what does good quality analysis look like in students' work?

Follow this work with a guided marking activity.

(See the explanation of guided marking in this chapter, below.)

Students' assessment literacy can be enhanced by involving them in assessment design and assessment judgements, but there are drawbacks. Students (and teachers) may not see this involvement as relevant to their studies. They may feel that they should be learning more content, more medicine or engineering. However, assessment is part of learning and needs to be fully integrated into the programme structure (see Chapters 3, 4 and 5). Activities to help develop students' assessment 
literacy, especially an understanding of academic standards, also need to be part of the programme; without an understanding of academic standards students cannot become self-directed learners (see box on previous page).

Peer assessment is widely advocated in the literature but students' perceptions of this vary. Students may view assessment design and marking as teachers' work (Wilson et al. 2015) and, in the education market economy, they may feel short changed. In recent studies, students have expressed resentment about doing the teachers' job and an increased student workload (Wilson et al. 2015; Van Zundert et al. 2010; Planas Lladó et al. 2014). They may also feel that they are not competent to take on these tasks and, if peer assessment is undertaken, may feel their peers are not competent. Preparing students and developing their competence is key to ensuring they understand and benefit from involvement in assessment.

\section{Establishing Trust}

Recently, many studies on peer assessment have raised concerns around issues of trust, fairness, friendship marking and peer pressure (Raes et al. 2015; Wilson et al. 2015; Cartney 2014; McConlogue 2012; Liu and Carless 2006). Students are concerned about their peers' ability to give good quality feedback and the perceived laziness of peer assessors. Factors that militate against effective peer assessment are students' lack of understanding of standards, the competitive higher education environment (Wilson et al. 2015), and modularisation of degree programmes, which creates difficulties in mapping assessment across a programme and building assessment literacy.

Wilson et al. $(2015,19)$ have called for a more 'nuanced' view of peer assessment, recognising the 'realities' of peer assessment in practice. Student resistance to peer assessment is particularly strong when peer assessment involves giving summative grades, and less resistant when students are involved in formative peer review activities. There is wide agreement that students need to be prepared for peer assessment (Topping 2010; Orsmond 2004; Falchikov 2004). Sluijsmans et al. (2002) have argued for an extended preparation period - not just a one-off workshop. Some of the common issues in peer assessment can be found in Table 7.1. 
Table 7.1: Peer assessment issues (sources: Liu and Carless 2006; Cartney 2014; McConlogue 2012; Wilson et al. 2015)

\begin{tabular}{|l|}
\hline Peer assessment issues \\
\hline Peers give widely different grades (summative assessment) \\
\hline Peers give inconsistent feedback - poor quality feedback \\
\hline Laziness of peer assessors \\
\hline Peers' lack of understanding of standards \\
\hline Competitive HE environment \\
\hline Friendship marking \\
\hline
\end{tabular}

It is clear from these studies that good preparation of students is essential; before involving students in assessment, the teacher needs to ensure they have a good understanding of academic standards on the programme and that they have had previous practice of designing tasks, working collaboratively, making judgements about peers' work, writing and responding to feedback and self-assessing.

\section{Developing Student Competency and Integrity}

Competence and integrity are seen as key to successful peer assessment. Carless (2009) argues that students need to acquire competency and integrity in order to perform the role of peer assessor. Competent peer assessors understand the required academic standards and are able to make judgements about the quality of peers' work, with integrity. They can also give good quality feedback and respond constructively to peers' feedback comments. For students to be competent, they need to understand academic standards and have enough experience assessing work in the relevant setting so that they can make a judgement about the standard of that work and self- and peer assess. In successful peer assessment, students demonstrate integrity and put effort into giving good quality feedback; when students feel their peers have not put effort into giving feedback, they lose confidence in their peers' judgements. Lack of integrity leads to 'anger' towards students who do not fully participate in peer assessment (Cartney 2014, 559). Competent peer assessors have acquired a good understanding of the purposes and processes of assessment and assessment standards, are able to make judgements about the quality of work and compose and use feedback to move on in their learning. 
Drawing on the research literature, I propose four key principles to consider when developing students' understandings of academic standards.

1. Students need to see a range of their peers' work. This may be exemplars from a previous year or a similar assessment. Sadler (2010) argues that student experiences need to mirror teacher experiences in order to develop a good understanding of quality; teachers see a wide range of student work and this helps them develop an understanding of quality.

2. Students need to articulate what they value in these exemplars, e.g. through oral or written comments. Articulating what they value is a powerful learning experience. Composing feedback is cognitively demanding and helps students develop assessment judgements as they assess peers' work (Nicol 2010; Nicol et al. 2014; McConlogue 2015).

3. Students discuss their value judgements with others and engage in dialogic feedback (Carless and Boud 2018) with peers and teachers. Through discussion in a community of practice, students compare their understandings and negotiate socially constructed standards within the group. (See Sadler 2014, Butler Shay 2004 and Chapter 6 for more on the socially constructed nature of academic standards.)

4. Students develop confidence in their peers' ability to assess and give feedback; peers are perceived as having good levels of assessment literacy (competency) and are trusted to give detailed and helpful feedback (integrity) (Carless 2009).

These principles can be used to design assessment activities to develop students' understanding of assessment. The flexible framework proposed in this chapter suggests ways of gradually introducing students to peer assessment, building expertise across a programme of study. A key aspect of the framework is ensuring that students are gradually introduced to the notion of academic standards and acquire experience in making assessment judgements. In the framework it is assumed that when students feel that their peers are competent, they are more likely to value peer feedback. If levels of trust in the group are not high, students can still develop their understanding of academic standards without engaging in peer assessment through engaging in stage one preparation activities (see below). 


\section{Activities for Developing Competence and Integrity}

\section{Stage One: Preparation Activities}

Falchikov (2004) points out the importance of preparation in getting students onboard. Preparation activities occur at the beginning of the programme, when students are in most need of checking their understanding of assessment standards and are most likely to accept working with peers as the 'norm' for this programme of study (Rudy et al. 2001). The aim is to move students away from relying on authoritative teacher feedback at an early stage, thus helping students to avoid 'learned dependence' (Yorke 2003, 489) on teacher feedback.

\section{Guided Marking}

This is a widely-used strategy, designed to help students explore and gain an understanding of teacher expectations and standards. Students read a range of written work from a previous year or view recorded presentations. The previous year assignments show a range of quality (for example, assignments judged by the teacher to be satisfactory, good and excellent) so that students see a range of possible responses to the assignment brief and can begin to make judgements about the quality of work (principle one above). Guided marking is organised either in a seminar or lecture, or online, before students start their own assignments so that their experience of reading and discussing these assignments helps them to understand teacher expectations. Students articulate their judgements in feedback comments (principle two above). It is crucial that the teacher organises online or face-to-face discussions about the judgements students make, as this gives students the opportunity to explain their judgements, raise issues and question the teacher about his/her judgement and what s/he values in the assignment (principle three above) - see box on following page.

\section{Morker's Commentory}

Explaining standards is difficult; showing a range of exemplars and explaining why the exemplars meet the standard helps students better grasp what they need to aim for. In a marker's commentary, teachers comment on past assignments explaining their assessment judgements 
Teaching idea - How to implement guided marking

Organise guided marking at the start of a module, as it helps students understand the standard of assignment required.

Start by collecting exemplar assignments from previous year students and gain permission to use these exemplars. If the module is new, use similar assignments from a related module. Explain the assignment to students either online or in class. Students then receive assessment guidelines and three exemplars that show a range of work (borderline to excellent); it is important that students see a range as this helps develop their understanding of quality (Sadler 2010).

Give students sufficient time to read, rank, give grades and make comments on the exemplars. This can be done online in a virtual learning environment, e.g. using a Moodle workshop (see below and https://docs.moodle.org/22/en/Workshop_module for a description of how to use Moodle workshop). Either online or in class, lead a discussion on the exemplars, comparing grades and comments. Prompt students to discuss key issues, e.g. presentation of results, criticality and creativity. It helps students to interpret standards and assessment criteria if you can point to examples of these criteria in the exemplars, explaining what you value in student work. Finally, give students practice in writing constructive feedback on the exemplars; they can post and share feedback online and you can also share your feedback comments. Lead a discussion (online or face-to-face) on what feedback students find helpful and why.

This activity helps students, especially first year students, to better understand what good quality work looks like in their discipline. It also helps you to explore and guide their thinking and share your knowledge of academic standards. Be prepared for lively discussion and for challenges to your grading and feedback comments.

of exemplar assignments, discussing what they value in the work and explaining difficult concepts like 'criticality' by pointing out concrete examples in the work: 'this is what I mean by criticality and here's an example in this assignment'. See the Stem Wishees website for examples of marker's commentaries (http://www.learningdevelopment.qmul. ac.uk/wishees). In recorded videos, teachers use exemplars to clarify their expectations and explain assessment standards. 
A follow-up discussion is organised, e.g. through a seminar or online forum, so that students can ask questions and critique the teacher's judgements (dialogic feedback, principle three above).

Teaching idea - How to make a marker's commentary

Use a marker's commentary to reinforce the guided marking activity or as a replacement. Marker's commentaries can be done wholly online or blended; students can read exemplars and listen to a recorded commentary online and discuss later in a lecture or seminar. To make a marker's commentary, first collect examples of a range of student assignments for your module, with permission to use, and anonymise.

Think about the assignment task you set and what you expected students to achieve. It is helpful to think about what you value in students' work; this may be criticality, creativity or a demonstration of professional competencies. Look for examples of these qualities in the range of exemplars. Make a short video or audio recording or write a short commentary on what you value in the exemplars, clarifying your expectations. You may want to listen to examples of teachers doing this on the Stem Wishees website (see http:// www.thinkingwriting.qmul.ac.uk/wishees/collections/quinnipiac/ microbiologyundergraduatereport/55529.html for an example). Post the written or recorded (audio or visual) commentaries online. Encourage dialogue; ask students to discuss the exemplars and commentaries. This can be done anonymously using an online forum. Follow up the discussion and post frequently asked questions (FAQs) with responses. Monitor use of the marker's commentary and use student feedback to improve your commentaries and clarify misunderstandings.

\section{Peer Review}

In peer review, students are provided with opportunities to articulate their judgements and try out their new understandings of teacher expectations by reading their peers' written assignments or listening to/ watching oral presentations and giving feedback. Principle two states that students articulate their judgements, either orally or in a written form. There is evidence that composing feedback is beneficial, and perhaps more beneficial than receiving it (Nicol et al. 2014; McConlogue 2015; Kim 2009). 
As giving feedback to peers is one area of contention (because of power relations and friendship marking (Liu and Carless 2006; Cartney 2014)), in order to maintain good group relationships this feedback is initially written for the teacher, and not shared with peers. In composing feedback, students articulate their understanding of assessment standards, giving the teacher some insight into what students understand and what they struggle to understand. Teachers comment and respond to student feedback either individually or, depending on class size, with generic feedback, explaining what they thought students did well, ways they could develop their feedback and what they should comment on. As students do not receive their peers' feedback, the conflict in the group that can arise is avoided while students develop expertise in articulating feedback. Students can use insights from peer review discussions to self-assess their work.

\section{Using Preporotion Activities}

Depending on the students' prior expertise, preparation activities could be performed several times at the beginning of a programme of study (e.g. throughout the first year of an undergraduate programme, or the first term of a postgraduate programme) so that students gradually build up expertise. There is evidence that, over time, the quality of students' feedback improves as their understanding of disciplinary constructs develops (Wen and Tsai 2008). As an added bonus, students can use their growing expertise to self-assess their own work before submitting, thus directing their own development.

After each of these activities, the group debriefs, evaluating how well the activity worked and what the group gained from it. Lessons are learned for the next iteration. The framework is flexible and designed to be adapted to any educational context; the teacher and students decide whether they want to progress to the next stage. They may decide to stay with stage one activities as these cover the first three principles for developing understandings of academic standards.

\section{Stage Two: Practising Activities}

Once students have sufficient experience of preparation activities, the group takes a decision as to whether to move on to practising activities. Depending on the context, some groups may feel most comfortable and derive the most benefit from stage one activities, and may wish to continue with these while other groups may move on quickly to stage 
two and three activities. (See below, How the framework might be used, for more suggestions.)

\section{Peer Review and Exchange of Comments}

Peer review of summative activities is obviously higher risk than peer review of formative activities and necessitates a level of competence, so that assessment feedback is perceived as reliable (or at least as reliable as teacher feedback). A level of integrity is developed so that competition and friendship marking (Wilson et al. 2015; Carless 2016) do not affect the feedback. Multiple peer assessors can help develop judgement as students see multiple views of their work and this can support students in composing a response (a rebuttal) to peer reviewer comments.

At this stage of the framework, students initially start a peer review of draft assignments or practice oral presentations. Students receive feedback on draft work or on practice presentations and then use this feedback to improve the final assignment before submitting for teacher marking. By this stage, the first three principles have been met, and the exchange of feedback comments has begun the process of developing trustful relationships within the group (principle four).

\section{Peer Assessment (Summative)}

For summative peer assessment, students need to have confidence in their peers' competence and integrity. In summative peer assessment, students award grades as well as providing feedback. Grading work, rather than just commenting, is more contentious and causes more student protest. Commonly reported problems are lack of engagement, poor quality feedback (leading to lack of trust in the peer assessor) and friendship marking (McConlogue 2015; Cartney 2014; Wilson et al. 2015). To minimise contention, peer assessment is introduced on small tasks, e.g. a background section of report (McConlogue 2012), which carry a small percentage of the overall final summative grade. After submission of the assignment, students attend a rehearsal marking (Falchikov 2004), where they are provided with a sample range of the assignments to be assessed; rehearsal marking can also be set up online. In the rehearsal marking, students have an opportunity to ask questions about how any difficult concepts or calculations should be marked. Following principle one, they see and grade a range of assignments. They discuss their grading in groups and with the teacher, and practise composing feedback comments. Students are now prepared to peer 
assess assignments. Assignments are allocated to students and, within an agreed deadline, they grade and write feedback comments which are automatically returned. Students receive their grades and feedback and then write a rebuttal to the peer reviewers.

As students develop the ability to give good quality feedback, the group decides whether to peer assess larger and more heavily weighted assignments. A requirement for moving on to the next stage is that teachers and students are confident of their own and their peers' ability to give reliable grades and feedback. To further establish trust, moderation and complaints procedures are set up. Friendship marking and grader reliability can be monitored, especially if an online system is used (e.g. a Moodle workshop, see Wilson et al. 2015 for an explanation). Complaints procedures provide a safety valve for dissatisfied students. Commentary on peer feedback, or a rebuttal, where peers explain whether the feedback was helpful and what they will use from it, mirrors the peer review process. The rebuttal provides a safety valve for students who feel disgruntled with their reviewers' comments and ensures that students take review seriously and give responsible comments. The rebuttal also helps reviewers reflect on the comments they compose and how they might be improved, thus developing their expertise. After each of these stages, the group debriefs, evaluating how well the activity worked and lessons learned are used to develop the next iteration or progression to the next stage.

\section{How to Organise and Moderate Peer Assessment}

Good organisation and preparation are essential for successful peer assessment (see Figure 7.1). Follow the guidelines for preparation above; for example, guided marking and rehearsal marking. Once students are ready to peer assess, ensure that their assignments are submitted and anonymised, e.g. use an online tool like a Moodle workshop (see below and https://docs.moodle.org/22/en/Workshop_module). Allocate peer assessors, ensuring each student receives multiple assessors; a Moodle workshop can be set up to automatically allocate multiple assessors. If possible, group assignments according to level and ensure peer assessors receive a range. Provide a feedback worksheet for guidance and/or feedback comments (ensure both have been used and discussed in preparation activities - do not introduce new worksheets at this stage). Ensure that students are aware of the moderation and complaints procedures. You need to be aware of any issues that arise during peer assessment so that you can resolve them quickly. Give peer assessors 
a deadline (e.g. two weeks). A Moodle workshop can be configured to automatically end access by the deadline and distribute grades and comments. Ensure you check grades and comments before they are made available to students; some software can help by identifying the spread of peer assessors' grades. Resolve any complaints and evaluate peer assessment using your reflections and student feedback to improve the next iteration.

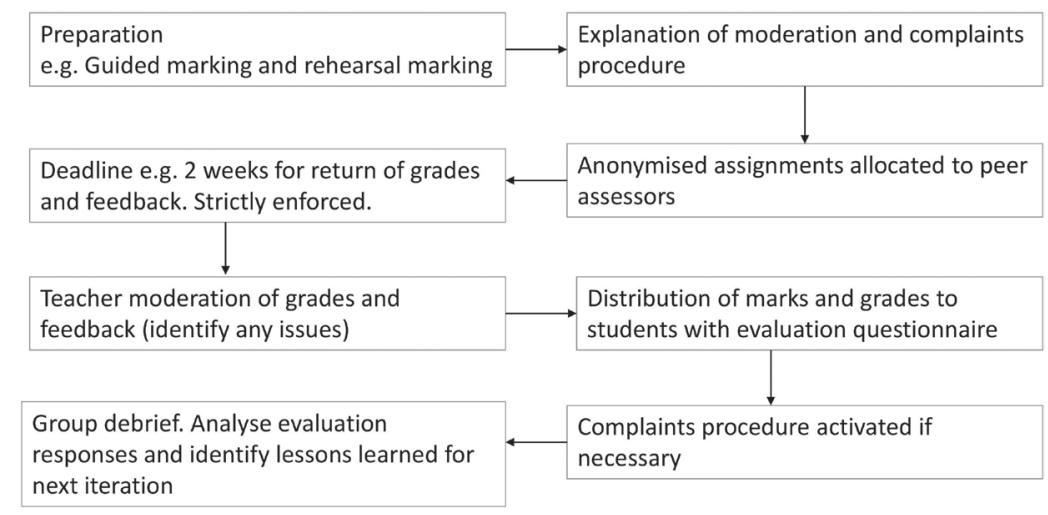

Figure 7.1: Organising peer assessment

\section{Using Software to Manage Peer Assessment}

Software can help enormously with the administration of peer assessment, especially in large classes. For example, Moodle can be configured to (adapted from Moodle 2019):

- $\quad$ set up practice 'rehearsal marking' activities; students mark exemplar assignments and compare with teacher's judgements

- collect submitted assignments

- $\quad$ anonymise and allocate assignments to peer markers

- host 'structured assessment forms', feedback worksheets, assessment criteria and 'rubrics'

- send reminders to peer assessors and close down when the deadline is reached

- $\quad$ collect and average marks from multiple markers

- permit teacher moderation of grades; teachers can 'overide' average peer assessor grade, if judged to be necessary

- distribute grades and feedback to students. 
(Adapted from Moodle 2019 Workshop Module: https://docs.moodle. org/22/en/Workshop_module. Also see https://docs.moodle.org/35/ en/Using_Workshop\#Workshop_grading for an explanation of grading.)

\section{Stage Three: Partnership}

Once students have completed preparation and practising activities (and how long this takes will vary depending on students' prior knowledge and experience) the group is ready to move on to the next stage, to collaborative assessment. The judgement about where to start and what to move on to is increasingly taken within the group with students and teacher collaborating, building a trustful relationship. For example, in a professional programme, the programme may start with stage one activities in the framework and move quickly through to stage three.

At the partnership stage, students have considerable expertise in making assessment judgements and composing, evaluating and acting on feedback. They also gain control over designing the assessment task, co-constructing assessment criteria, giving feedback and grades (McConnell 2002, 2006). This stage requires a high level of competency and integrity; the group needs to agree academic standards. The teacher's role is to facilitate group discussions, provide guidance on time commitments, mediate, and ensure student-developed assessments meet quality assurance and institutional requirements. To be able to handle this stage, students need to be acculturated into academic standards and assessment processes in the institution, and have developed expertise in making assessment judgements. As above, moderation and student complaint procedures should be clear.

\section{How the Framework Might be Used}

In an undergraduate degree, this framework could be used to develop understandings of academic standards across the programme, starting with stage one activities in the first year and progressing, if the group is ready, to stage three by the final year. Taught postgraduate programmes and continuing professional development courses, might begin with guided marking (stage one), but progress quickly through the stages and introduce collaborative assessment early in the programme or in the second semester (see McConnell 2006 for an example of this). As 
groups develop differently, interact differently, and as building a trustful relationship is especially essential to stage three of the framework, it is important the group makes a judgement about how fast to progress through the stages.

The institutional structures for quality assurance may present problems; for most programmes, the assessment diet is set and approved at the outset of the course. In order to involve students in decisions about the framework stage(s) most appropriate for their cohort, there would need to be flexibility so that these decisions could be made and reviewed throughout the programme, depending on the cohort's needs, how they get along together and how quickly their expertise in giving constructive feedback develops.

Activities that develop students' understanding of academic standards and provide lots of opportunity for dialogue, so they can compare their constructions with peers' and teachers' constructions, need to be included in the programme design. Figure 7.2 summarises the stages and relevant activities and corresponding assumed development of competency and integrity.

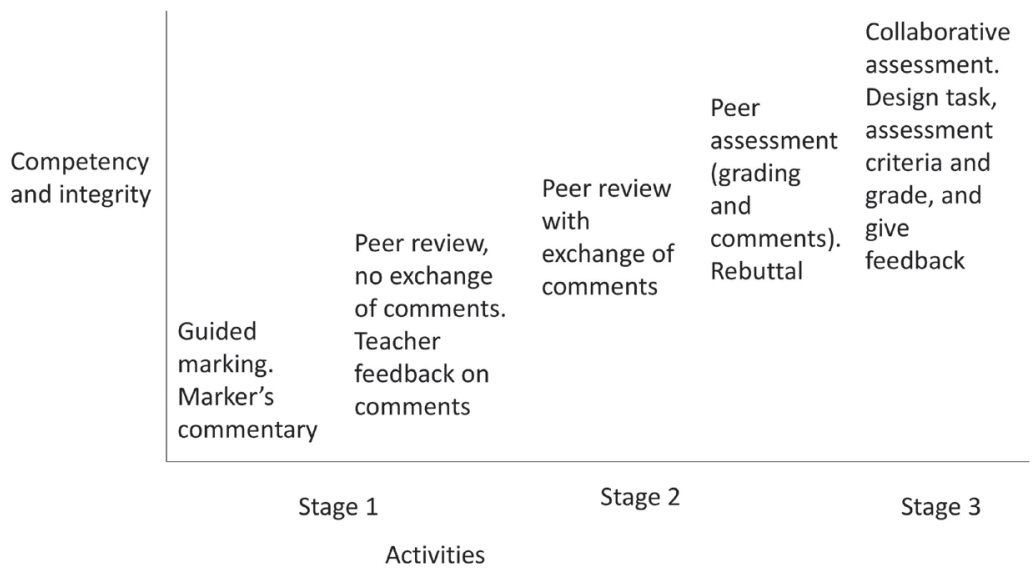

Figure 7.2: Stage 1-3 activities (preparation to partnership)

The following case study discusses collaborative assessment in an online master's programme, illustrates student involvement in co-designing tasks, constructing assessment criteria, giving feedback and agreeing grades. 


\section{Case Study: Peer and Collaborative Assessment in an Online}

Master's Course

Type of programme - MEd in e-Learning

Mode - fully online

Level - postgraduate

Cohort - home and international students

Learning approach - collaborative learning community (community of practice, democratic approach to learning and power relationships)

What's of interest - use of collaborative assessment; students design the assessment tasks, specify standards collaboratively, devise assessment criteria, work in groups or individually and carry out self-peer-teacher review of assignments.

This fully online master's programme recruits students interested in e-learning, typically education professionals, e.g. teachers and librarians. The programme is run entirely online, with students working collaboratively in groups, or with a teacher, in small learning sets. The groups communicate through conferencing software with areas for social chat and areas for collaborative and co-operative learning. At the start of the programme there is an initial 'socialising' stage, where students exchange information and start to form a community (Brauer et al. 2019; Salmon 2010, 2019). For example, they may write a professional story, reflecting on the key influences on their practice and share appropriate sections with the group. Throughout the programme, the emphasis is on students working together, either collaboratively on student-designed tasks, or co-operatively on individual tasks, sharing discussions and supporting each other. Assessment is seen as an integral part of learning on the programme; assessment is 'part of the content of the course' (McConnell 2006 , 93). The learning community communicates through online fora, divides into smaller learning sets to work on specific projects and tasks, and comes together in online workshops. The action research approach to learning in the programme means students are involved in a range of small-scale research projects and in discussions and critique of research paradigms and methodologies.

\section{The Role of the Student}

Students work as part of a learning community and are required to participate actively in online discussions, to share, discuss and support 
each other's learning. Working together, the groups devise and negotiate assessed tasks. In designing the tasks, students also discuss what academic standard their work needs to reach and agree the design of the task and assessment criteria. This collaborative construction of the tasks and mutually agreed assessment criteria helps students better understand academic standards on the programme. Groups are able to choose the assessment topic (see Chapter 9 for a discussion of assessment choice and inclusive practice) and receive support from their peers and the teacher. In asynchronous online discussions, they explore ideas and share resources. Drafts are self-peer-teacher reviewed; the student first reviews their own work, identifying areas for development and requesting support. Peers and the teacher work to help the student with suggestions for ways of developing and enhancing their work.

\section{The Role of the Teocher}

The teacher guides students and mediates between student desires and institutional regulations. $\mathrm{S} /$ he ensures that the assessment tasks are valid and of the appropriate level and feasible within the module timeframe. The democratic approach to power relationships in the programme means that the teacher's review and assessment of student work can be challenged by individual students or the group as a whole. The final grade for any assignment is agreed across the whole learning community (which includes the teacher).

Students are, on the whole, very positive about experiencing collaborative assessment. One student commented:

The assessment process is a lot more integrated into the whole learning process. Instead of being something 'out there' and threatening, it can actually be a supportive and motivating process. (McConnell 2006, 140)

Others commented on the difficulty of offering criticism that might offend. One commented:

I wouldn't exactly say ‘too kind' but each peer reviewer has come in with very, very constructive remarks indeed ... (McConnell 2006, 132) 
While another expected the teacher to intervene:

I think saying the really hard things is the responsibility of the teacher, because despite the fact that I know how keen you (the teachers) were in dismantling those differences, the bottom is not possible, and there were times when I thought 'no I want teacher intervention here' ... (McConnell 2006, 127)

\section{Further Reading}

For a full account of this programme and evaluation data, see the titles below.

McConnell, David. E-Learning Groups and Communities. Maidenhead: Open University Press, 2006.

McConnell, David. 'The Experience of Collaborative Assessment in e-Learning', Studies in Continuing Education 24, no. 1 (2002): 73-92.

For research on online socialisation see:

Brauer, Sanna, Anne-Maria Korhonen and Pirkko Siklander. 'Online Scaffolding in Digital Open Badge-Driven Learning', Educational Research 61, no. 1 (2019): 53-69.

Salmon, Gilly. 'The Five Stage Model'. Accessed 10 November 2019. www.gillysalmon.com/five-stage-model.html.

Salmon, Gilly, Ming Nie and Palitha Edirisingha. 'Developing

a Five-Stage Model of Learning in Second Life', Educational Research 52, no. 2 (2010): 169-82.

\section{Follow-Up}

\section{Reading}

To learn more about the pitfalls of peer assessment, read:

Wilson, Michael John, Ming Ming Diao and Leon Huang. "'I'm Not Here to Learn How to Mark Someone Else's Stuff": An Investigation of an Online Peer-to-Peer Review Workshop Tool', Assessment and Evaluation in Higher Education 40, no. 1 (2015): 15-32. 
For more on trust and integrity, read:

Carless, David. 'Trust, Distrust and Their Impact on Assessment Reform', Assessment and Evaluation in Higher Education 34, no. 1 (2009): 79-89.

For an investigation and evaluation of collaborative learning, read:

McConnell, David. E-Learning Groups and Communities. Maidenhead: Open University Press, 2006.

\section{Investigating Your Practice}

Introduce guided marking in your programme, especially at the beginning of core modules. Collect students' perceptions of what they feel they learned from the guided marking activities and monitor performance. Discuss with colleagues. What impact has guided marking had (if any) on students' performance and understanding of standards. Can you see any evidence of development in their work, e.g. are research results more clearly presented? Are literature reviews more critical?

Work with students and colleagues to redesign assessment on your programme and introduce activities to prepare students for peer assessment. Plan stage one activities (see above) at the beginning of your programme, across several core modules. You could create a throughline of assessment activity across the programme (see Chapter 4), with staged introduction of preparation and practising activities (stages one and two above). Evaluate the effectiveness of these activities with students, e.g. student facilitated focus groups, and staff (through, for example, conversations, see Kvale 1996). Identify lessons learned and refine activities for subsequent years. 


\section{Chapter 8 \\ Giving Good Quality Feedback}

Students express dissatisfaction with feedback in higher education in student satisfaction studies, e.g. the National Student Survey (Office for Students 2019) and Postgraduate Taught Experience Survey (Advance HE 2019a). This chapter investigates why students are dissatisfied with teacher feedback and suggests ways of improving feedback. I consider how to ensure that feedback is of good quality, and that students understand and can make use of feedback. I discuss the importance of involving students in the feedback process, developing student ability to judge standards of their own and peers' work and developing the student's ability to self-assess and become an independent learner. Students need opportunities to learn from dialogue around feedback, with peers and teachers. Composing feedback on peers' work enhances students' understandings of feedback, enabling them to self-assess their own work and direct their learning. The chapter will also look at the problems of involving students in assessment and will emphasise the importance of preparation addressing the question of how to develop evaluative judgement (Tai et al. 2018).

Boud and Falchikov (2007) argue that 'assessment rather than teaching, has a major influence on students' learning. It directs attention to what is important. It acts as an incentive for study. And it has a powerful effect on what students do and how they do it' $(2007,3)$. Some assessment practices are focused on students demonstrating what they know, rather than focusing on the learning process and how students will continue to learn after they leave the institution. Sustainable assessment involves students completing tasks which equip 'students to learn for the long term' (Boud and Falchikov 2007, 5), developing knowledge and skills that can be used after their higher education studies, so that when 
they are faced with life and professional challenges, they can draw on a 'repertoire of assessment-related practices' (Boud and Falchikov 2007, 5) that they have developed to help them problem solve.

Assessment is highly regulated and is often equated with quality assurance and measuring outcomes rather than promoting learning.

Students are constructed as 'passive subjects' (Boud and Falchikov 2007, 17); assessment is something that is done to them. Sustainable assessment requires students to be active in assessment, determining 'what is to be learned, how it is to be learned, and how to judge whether they have learned it or not' (Boud and Falchikov 2007, 18). Similarly, students are often passive recipients of feedback messages from teachers and may not understand or may misunderstand those messages. This creates 'learned dependence' (Yorke 2003, 489) on the teacher. To move away from learned dependence, students need to learn how to make judgements and have practice in evaluating evidence, appraising situations and drawing conclusions (Boud and Falchikov 2007, 19).

\section{Why are Students Dissatisfied with Feedback?}

Dissatisfaction with feedback has been reported in the literature and in student satisfaction surveys, e.g. NSS (Office for Students 2019) and PTES (Advance HE 2019). Dissatisfaction centres around the timing of feedback, feedback quality and student ability to use feedback. Some key feedback issues include the following.

- Slow turnaround times and dissatisfaction with the quantity of feedback given and/or generic feedback (feedback given to the group, not to the individual).

The massification of higher education in some countries has led to large class sizes (e.g. 700 students). Dialogic feedback is individual, personalised, open to discussion and clarification, and supports students in planning their learning development. Large classes need increased resources in order to give dialogic, individualised feedback to students. With large classes, feedback turnaround times can be more than four weeks, and the longer the turnaround, the more feedback becomes increasingly less relevant to students who have moved on to tackling other assessments. Alternatives such as generic feedback and the use of peer assessment, which can decrease turnaround times, can often produce hostile reactions from students (Wilson et al. 2015), who feel 
that their individual needs are not being met. See Chapter 7 for a detailed discussion of peer assessment.

- $\quad$ Feedback is not useful for the next assignment.

This is both a feedback issue and a design issue. Students need to hear or generate suggestions on ways of developing their work, and they need to be able to act on these suggestions in their assignment. Assessments often occur at the end of a module, so feedback needs to be relevant to the assignment in the next module. If there is no opportunity to use the feedback immediately, it becomes irrelevant (Price et al. 2010). Teachers report students not picking up feedback and the opening rates for feedback in virtual learning environments can be low. One inference may be that students do not find feedback useful for their next assignment so do not bother to collect or open it.

- $\quad$ Students do not understand the feedback given.

It is essential to extend higher education to groups that have traditionally been excluded and have not had the opportunity to study in higher education. Non-traditional students in higher education require changes in traditional curricula to address their needs. Support is beneficial for all students, especially students in diverse cohorts with diverse needs, to help them understand ways of studying and thinking within disciplines, and facilitate understanding of academic standards. If students do not understand standards and teacher expectations, they are unlikely to be able to make sense of teachers' feedback or understand how to use it to develop. In essence, teachers spend a lot of time composing feedback which students may not understand or may not be able to use (Ivanič et al. 2000; Price et al. 2010). It seems student bewilderment about how to use feedback to improve their work fuels dissatisfaction.

- $\quad$ Students feel over-burdened with assessment (Harland et al. 2015).

Increasing use of modularisation, standalone modules and smaller modules has exacerbated the problem of overassessment in higher education. A common practice is to have two pieces of assessment for each module; only one assessment increases the risk of students doing badly on the module or failing. Two or more assessments provide students with more opportunity to demonstrate knowledge and skills, but also has the consequence of substantially increasing the number of assessments, 
especially if the number of modules has been increased. The assessment load puts pressure on teachers and students; it becomes difficult to find time to cover all the module content and find time to prepare students for different types of assessments. Students faced with an increased amount of assessment have no time to do formative assessments, or to have dialogue around feedback with peers and teachers. Increased assessment can force students to become strategic learners, seeking cues on ways to cut corners and achieve good marks. The burden of assessment on students and teachers seriously impacts on good quality learning (see Chapter 4 for more on overassessment).

\section{- Dependency on exams.}

In response to large class sizes and concerns around plagiarism of coursework, essay mills and contract cheating (Medway et al. 2018; Amigud and Dawson 2019) exams have become more widely used. Contract cheating entails students submitting work that they have paid someone to write for them; this can entail either buying an essay from a website or paying a contractor to write an assignment. Similarity software cannot detect contract cheating if the contractor has written original content. Concerns over the growth of websites offering such services has led some institutions to prefer a greater weighting of exams over coursework assessment. While some students prefer exams, others may be disadvantaged by an overreliance on exams and there is no guarantee that exams will reduce cheating. With increasing concern over student mental well-being in higher education, increased stress needs to be avoided. Exams often occur at the end of a module and feedback, if it is given, may not focus on how students can develop their learning.

- $\quad$ The affective dimension.

Feedback can have an adverse effect on student learning if the student perceives the feedback to be critical, negative and a comment on their knowledge. The emotional aspect of feedback is under-researched, but studies suggest that power dynamics in higher education can be destructive; students perceive teachers as authoritative and negative criticism from teachers can demotivate students. Ryan and Henderson (2018) suggest that international students and students who receive feedback that does not meet their expectations are most at risk of negative responses. In a study of over 4,500 students, they found that 42.6 per cent of international students felt discouraged by feedback, compared 
to only 35.4 per cent of domestic students. Students who receive lower than expected grades also experienced negative emotions. The authors conclude that feedback dialogues and developing trust between students and assessors can support students to learn from feedback.

- Use of (unsupported) teaching assistants (TAs).

As teachers become more pressed for time and accumulate larger marking workloads, they may look for help from teaching assistants, typically postgraduate students. TAs can give excellent feedback as they are closer to the student experience but they need to be supported, mentored and offered professional development; in addition their work needs to be moderated. It is important to ensure TAs have clear understandings of academic standards, that they understand the role of feedback, are aware of the effects of destructive feedback and have time to engage in dialogic feedback (Ryan and Henderson 2018). TAs can make a valuable contribution to a programme, but only if fully supported; this support and mentoring of TAs creates extra workload for teaching staff so more resources need to be available.

- Quality and consistency of feedback.

Academic departments, especially in research intensive institutions, may not make time to discuss standards and compare feedback given by markers. Without discussion, teachers can develop their own (possibly) idiosyncratic views of assessment standards and feedback. This can happen with experienced and inexperienced teachers. Consistency of feedback messages can be better achieved through dialogue between teachers and between teachers and students, checking understanding and socially constructing standards (Sadler 2014) through calibration activities. See below for a discussion of peer review of feedback and see Chapter 6 for an explanation of socially constructed academic standards.

- Too many/too few varieties of assessment.

Diversity in assessment needs to be carefully managed. Too few varieties can disadvantage some students. See Chapter 2 for a discussion of essayist literacy and how the essay can disadvantage non-traditional students (Lillis 2001). However, too many assessment varieties - blogs, vlogs, reflective pieces, quantitative lab reports, posters and oral presentations - may confuse students who need to have practice in different varieties of 
assessment (Gibbs and Simpson 2005). Good practice involves designing a range of carefully planned assessments, linked over a programme. Often, assessments are not connected across a programme; there is no through-line of assessment activity so that students can take learning from one assessment into the next. Assessments need to be planned so that students get practice in assessment varieties and can learn how to get good at each variety before they are summatively assessed. Practice in assessment is vital for diverse student cohorts, as is the opportunity to choose assessment tasks so that students can demonstrate learning in a way that plays to their strengths (see Chapter 9 on inclusive assessment).

\section{Evaluative Judgement}

Evaluative judgement is the 'capability to make decisions about the quality of work of self and others' (Tai et al. 2018, 5) and not just to make those judgements but to defend them, argue persuasively, listen to other arguments and consider whether a judgement needs to be modified. Evaluative judgement can be developed through peer learning, for example through self and peer assessment and through analysing exemplars of assignments with others (Boud et al. 2018). Typically, in higher education, students may not see examples of their peers' work and this makes it difficult for them to get a sense of the academic standards on the programme and to benchmark their own work. Dawson et al. (2018) make the distinction between epistemological capabilities (what students know and can do) and ontological capabilities (what they are learning to be) and argue that evaluative judgement is 'an epistemic capability, which students use in determining if they can act in particular situations that are changing dynamically' $(2018,2)$.

Evaluative judgement is not a new concept but using evaluative judgement as an organising principle for designing learning and assessment is novel (Ajjawi et al. 2018, 7-17). Rather than positioning students as passive recipients in assessment practices, evaluative judgement places the student at the centre, involving them in assessment design and assessment judgements. In order for students to take on this role they need to have a good understanding of the academic standards in the programme and of what constitutes good quality work (Ajjawi et al. 2018). Research in academic literacies shows that notions of quality in student work are discipline specific and epistemologically bound (Lea and Street 1998), so it is important that students develop an understanding of quality in their discipline(s). Evaluative judgement fits with 
the notion of sustainable assessment, as students have the opportunity to develop a 'capability that extends beyond the individual and any immediate piece of work' (Ajjawi et al. 2018, 9). Ajjawi et al. $(2018,11$ ) suggest five steps for developing informed judgement:

1. Identifying oneself as an active learner.

2. Identifying one's level of knowledge and the gaps in this.

3. Practising testing and judging.

4. Developing these skills over time.

5. Embodying reflexivity and commitment.

To develop evaluative judgement, students need opportunities to make judgements and calibrate those judgements with others, listening to and evaluating information from others so that they achieve 'an internal calibration of quality' (Ajjawi et al. 2018, 11). The external information used to develop calibration judgements comes from peers and teachers, for example, 'feedback comments [from teachers] should be deployed to help students calibrate their own judgements ...' (Boud et al. 2015, 14). This requires a reconceptualisation of feedback in higher education, a reconceptualisation that places students at the centre of feedback processes as active participants. Molloy and Boud (2013) propose a conception of feedback in which students have control and agency to initiate feedback. They distinguish two types of feedback practices which they term mark one and two. In mark one, teachers are engaged in telling students how to develop. They monitor student achievement and adjust feedback on subsequent tasks to guide student development. In contrast, in feedback mark two, learners are active and have 'agency and choice' (Molloy and Boud 2013, 22). Students solicit feedback and use it to develop their learning; feedback then becomes a part of sustainable assessment as students use it to develop their learning both within the university and in professional settings when they leave higher education. Solicited feedback from peers and teachers has a role to play in developing evaluative judgement; this 'external' feedback helps students to moderate and develop their own judgement as they consider and analyse the evaluations of others. In this way, solicited feedback builds 'student capacity for making judgements about their subsequent work' (Molloy and Boud 2013, 22). The external feedback giver challenges and helps calibrate the learner's judgement, encouraging greater objectivity on their work. However, it can be demanding for learners to initiate the feedback process so building in support for learners in initiating feedback is important. Similarly, learners need guidance on what to do with the 
feedback they receive and how to use it to progress. This has implications for programme design as the programme needs to include practice tasks that allow students to develop skills and knowledge, and to practise receiving and acting upon feedback multiple times.

Molloy and Boud identify seven features of feedback mark two, namely:

1. Students are orientated not only to standards of work (learning outcomes) but also to the purpose of feedback. With this explicit orientation, students are more likely to see feedback as a process they can use, rather than a tool imposed on them.

2. Students judge their own work and are encouraged to articulate this judgement (self-evaluation).

3. Students seek or solicit feedback on those aspects of their work that matter to them most (for example asking the external source to comment on particular aspects of their performance that require improvement). This serves to cue educators and external providers of information into what to focus on to best help learners achieve their goals. This honesty in acknowledging limitations in their own practice does leave them vulnerable, and this honesty can be compromised if students are overly attuned to the summative assessment process, that is, they are always attempting to 'show their best selves' to the educator.

4. Educators or 'others' provide performance information to the learner.

5. The learner then engages in a comparative process where they combine the internally and externally generated judgements and decide how to meaningfully interpret these messages.

6. The comparison of judgements, and how these relate to the standards or goals of work, are used to generate a plan for improved work.

7. The strategies are implemented in the subsequent participation in later tasks.

(quoted from Molloy and Boud 2013, 24)

Teachers may have different conceptions of quality and may give different feedback to learners (see Chapter 6 on marker reliability) so the aim is to have dialogue around feedback where student and teacher can negotiate understandings of standards. It is unlikely that teachers will have 
calibrated standards but if they do, they can share calibration resources with students and use guided marking to develop student understanding of academic standards.

\section{How to Develop Good Feedback Practices in a Teaching Team}

In order to develop student understanding of feedback and assessment standards, it is necessary to first develop teachers' understanding of standards. Chapter 6 discusses ways of working towards a consensual understanding of standards in a programme team, and in a discipline through national calibration. Ensuring discussions across the team is key to enabling the team to refer to common academic standards and give consistent, good quality feedback to students. This can be achieved through peer review of feedback using a tool such as the feedback profiling tool described in Hughes et al. (2015). In a review of the literature, they identified five 'empirically and theoretically derived categories of feedback [namely]: praise, ipsative (comments on progress, see below), critique, advice and questioning' (Hughes et al. 2015, 1080). Their study drew on Orsmond and Merry's (2011) categorisations of feedback. They found that 'praise' was the most frequently used category, while 'suggestions for future assignments' was rarely used. Applying the tool to feedback in five modularised postgraduate programmes, they found that, in these programmes, feedback from one module did not 'open up a dialogue to continue from one module to the next within a programme' (Hughes et al. 2015, 1080).

The purpose of feedback is to enable students to effect change in the quality of their work: 'Feedback is a process whereby learners obtain information about their work in order to appreciate the similarities and differences between the appropriate standards for any given work, and the qualities of the work itself, in order to generate improved work' (Molloy and Boud 2013, 6).

So, if students are unable to effect change, then feedback is ineffective. Telling (Sadler 2010) students what to do is transmissive teaching, and telling students how to develop, is often ineffective because students do not understand the feedback or do not know what to do with the feedback. In a teacher-centric approach to assessment, such as in feedback mark one, 'assumptions are made that students will readily learn from corrective feedback and prescriptive guidance' (Hughes et al. $2015,1081)$. For students to make use of feedback, they need to develop 
constructions of academic standards on their programme, benchmark their own work, initiate feedback from others and engage in dialogue on how to move their work from where it is now to the next level.

\section{Reviewing Teachers' Feedback in a Programme}

Consistency in feedback is important. Students may receive extensive feedback from one teacher and significantly less from another. Teachers may be choosing to comment on very different issues, so it is important to have dialogue in a programme team about what constitutes good quality feedback, what areas of feedback should be highlighted and how best to give students developmental guidance. One way of ensuring greater consistency is to carry out peer review of feedback. Begin by identifying an area that needs attention and the level of work you want to start with. There may be issues around writing the discussion section of a report, carrying out a literature review, student presentation skills and developing cogent arguments. Select some student assignments of the appropriate level (e.g. first year or final year) which illustrate the issues and, with permission, collect teacher feedback on these assignments. Anonymise and distribute the assignments and feed back to the teaching team. Ask them to read and analyse the feedback given. You might suggest that they use the feedback profiling tool (see below) to help with this. Use the categories in the tool to categorise feedback comments, e.g.

So, for example, in the feedback, 'When you mention Y's model you do so uncritically, but you have responded to feedback on your draft and now mention the limitations of applying model $\mathrm{Z}$ to your design', the first section is a critique while the second part of the sentence is a reference to making progress. This would therefore be scored as 1 point for $\mathrm{C} 2$ and 1 point for P2. (Hughes et al. 2015, 1084)

Continue analysing the feedback comments and count each instance of each category, e.g. instances of praise and instances of giving advice. Tally the score for each category (the score is the number of instances of each category). Rank the scores so that you can easily see a profile of the feedback given. 
Table 8.1: Feedback profiling tool

Assessment Careers JISC funded

Assessment Careers Feedback Analysis Tool

Programme

Module .

. Student Name

(to be anonymised)

Grade if known ....................... Assessor(s)

(to be anonymised) Formative or summative assessment

\begin{tabular}{|c|c|c|c|c|c|}
\hline Category of feedback & Code & Sub-category & Examples & Score & $\begin{array}{l}\text { Rank } \\
\text { order }\end{array}$ \\
\hline Giving praise & $\mathrm{P} 1$ & & 'A well-constructed argument...'. & & \\
\hline $\begin{array}{l}\text { Recognising progress } \\
\text { (ipsative) }\end{array}$ & P2 & & $\begin{array}{l}\text { 'This represents a significant improvement ...' 'You have } \\
\text { taken on board critique ...' }\end{array}$ & & \\
\hline \multirow{3}{*}{ Critical feedback } & $\mathrm{C} 1$ & Correction of errors & Spelling, grammar, referencing etc. & & \\
\hline & $\mathrm{C} 2$ & Factual critiques (of content) & 'I do not think you can say X.' 'This is not in enough depth.' & & \\
\hline & C3 & $\begin{array}{l}\text { Critique of approach (structure } \\
\text { and argument) }\end{array}$ & 'It would have been better to conclude with Y ...' & & \\
\hline \multirow{3}{*}{ Giving advice } & A1 & Specific (to current assignment) & 'You might want to consider X ...' & & \\
\hline & A2 & $\begin{array}{l}\text { General points (specific to } \\
\text { current assignment) }\end{array}$ & $\begin{array}{l}\text { e.g. on depth, argument and structure: 'There is scope to } \\
\text { tease out further detail on X ...' }\end{array}$ & & \\
\hline & A3 & For future assignments & 'In your next essay you should consider Y ...' & & \\
\hline Clarification requests & Q & & 'What do you mean by Z?' & & \\
\hline Unclassified statements & $\mathrm{O}$ & & $\begin{array}{l}\text { Statements which do not make a judgement, e.g. } \\
\text { descriptions of the work. }\end{array}$ & & \\
\hline
\end{tabular}

Find out more about the feedback profiling tool here: http://jiscdesignstudio.pbworks.com/w/page/50671006/Assessment\%20Careers\%20Project 
Table 8.1 shows the feedback profiling tool, which you can find out more about here: http://jiscdesignstudio.pbworks.com/w/page/50671006/ Assessment $\% 20$ Careers\%20Project

Arrange for teachers to share their thoughts on the feedback, they can do this either at a workshop (scheduled alongside a departmental meeting, for example, to maximise availability of teachers) or online using a virtual learning environment where teachers can anonymously post comments on an online forum. Compare scores and profiles across the team and discuss disagreements. The aim is to achieve an agreed understanding of how to best give feedback and guide students to achieve the academic standards on the programme. The feedback profiling tool enables teaching teams to reflect on the categories of feedback they are giving, how consistent the feedback profile is between teachers and whether students are being challenged (through questioning) to develop their constructions of good quality work. Watch this video of how one teaching team approached peer review of feedback and the guidelines they developed for teachers and students: https://mediacentral.ucl. ac.uk/Play/8045.

The feedback profiling tool can also be used with students to help develop their understanding of both academic standards and feedback. Following a feedback mark two approach, students can initiate feedback and analyse feedback using the tool; discussing their analysis with teachers could be illuminating for both parties. The categorisation in the tool indicates the purpose of feedback comments and facilitates analysis of these comments. The tool could also be used with peer assessors (see Chapter 7) to analyse and reflect on the feedback they give and receive.

\section{Ipsative Assessment}

As a result of modularisation, feedback seems to be contained within the module, rather than supporting students' long-term development. Hughes has suggested that 'ipsative feedback' best supports development: 'An ipsative formative assessment activity allows a learner to demonstrate progress and change through repeating activities or through comparing activities that address comparable knowledges and skills. Ipsative feedback then informs the learner of how s/he has progressed, or not, since a previous assessment' (Hughes 2014, 75).

The competitive nature of modern higher education benefits high achieving learners. Ipsative assessment is about 'being as good as you can be at that point in time' (Hughes 2014, 5) and recognising student's progress not in improved grades but in relation to their previous work. 
Ipsative assessment is self-referential and not measured against external standards. It is like a personal best in athletics; an athlete may not win the race, but they may have produced their best performance. Ipsative assessment allows assessors (self, peers and teachers) to recognise and celebrate progress, even if progress does not result in an increased degree classification.

\section{Using Audio Feedback}

Technology is increasingly playing a role in delivering feedback and enhancing the immediacy of feedback for example, audio feedback can be given on students' work and most virtual learning environments contain tools for recording feedback (Lunt and Curran 2010). Audio feedback is claimed to provide a richer, more personalised experience to students as they respond to teacher's intonation in recordings. A recent large-scale study by Zimbardi et al. (2017) tracked undergraduate student use of both audio and written feedback in a virtual learning environment in two biomedical science courses in a research-intensive Australian university. Students were required to undertake assessments, involving writing reports, to develop their ability to write a scientific journal article. The cohorts were large; a total of 5,960 reports were submitted and marked by 38 markers who used both typed and audio feedback. They found that markers' audio annotations had nearly eight times the number of words as typed annotations, so significantly more feedback was given to students in audio annotations. However, the quality of the audio feedback was not investigated; the increased word count may arise from the kind of padding naturally used in speech. Students use of feedback could be tracked through the number of clicks and matched to their academic performance. They found high rates of opening and use of feedback in both first- and second-year students; ' $92 \%$ of first year and $85 \%$ of second-year students accessed their feedback, with 58\% accessing their feedback for over an hour' (Zimbardi et al. 2017, 625). Both years were less likely to use the feedback from the final report, suggesting that students used feedback from the earlier report to improve their final report. 
Teaching idea - Paraphrasing feedback

To check on student understanding of feedback, ask students to paraphrase and explain feedback comments.

After you or students (peer assessors) have marked and given written or audio feedback on an assignment, ask students to look over the feedback and either post online a comment that they did not understand or a comment they could understand and found useful (explaining why it was useful). Ask students to paraphrase the comment and explain what they think it means and how they will use this comment to develop their work. Then ask them to look at their peers' comments and, if they can, paraphrase any comments their peers have not understood.

Review the comments and identify feedback that students appear to have understood and the feedback that students have not understood. Use exemplars of students' work to illustrate feedback that students have misunderstood. Repeat the exercise for the next assignment to check whether students better understand and can give and use feedback.

Nicol (2010 and Nicol et al. 2014) argues that composing feedback is more cognitively demanding than receiving feedback. When students articulate what they value in a peer's work, they are articulating their understanding of academic standards on the programme. Students may learn more from the process of judging others' work than from receiving feedback comments on their own work. The case study below explores what one peer assessor learned from making judgements about students' work and composing peer feedback.

\section{Case Study: a Peer Assessor Learning from Composing Peer Feedback}

Type of programme - BEng

Mode - blended

Level - undergraduate

Cohort - home and international

What's of interest - study of what a peer assessor learns from composing feedback 
This case study (McConlogue 2015) describes the experiences of a peer assessor, focusing on what she learned from composing peer feedback. Ferdous was a second year undergraduate student in medical engineering, at the time of the study. She was studying at a UK researchintensive university, based in an ethnically diverse community. Ferdous was born in Somalia and educated in the UK from the age of 12. She is multilingual, describing English as her third language. She was a diligent student with previous experience of marking student work at secondary school, under the supervision of her teacher.

In the study, Ferdous took part in peer assessment of a lab report. After submitting her report, she attended a 'rehearsal marking' session (Falchikov 2004). She had been given three lab reports and the assessment criteria, and had read and written grades and comments on the reports. In the rehearsal marking session, she discussed these comments in a group, compared grades and discussed the assessment criteria. Each group tried to reach a consensus on the exemplars and the teacher collated the results. The teacher joined in the discussion and explained how she had assessed the lab reports. She prepared students for peer assessment of their lab reports by answering questions about technical issues. After the rehearsal marking, students were allocated four reports and given two weeks to mark and submit their grades and comments. To ensure students saw a range of reports, the teacher had pre-sorted the reports into four groups, depending on her judgement of their quality, and students were allocated a report from each group; so they received a borderline report, some good reports and an excellent report (according to the teacher's judgement). Each report had multiple peer markers and marks and comments were uploaded and distributed online.

Ferdous set about peer assessing almost immediately, skimming the reports and making notes on the basics, e.g. word length, relevant sections etc. She then used her knowledge of the assessment criteria, the discussion in the rehearsal marking and the task instructions to begin to write more detailed comments on the reports. She diligently composed around 500 words of peer feedback for each report and estimated that it took her about four to five hours to mark the four reports.

She seemed to learn a great deal from reading and commenting on the reports. She benchmarked her own work against her peers. She learned from the weaker reports, seeing things that had been done well in them. She said she could see 'negatives and positives in everyone's report'. Seeing the range seemed to help her develop ideas of how to improve her own work and what she needed to do to move on to the next 
level. The process of comparing her work and her peers' reports, writing comments and interpreting the assessment criteria seemed to develop her understanding of academic standards. Interestingly, seeing a range of reports seemed far more important than seeing an 'excellent' report. Ferdous commented that the excellent report was 'complicated' and that she 'couldn't replicate it', suggesting that it was too far removed from her own stage of development. The other reports helped her develop ideas and strategies for moving on.

\section{Further Reading}

Falchikov, Nancy. 'Involving Students in Assessment', Psychology Learning and Teaching 3, no. 2 (2004): 102-8.

McConlogue, Teresa. 'Making Judgements: Investigating the Process of Composing and Receiving Peer Feedback', Studies in Higher Education 40, no. 9 (2015): 1495-506.

Nicol, David, Avril Thomson and Caroline Breslin. 'Rethinking Feedback Practices in Higher Education: A Peer Review Perspective', Assessment and Evaluation in Higher Education 39, no. 1 (2014): 102-22.

\section{Follow-Up}

\section{Reading}

On evaluative judgement:

Tai, Joanna, Rola Ajjawi, David Boud, Phillip Dawson and Ernesto Panadero. 'Developing Evaluative Judgement: Enabling Students to Make Decisions about the Quality of Work', Higher Education 76, no. 3 (2018): 467-81.

Boud, David, Rola Ajjawi, Phillip Dawson and Joanna Tai. Developing Evaluative Judgement in Higher Education: Assessment for Knowing and Producing Quality Work. London: Routledge, 2018.

On what students learn from composing feedback:

McConlogue, Teresa. 'Making Judgements: Investigating the Process of Composing and Receiving Peer Feedback', Studies in Higher Education 40, no. 9 (2015): 1495-506. 
Nicol, David, Avril Thomson and Caroline Breslin. 'Rethinking Feedback Practices in Higher Education: A Peer Review Perspective', Assessment and Evaluation in Higher Education 39, no. 1 (2014): 102-22.

Think about how you could provide opportunities to develop students' evaluative judgement on your programme. What activities could you introduce? For ideas see:

Boud, David, Rola Ajjawi, Phillip Dawson and Joanna Tai. Developing Evaluative Judgement in Higher Education: Assessment for Knowing and Producing Quality Work. London: Routledge, 2018.

\section{Investigating Your Practice}

Investigate feedback in your team. Carry out a peer review of feedback (see a suggested plan in the section 'How to develop good feedback practices in a teaching team' above). Use the feedback profiling tool or similar to analyse feedback. Involve the team and students in creating guidelines for feedback. Implement the new guidelines and follow-up with an evaluation of teacher and student perceptions of whether the quality and usefulness of feedback improved. 


\section{Part 3 \\ INCLUSIVITY}





\section{Chapter 9}

\section{Developing Inclusive Curriculum and Assessment Practices}

The widening participation agenda in higher education has brought more diverse groups of learners into higher education; these learners often have non-traditional educational backgrounds, and this necessitates a change in the curriculum, including assessment, to meet the needs of a diverse student body. This chapter explores diverse learner characteristics, such as social background, disability, gender, race and sexuality, and how these characteristics intersect to create multiple exclusions. The chapter discusses how assessment design needs to change in order to be more inclusive and practical solutions, such as choice in assessment, are proposed. Good, inclusive assessment practices can help all students achieve their potential.

'Inclusive assessment does not compromise academic or professional standards but improves the opportunities for all students to demonstrate their acquisition of the learning outcomes' (University of Plymouth, 2016).

You have probably seen the 'fair test' cartoon. A bird, monkey, penguin, elephant, fish, seal and dog are all given the same test and asked to climb a tree. For some this is an immensely easy task, for others impossible. Similarly, with diverse student cohorts in higher education, setting all students the same task does not ensure fairness. Field trips that exclude students with mobility issues or students with caring responsibilities are not equitable. Types of assessment can also discriminate. Lillis (2001) critiques the traditional academic essay as the default assessment task which, she claims, advantages students from certain educational backgrounds while disadvantaging students 
from non-traditional educational backgrounds or students with learning differences such as dyslexia. Developing fair and equitable assessment and programmes of study entails ensuring that diversity is represented in the curriculum and in types of assessment, and that students are fully involved in assessment design. Choice in well-designed assessments enables students to demonstrate their learning and avoids disadvantaging groups of students.

Working with students to explore inclusive curriculum design can be immensely rewarding for both teachers and students; challenging traditional curricula can stimulate new thinking within the discipline. Inclusive curriculum design involves not only changing content but also the way we teach and assess; programmes need to incorporate fair and equitable assessment. Anti-discriminatory legislation identifies protected characteristics such as age, disability, gender, race and sexuality. Scholarly work, such as work in the fields of disability studies, gender studies, critical race awareness and queer studies, has raised awareness of the discriminatory nature of traditional curricula and assessment practices (Moore-Cherry et al. 2016). Much work is being done worldwide to challenge curricula and research paradigms that marginalise others.

In a seminal article, Kimberlé Crenshaw (1989) identified ways in which individuals belonging to several marginalised groups were multiply disadvantaged and called this 'intersectionality'. She explored the concept of 'intersectionality', highlighting ways in which multiple interlocking characteristics combine to create multiple disadvantages. Crenshaw proposed an influential analysis of systems of power within societies which create structures and processes that benefit the dominant group and work to exclude marginalised groups. Marginalised groups are excluded from systems of power in society; individuals who intersect several marginal groups are multiply excluded. For example, an individual with a disability, belonging to an ethnic minority and identifying as non-binary may face multiple disadvantages. All these characteristics, each of which may individually trigger discrimination, can interact to multiply exclude.

\section{Barriers to Participation}

Academia has traditionally been populated and led by middle-class white men. This demographic is changing but the influence of this legacy may linger on in curricula, and affect who teaches, what is taught, how 
teaching is done and how students are assessed. Traditional ways of thinking and carrying out research in the disciplines may exacerbate this exclusion. Henrich et al. (2010) argue that behavioural scientists use an unrepresentative population sample in research studies. They claim most studies use 'Western, educated, industrialized, rich and democratic (WEIRD)' (Heinrich et al. 2010, 29) participants, typically American undergraduates. Results are then skewed because of the restricted nature of the sample and yet are often generalised to the human population as a whole. They argue that journal editors and grant awarding bodies need to work with researchers to ensure that diverse populations are studied in order to 'develop interdisciplinary, international research networks for long-term studies on diverse populations using an array of methods, from experimental techniques and ethnography to brain-imaging and biomarkers' (Heinrich et al. 2010, 29).

Research in developing countries is often not published in mainstream, English-medium international journals. Websites that promote research from non-Western countries are appearing and provide dissemination of scholars' work (see for example the African Journals Online library which hosts 523 journals, including 260 open-access journals, https://www.ajol.info). Another barrier to research is the considerable cost of equipment and laboratories. Burns et al. (2019) report on a neuroscience study that overcame this problem by using portable equipment to study persuasion in Jordan with an Arabspeaking sample. While Muthukrishna et al. (2018), in an effort to make the literature less WEIRD, produced a cultural distance scale to identify societies that could usefully be compared. The authors explain the scale:

[...] provides a means to measure the psychological and cultural distance between two societies and create a distance scale with any population as the point of comparison. Since psychological data is dominated by samples drawn from the United States or other WEIRD nations, this tool provides a 'WEIRD scale' to assist researchers in systematically extending the existing database of psychological phenomena to more diverse and globally representative samples. (Muthukrishna et al. 2019, 2)

They claim that '.. there exists no systematic method for determining which societies will provide useful comparisons or even the size of the psychological differences - the cultural distance-between societies, be they non-Western, less-educated, less-industrialized, poorer, non-democratic or some subset of these' (Muthukrishna et al. 2019, 1) and that the 
cultural distance scale fills this gap. The cultural distance scale can be viewed here: http://culturaldistance.muth.io.

\section{Social Background}

Research on social background and access to education shows inequality in participation in higher education. Students from low-income households are less likely to study at universities, especially elite universities. This seems to be the picture worldwide; in a thorough report on government policy commitments to equity in higher education worldwide, Salmi reports that:

[a]vailable data show that participation in higher education continues to be unequal from a social background perspective. Research produced by UNESCO in 2016, looking across 76 mainly low-income countries, found that only 1 per cent of the poorest 25-29-year olds had completed at least four years of higher education, compared to 20 per cent of the richest. Furthermore, disparities in access to higher education are amplified by inequalities in success by social background during the course of studies. (Salmi 2018, 5)

In addition to social background, other characteristics intersect to exclude students, for example, in China, Li (2015) found a participation gap between urban and rural poor students.

Research on admissions to elite universities, indicates that social background inequity is more pronounced, with lower rates of participation from students from low-income households.

Reasons for this inequity may vary from country to country. In the UK, Anders (2012) investigated the link between household income and university entry and concluded that universities do not discriminate, but that poorer students are less likely to apply to elite universities. Anders claims:

These findings suggest that policies aimed at reducing the university participation gap at the point of entry are likely to face small rewards. More likely to be successful are policies aimed at closing the substantial applications gap, particularly by ensuring that students from poorer backgrounds have the necessary qualifications to apply. $(2012,185-6)$ 
In China, Luo et al. (2018) found that changes in entrance qualifications advantaged students from richer households applying to elite universities.

Government policies designed to increase equity tend to focus on financial aid for poorer students (Salmi 2018). The most advanced countries 'have a comprehensive equity strategy' to promote equality of access to higher education; these are typically rich countries, but Cuba stands out as a country that has promoted equity since 1959 (Salmi 2018, 11).

Financial incentives are important but Salmi also argues for interventions to increase attainment and success. Belonging interventions that affirm students' values and stress that different backgrounds matter, have been shown to be successful in reducing the social-classachievement gap in the USA (Stephens et al. 2014; Harackiewicz et al. 2014). Stephens et al. (2014) found that their intervention, valuing diverse student backgrounds, increased first generation student grades and increased their take up of university support services.

\section{Black and Minority Ethnic (BME) Attainment Gap}

Researchers in the UK have identified a gap in attainment between white students and black and minority ethnic (BME) students (Woolf et al. 2011; Richardson 2008). In a meta-analysis of 23 reports on the performance of medical students, Woolf et al. (2011) found that ethnic differences were widespread and significant, that the attainment gap has existed for over three decades and is found in both undergraduate and postgraduate assessment. Mountford-Zimdars et al. (2017), in a wideranging report on the attainment gap, suggest that institution-wide interventions that address both the curriculum and assessment design are most likely to effect change (see Mountford-Zimdars et al. (2017) for a range of suggestions).

Decolonising the curriculum movements worldwide call for a critical scrutiny of curricula that has historically favoured Western, white, male, middle-class perspectives; these perspectives are often reflected in curriculum content and reading lists. There is a move to review reading lists with students to identify cultural bias and include more texts and perspectives from marginalised scholars. Controversial areas of research, for example eugenics, are being investigated and re-evaluated (see UCL's inquiry into eugenics and Francis Galton's legacy, UCL 2018).

In medical education, the needs of marginalised groups can often be overlooked. Gishen and Lokugamage (2019) report on a project to 
diversify and decolonialise a medical education programme. Working with teachers, students and the public they have changed the medical curriculum and raised awareness of the health needs of marginalised groups. For example, medical students are taught to recognise signs of anaemia and cyanosis in BME patients. Case studies from a range of marginalised groups are used to raise awareness of issues such as caring for a transgender male patient with breast cancer.

\section{Disability and the Social Model}

Disability scholars have described two contrasting models of disability (Oliver 1995, 2004). The first, and the traditional model, they have termed the 'medical model' of disability. The medical model focuses on impairments and ways of 'fixing' them, essentially fixing the individual so that they can function and fit in with the current societal norms. In contrast, the social model argues that it is the way society is organised that marginalises and restricts people with disabilities, putting up barriers to their full participation in society. Shakespeare explains the social model makes '... the distinction between disability (social exclusion) and impairment (physical limitation)' (2006, 215).

The issue becomes how to structure society so that it is inclusive and accepting, valuing difference, instead of creating barriers to participation. Removing barriers to participation in educational activities gives disabled students access to learning opportunities on their programmes of study. In the social model, disabilities are not seen as impairments but as 'human variations' (Felten and Bauman 2013, 370); a diverse student cohort with a range of human variations brings a rich variety of perspectives to a field of learning:

Taking an inclusive approach to partnership often requires staff and institutions to reframe their perceptions of students (and colleagues) who have traditionally been marginalised. For instance, deafness is commonly understood as hearing loss. As a result, deaf people are seen as needing to be 'fixed' or 'cured' before they can be full participants in the community. That belief, however, is often at odds with the life experiences of many deaf people. Instead of considering deafness as a loss, it also can be recognised as:

'an expression of human variation that results in bringing to the fore specific cognitive, creative, and cultural gains that have been overlooked within a hearing-centered orientation' (Felten and Bauman 2013, 370). In this conception, hearing loss gives way to 
'deaf-gain' (Bauman and Murray 2010). Rather than focusing on real or perceived deficits of certain groups of students, adopting a 'deaf-gain' perspective highlights the distinct capacities, assets and valuable perspectives that different students bring to the co-creation of learning and teaching through, for example, sharing of classroom experiences from a range of perspectives to enable thoughtful pedagogical redesign for the benefit of all students and staff. (Bovill et al. 2016, 204)

\section{Creating an Inclusive Curriculum and Designing Inclusive Assessment}

\section{Collaborating with Students}

An inclusive curriculum and inclusive assessment practices can be created by working in partnership with students and community members. Changes in medical curricula have been devised by involving patients in redesign; helping medical students to better understand the perspectives of marginalised groups and how the curriculum and clinical practice can be shaped by these perspectives. For example, in ophthalmology, Rosie Gilbert describes how she invited sight-impaired patients into her course to give students the patient perspective of eye disease. A student commented that in labs she works with a protein or genes and does not connect this work with patients. By inviting patients into the course, Rosie feels students get a better understanding of the emotional aspect of visual loss. You can see a video of this work here: https://www.youtube. $\mathrm{com} /$ watch? $\mathrm{v}=\mathrm{gGjeBK} 4 \mathrm{PqmM} \&$ feature $=$ youtu.be $\& \mathrm{yt} \% 3 \mathrm{Acc}=\mathrm{on}$.

Similarly, addressing the needs of LGBT + patients with medical students raised awareness of LGBT+ health needs. Jess Salkind, a junior doctor, and Ginger Drage describe involving LGBT+ patients in a workshop to educate medical students about LGBT + health issues to overcome the lack of training in this area. The workshop was a compulsory part of the medical programme for fifth year (penultimate year) medical students and covered the health inequalities experienced by LGBT+ patients. There were discussions of scenarios and good practice. Most importantly, trans visitors spoke about their experiences of health care in a supportive environment and encouraged medical students to ask whatever questions they wanted. The workshop was evaluated, and participants were asked how comfortable they felt taking medical history from a trans patient. Before the workshop 26 per cent said they 
felt comfortable, after the workshop 82 per cent felt comfortable. You can watch a video about the workshop here: https://www.youtube.com/ watch? $v=\mathrm{kBbawKTfaEE} \&$ feature $=$ youtu. $b e \& \mathrm{yt} \% 3 \mathrm{Acc}=\mathrm{on}$.

Read more about trans patients and health in an article written by transgender authors (Lewis et al. 2017) in the British Medical Journal $(B M J)$.

\section{Inclusive Assessment: Practical Implications}

An inclusive curriculum necessitates inclusive assessment. Inclusive assessment involves removing barriers to learning and enabling students to demonstrate knowledge and skills in a form that allows them to excel. This can be done through a combination of 'modified assessment provisions (MAP)', and an assessment design that allows learners to choose a type of assessment that showcases their learning. O'Neil explains: 'Inclusive assessment benefits students as they can chose assessment to suit their strengths, learning style, needs, time constraints, personal or employment commitments' $(2011,14)$.

Providing choice in assessment is not only good for learners, it is also more efficient for teaching and administrative staff. Allowing choice reduces the need for complicated modified assessment provisions which can be costly, e.g. providing more time in examinations necessitates funding additional invigilators (O’Neill 2013). Inclusive assessment design is essentially good practice. Students benefit from being involved in designing assessment tasks, constructing assessment criteria and making judgements about their own and their peers' work (see Chapter 7 for guidance on peer assessment). Through this involvement they are helped to gain a good understanding of assessment standards and helped to monitor and develop their work.

Introductory modules or formative modules which help students to understand ways of thinking in the discipline (Entwistle 2005) and also assessment method(s), promote equity in diverse cohorts. These modules typically run at the start of a programme and give students practice in understanding and analysing key ideas, critical appraisal and practice in ways of communicating ideas within the disciplines in oral and written assignments. Thinking Writing (2019) activities, such as short write-to-learn tasks and longer writing tasks, embedded in the discipline teach students how to communicate thinking in written texts and support writing development. This is particularly important for students from non-traditional backgrounds. Interventions aimed at supporting student thinking and writing can be found in most disciplines, 
e.g. psychology (Wentworth et al. 2017). Divan et al. (2015) found that most international students on a UK master's programme in biology agreed that writing assignments on the course were different from their previous studies. Divan et al. (2015) introduced a writing intervention at the beginning of the course and compulsory sessions in academic writing in the first two weeks; they claim this intervention reduced plagiarism.

\section{Designing Choice in Assessment}

Choice in assessment does not mean giving an advantage to a group of students. Equity in assessment choice is key, so it is important to create a range of assessments of similar complexity and involving similar effort and time from students. Some students prefer to take examinations; they have developed strategies to enable them to cope with the pressurised workload and stress of exams. Others find this pressure debilitating and are prevented from doing their best work in an exam. For these students, an alternative assessment method is needed. Exam anxiety seems to affect students from a diverse range of cultures; Arana and Furlan (2016) investigated exam anxiety in Argentine students and found that perfectionists were more likely to suffer. The method of assessment was found to affect test anxiety in Saudi undergraduate medical students with students rating long case examinations and objective structured clinical examinations (OSCEs) as the most stressful (Guraya et al. 2018).

The Universal Design for Learning (UDL) project addresses the issue of engaging all learners through a range of learning design using diverse media and inclusive assessment practices. Comprehensive guidance and resources for designing and assessing learning are available on the UDL (2019) website. The website provides practical advice on ways of designing learning and assessment to address learner variability and enable all learners to articulate their knowledge and demonstrate their learning. Barriers for learners and ways of removing these barriers from assessment tasks are discussed:

\section{Possible Barriers}

Assessments that have a single response mode (asking learners to draw diagrams for every answer)

Using the same format for response for all assessments (using only multiple choice, written response) 


\section{Assessment Options}

The demands associated with responding to any assessment are not always construct relevant. In other words, if the goal of the assessment is to understand the processes involved in cell division, then asking the learner to write an essay and grading the construction of the essay may not be relevant to the task of understanding that the learner really needed to know. Supporting strategic and organizational abilities and allowing students to express acquired knowledge and skills in diverse ways can be built into a variety of assessments.

Choices, again, can be helpful. For example, an assignment on identifying barriers to economic expansion in post-World War II Europe could include the options of an essay, PowerPoint presentation, video, or infographic to achieve the same goal. Demonstrating understanding of text can be expressed by students choosing keepers (items from the text the learner finds important and relevant) and generating queries (questions created by the learner to be answered later) about the content. These can be expressed in written or verbal form, in a group or alone.

(UDL, http://udloncampus.cast.org/page/assessment_udl)

An issue in designing assessment choice is whether assessment tasks are equivalent. Attempts have been made to compare types of assessment and student effort in order to develop task equivalences. This is problematic as equivalences depend not only on word length or effort but also on the complexity of the task; a short piece of writing, like an abstract, can involve more thinking and redrafting than a longer piece. Some institutions have attempted comparisons of types of assessment task in order to ensure equity. For example, a project at London South Bank University established equivalences to a 1,000-word written assignment (University of Plymouth, 2016). Assessment type equivalences included a verbal presentation of 20 minutes or a group presentation of ten minutes per member. Group essays of around 750-1,000 words per member and unstructured journal reflections of 2,000-3,000 words were also judged to be equivalent to a 1,000-word essay. Roehampton University, 'What's it Worth' project has suggested assessment equivalences for a twenty credit module, for example, they suggest a 4,000-6,000-word coursework assignment is equivalent to a 120 minute written exam or a 60 minute practical exam such as a viva (University of Plymouth, 2016). Drawing on 
this work, teachers could set an assessment task, e.g. researching a key concept, and allow students to choose whether to present their work in a 1,000-word report or a 20-minute presentation. It is obviously difficult to make these task comparisons; group work can be more time consuming than individual work and frustrating if the group has inefficient working practices. Task equivalences may also be affected by discipline. Discuss task equivalences with colleagues and students and find a consensus that works in your teaching context. You may need to refine task equivalences, but offering all students choice of task, and guidance on how to make that choice, helps to make assessment more inclusive.

The advantage of assessment choice for students is that they can choose an assessment type that plays to their strengths and allows them to show what they can do. For teachers and administrators, the advantage is that students' needs are met without complicated and costly alternative arrangements, such as additional examination time and longer extensions. However, a key principle is that assessment choice should not result in easier assessments, or assessments that avoid testing key aspects of learning. Similarly, the academic standards for the assessments must be equivalent; developing an understanding of what teachers value in student work at each level of the programme is important. Involving students in creating assessment criteria helps share standards. Plymouth University offer the following guidance for thinking through assessment choice.

1. Consider offering a choice of two assessment methods in a number of modules, this may reduce the numbers of complex modified assessments required.

2. Students have different strengths, learning styles, time commitments; these affect their performance in assessment.

3. Some simple modified assessment provisions may still be required (e.g. the use of computers in written exams and extra time in tests).

4. Ensure both assessment methods use the same detailed assessment criteria.

5. Consider offering all students a choice of typing or handwriting in examinations.

6. Are the assessment methods commensurate and equitable? Consider the equity of hours, effort and standards.

7. Is the assessment method suited to individual, group work or both? 
8. When offering assessment choice what is the 'default' assessment method? This can be used if students fail to inform staff of their assessment choice? (Quoted from Plymouth University 2016,14)

Academic standards must remain the same, irrespective of which method of assessment is used. Developing similar criteria to make judgements about a range of tasks can help to align standards, but remember that criteria are open to interpretation, so activities to discuss and share understanding of criteria are essential. Use of exemplars and discussion between teachers and students can clarify appropriate standards (see Chapter 6).

Guidance for designing inclusive assessment (adapted from Plymouth University 2016, 7).

1. Ensure students have a good understanding of standards on the programme through guided marking activities (see Chapter 6), and formative tasks with peer and teacher feedback.

2. Check assessment tasks to ensure there is no inherent bias that may disadvantage particular groups of students. For example, field trips may disadvantage students with limited mobility. Study abroad opportunities may disadvantage marginalised groups of students who do not feel safe in countries where LGBT+, gender and race are discriminated against. It is important to involve students in planning field trips and study abroad opportunities and ensure that appropriate alternatives are provided. If field trips are inaccessible or study abroad typically occurs in countries with discriminatory practices, consider cutting these activities from the programme and developing more inclusive opportunities. Additionally, family and caring responsibilities and financial issues may exclude students from taking part in any activity organised outside of normal study hours and in other locations.

3. Are all assessments designed to minimise plagiarism and academic dishonesty? Consider setting different assessment questions or case studies for each student. Ensure that the same assignment/exam questions are not used every year. Research-based learning tasks that require students to work on different topics (e.g. the mystery specimen, see Chapter 5) help minimise plagiarism.

4. Are assessments designed to allow students to follow and develop their own interests with guidance from teachers? 
5. Check your programme for bunching of assessments. Plan assessment across a programme (not just in individual modules, see Chapter 4) and across the year. Ensure teachers and students have time to give and receive feedback. Schedule time into the programme to do this.

6. Are pre-assessment discussions with students and activities such as guided marking organised? Are post-assessment feedback sessions organised?

7. Do markers have a consensual understanding of academic standards on the programme? Are calibration activities scheduled so markers can agree standards? (See Chapter 6 for guidance.)

8. Is marking time scheduled into the programme to ensure markers can meet feedback deadlines? Avoid scheduling other activities that would demand markers' time.

9. Ensure assessments are aligned across a programme so that feedback from one assessment can be used to improve the next assessment. (See Chapter 4 on designing assessment across a programme.)

Inclusive assessment practices benefit all students. Students with disclosed disabilities may have a statement of reasonable adjustment (SORA) but many students may have undisclosed disabilities with no access to reasonable adjustments; by ensuring assessment is inclusive all students can choose appropriate methods to demonstrate their learning.

\section{Follow-Up}

\section{Reading}

On intersectionality read: Crenshaw, Kimberlé. 'Mapping the Margins: Intersectionality, Identity Politics, and Violence Against Women OF Colo', Stan. L. Rev. 43 (1990): 1241.

On decolonising and disability read: Meekosha, Helen. 'Decolonising Disability: Thinking and Acting Globally', Disability and Society 26, no. 6 (2011): 667-82.

On developing student writing read: Bean, John C. Engaging Ideas: The Professor's Guide to Integrating Writing, Critical Thinking, and Active Learning in the Classroom. 2nd ed. San Francisco: Jossey-Bass, 2011.

On social background and inequality, the National Education Opportunities Network (NEON) works to help widen access to higher 
education. Their website has an excellent range of resources and events: https://www.educationopportunities.co.uk.

NEON sponsors the World Access to Higher Education Day (WAHED) website, with resources and research on education access worldwide at www.worldaccesshe.com.

\section{Investigating Your Practice}

Think about how you could introduce choice in assessment in your module(s) or programme(s). What challenges would you face and how could these be overcome? For ideas, see O'Neill, Geraldine, ed. A Practitioner's Guide to Choice of Assessment Methods within a Module: Case Studies for University College Dublin. Dublin: UCD Teaching and Learning, 2011. Available at: http://eprints.teachingandlearning.ie/3266/1/ O’Neill\%202010\%20A\%20Practitioners\%20Guide.pdf.

Review your curriculum. Working with colleagues and students, carry out a review of your curriculum. There are various tools you can use:

The Toolbox Diversity in Education website at Utrecht University suggests further reading, gives examples of good practice and provides tools that can be used to review curricula: https://xerte. uu.nl/play.php?template_id $=1127$.

The UCL Inclusive Curriculum Health Check offers a short questionnaire for reviewing teaching and assessment on your programme: https://www.ucl.ac.uk/teaching-learning/ sites/teaching-learning/files/ucl_inclusive_curriculum_ healthcheck_2018.pdf.

Another, longer checklist can be found here, from Edith Cowan University: https://intranet.ecu.edu.au/_data/assets/ pdf_file/0006/772791/checklist-for-an-inclusive-curriculum.pdf. 


\section{Chapter 10 conclusion}

In this guide, I have aimed to help you bridge the gap between theory and research on teaching, learning and assessment and your practice. I have aimed to show how theoretical ideas and findings from research can be used to help you develop as a teacher and to enhance your assessment practices. But I have also emphasised the importance of your practical knowledge (Elbaz 2019), the knowledge that you have acquired through years of learning and teaching in higher education. Exploring this practical knowledge is key to your growth as a teacher. No two teaching contexts are the same, so it is unlikely that what works in one context can be transferred and used effectively in another without any changes. Adaptations are needed to ensure that an approach or activity works well in your context. There are ideas for exploring your assessment practices at the end of every chapter (investigating your practice) and I hope you have found these enjoyable and illuminating. I hope that by working with colleagues and students you have gained a more profound understanding of how assessment can help your students learn, and that together you have devised ways of implementing and evaluating new approaches.

A key concept in this guide is that both teachers and students need to work together to develop an agreed understanding of academic standards on their programme and that academic standards are socially constructed (Sadler 2014; Butler Shay 2004). This involves teachers in dialogue with colleagues to explore and harmonise their beliefs about disciplinary standards. Students engage in this dialogue and share their beliefs, and together this community of teachers and students can come to a shared perspective on academic standards, as far as possible. Given the nature of learning and performance in higher education, there will always be differences in judgement of the quality of assessed work, 
but by analysing exemplars and calibrating judgements, it is possible to come closer to a consensus. Consensual understanding of academic standards can then be used to review and design programmes of study; when you know what level of work students should reach by the end of a programme, it is easier to work backwards through the programme and collaborate with students to design scaffolding tasks to help them reach that standard. Similarly, a consensual understanding of academic standards is crucial to making reliable assessment judgements. With this knowledge, teachers can more quickly and more accurately grade students' work. More importantly, students can self- and peer assess and become confident, self-directed learners.

Throughout the guide, especially in Chapter 9, I have emphasised that assessment should be inclusive. The decolonising the curriculum movement has highlighted the exclusive nature of curricula in higher education and the need to review and bring in diverse perspectives from previously marginalised groups. Students have taken a lead in this movement, agitating for change and asserting their right to bring knowledge from their communities and cultures into the curriculum. Alongside this movement for change in the curriculum is the impetus to open up assessment practices. This ensures inclusivity through developing choice and preparing students for appropriate assessment, so that they have the means to fully demonstrate their achievements. Chapter 9 in this guide suggests ways of achieving this and of reviewing your curriculum and assessment practices to ensure inclusivity.

Marking assessments can seem like a chore or source of stress for teachers, but assessment can be a rich learning experience for both teachers and students. In Chapter 5, I reported on inspiring work where students direct and develop research which contributes to their community and knowledge building in their disciplines. This work can be enormously enriching for teachers, introducing them to new areas of their discipline. Wills (2014) describes how her students engaged with local groups to contribute to knowledge making in the community and to engage in democratic processes, effecting change. Chang (2005) described how he enabled students to research and build knowledge in their discipline, publishing their ground-breaking work. He drew on students' work in the exam, cited them as experts and helped students develop an inheritance mechanism to hand over their notes and data to their successors. In this way, a community of researchers was created, building on the work of predecessors. These expert students are able, with guidance, to become fully involved in assessment, develop evaluative judgement and make competent assessments of their peers' 
work. They have the integrity to give good quality feedback to peers and learn from this experience. Nicol (2014) argues that composing peer feedback is more demanding and a richer learning experience than receiving feedback. Peer and collaborative assessment is a tremendously valuable learning experience for students that helps them competently judge their own work and enables self-directed learning. Collaborative assessment enables students to become full members, alongside their teachers, in a community of practice, setting academic standards and making judgements about the quality of their own and their peers' work. The staged activities described in Chapter 7 demonstrate how you can scaffold learning and assessment to help students move from legitimate peripheral participation in this assessment community of practice, to full members. See Chapter 2 for more discussion of communities of practice and legitimate peripheral participation.

Research-based learning and collaborative assessment can be powerful learning experiences for students but, as Brew (2006) points out, teachers have more academic capital than students. Teachers can strongly influence students, so the trick is to share knowledge and support students without dominating or suppressing creativity. Scaffolding learning tasks, such as identifying tasks (e.g. Meet the Researcher in Chapter 2), can help students explore ways of thinking and practising in the discipline without crushing their originality. Scaffolding identifying tasks helps students to develop and tackle more open assessments, eventually leading to authoring tasks, involving knowledge building.

If you have read this entire guide, you are obviously a committed and motivated teacher. I hope you have been encouraged and stimulated by ideas within this guide, and that you will spend some time thinking about what you have learnt and how you can apply that to your teaching. Has anything struck a chord with you and illuminated an aspect of your teaching? What do you want to explore further and how can you engage with others, colleagues and students, in this exploration? You may find it useful to look back over the investigating your practice sections at the end of every chapter and refine ideas for the areas you want to develop. Good luck with your journey. 


\section{References}

Adie, Lenore, Margaret Lloyd and Denise Beutel. 'Identifying Discourses of Moderation in Higher Education', Assessment and Evaluation in Higher Education 38, no. 8 (2013): 968-77.

Aditomo, Anindito, Peter Goodyear, Ana-Maria Bliuc and Robert A. Ellis. 'Inquiry-Based Learning in Higher Education: Principal Forms, Educational Objectives, and Disciplinary Variations', Studies in Higher Education 38, no. 9 (2013): 1239-58.

Advance HE. 'PTES: Postgraduate Taught Experience Survey', (2019a). Accessed 10 November 2019. www.heacademy.ac.uk/institutions/surveys/postgraduate-taught-experience-survey.

Advance HE. 'The Degree Standards Project', (2019b). Accessed 10 November 2019. www.heacademy.ac.uk/degree-standards.

Ajjawi, Rola, Joanna Tai, Phillip Dawson and David Boud. 'Conceptualising Evaluative Judgement for Sustainable Assessment in Higher Education'. In Developing Evaluative Judgement in Higher Education: Assessment for Knowing and Producing Quality Work, edited by David Boud, Rola Ajjawi, Phillip Dawson and Joanna Tai, 7-17. London: Routledge, 2018.

Amigud, Alexander and Phillip Dawson. 'The Law and the Outlaw: Is Legal Prohibition a Viable Solution to the Contract Cheating Problem?', Assessment and Evaluation in Higher Education (2019): 1-11. Accessed 9 November 2019. https://doi.org/10.1080/0260293 8.2019.1612851.

Anders, Jake. 'The Link between Household Income, University Applications and University Attendance', Fiscal Studies 33, no. 2 (2012): 185-210.

Arana, Fernán G. and Luis Furlan. 'Groups of Perfectionists, Test Anxiety, and Pre-Exam Coping in Argentine Students', Personality and Individual Differences 90 (2016): 169-73.

Ashwin, Paul, Andrea Abbas and Monica McLean. 'How Does Completing a Dissertation Transform Undergraduate Students' Understandings of Disciplinary Knowledge?', Assessment and Evaluation in Higher Education 42, no. 4 (2017): 517-30.

Barnett, Ronald. 'Supercomplexity and the Curriculum', Studies in Higher Education 25, no. 3 (2000): 255-65.

Barnett, Ronald. 'Knowing and Becoming in the Higher Education Curriculum', Studies in Higher Education 34, no. 4 (2009): 429-40.

Barradell, Sarah, Simon Barrie and Tai Peseta. 'Ways of Thinking and Practising: Highlighting the Complexities of Higher Education Curriculum', Innovations in Education and Teaching International 55, no. 3 (2018): 266-75.

Bassey, Michael. 'Case Study Research'. In Educational Research in Practice: Making Sense of Methodology, edited by Joanna Swann and John Pratt, 111-23. London: Continuum, 2003.

Bauman, H-Dirksen L. and Joseph J. Murray. "Deaf Studies in the 21st Century: "Deaf-Gain" and the Future of Human Diversity'. In The Oxford Handbook of Deaf Studies, Language, and Education, Volume 2, edited by Marc Marschark and Patricia Elizabeth Spencer, 210-25. New York: Oxford University Press, 2010.

Bean, John C. Engaging Ideas: The Professor's Guide to Integrating Writing, Critical Thinking, and Active Learning in the Classroom. 2nd ed. San Francisco: Jossey-Bass, 2011. 
Beutel, Denise, Lenore Adie and Margaret Lloyd. 'Assessment Moderation in an Australian Context: Processes, Practices, and Challenges', Teaching in Higher Education 22, no. 1 (2017): 1-14.

Bloxham, Sue. 'Marking and Moderation in the UK: False Assumptions and Wasted Resources', Assessment and Evaluation in Higher Education 34, no. 2 (2009): 209-20.

Bloxham, Sue, Peter Boyd and Susan Orr. 'Mark My Words: The Role of Assessment Criteria in UK Higher Education Grading Practices', Studies in Higher Education 36, no. 6 (2011): 655-70.

Bloxham, Sue, Jane Hudson, Birgit den Outer and Margaret Price. 'External Peer Review of Assessment: An Effective Approach to Verifying Standards?', Higher Education Research and Development 34, no. 6 (2015): 1069-82.

Bloxham, Sue, Clair Hughes and Lenore Adie. 'What's the Point of Moderation? A Discussion of the Purposes Achieved through Contemporary Moderation Practices', Assessment and Evaluation in Higher Education 41, no. 4 (2016): 638-53.

Bloxham, Sue and Margaret Price. 'External Examining: Fit for Purpose?', Studies in Higher Education 40, no. 2 (2015): 195-211.

Bolton, Gillie. Reflective Practice: Writing and Professional Development. 3rd ed. London: SAGE Publications, 2010.

Borg, Simon. Teacher Cognition and Language Education: Research and Practice. London: Bloomsbury Academic, 2015.

Boud, David. 'Avoiding the Traps: Seeking Good Practice in the Use of Self Assessment and Reflection in Professional Courses', Social Work Education 18, no. 2 (1999): 121-32.

Boud, David. 'Sustainable Assessment: Rethinking Assessment for the Learning Society', Studies in Continuing Education 22, no. 2 (2000): 151-67.

Boud, David, Rola Ajjawi, Phillip Dawson and Joanna Tai. Developing Evaluative Judgement in Higher Education: Assessment for Knowing and Producing Quality Work. London: Routledge, 2018.

Boud, David and Nancy Falchikov, eds. Rethinking Assessment in Higher Education: Learning for the Longer Term. London: Routledge, 2007.

Boud, David, Romy Lawson and Darrall G. Thompson. 'The Calibration of Student Judgement through Self-Assessment: Disruptive Effects of Assessment Patterns', Higher Education Research and Development 34, no. 1 (2015): 45-59.

Boud, David and Rebeca Soler. 'Sustainable Assessment Revisited', Assessment and Evaluation in Higher Education 41, no. 3 (2016): 400-13.

Bovill, C., A. Cook-Sather, P. Felten, L. Millard and N. Moore-Cherry. 'Addressing Potential Challenges in Co-Creating Learning and Teaching: Overcoming Resistance, Navigating Institutional Norms and Ensuring Inclusivity in Student-Staff Partnerships', Higher Education 71, no. 2 (2016): 195-208.

Brauer, Sanna, Anne-Maria Korhonen and Pirkko Siklander. 'Online Scaffolding in Digital Open Badge-Driven Learning', Educational Research 61, no. 1 (2019): 53-69.

Brecher, Bob. 'Complicity and Modularisation: How Universities Were Made Safe for the Market', Critical Quarterly 47, no. 1/2 (2005): 72-82.

Brew, Angela. Research and Teaching: Beyond the Divide. Basingstoke: Palgrave Macmillan, 2006.

Brookfield, Stephen D. Becoming a Critically Reflective Teacher. 2nd ed. San Francisco: Jossey-Bass, 2017.

Brown, Sally and Danny Saunders. 'The Challenges of Modularization', Innovations in Education and Training International 32, no. 2 (1995): 96-105.

Burns, Shannon M., Lianne N. Barnes, Ian A. McCulloh, Munqith M. Dagher, Emily B. Falk, J. Douglas Storey and Matthew D. Lieberman. 'Making Social Neuroscience Less WEIRD: Using fNIRS to Measure Neural Signatures of Persuasive Influence in a Middle East Participant Sample', Journal of Personality and Social Psychology (2019).

Butler Shay, Suellen. 'The Assessment of Complex Performance: A Socially Situated Interpretive Act', Harvard Educational Review 74, no. 3 (2004): 307-29.

Carless, David. 'Trust, Distrust and Their Impact on Assessment Reform', Assessment and Evaluation in Higher Education 34, no. 1 (2009): 79-89.

Carless, D. 'Trust and its Role in Facilitating Dialogic Feedback'. In Feedback in Higher and Professional Education: Understanding It and Doing It Well, edited by David Boud and Elizabeth Molloy, 100-13. London: Routledge, 2013.

Carless, D. UOC - Universitat Oberta de Catalunya: 'Feedback designs to promote dialogue', last modified April 6, 2016. www.youtube.com/watch?v=PxgkLR7kN4I\&t=1814s. 2016. 
Carless, David and David Boud. 'The Development of Student Feedback Literacy: Enabling Uptake of Feedback', Assessment and Evaluation in Higher Education 43, no. 8 (2018): 1315-25.

Carroll, Jude. A Handbook for Deterring Plagiarism in Higher Education. Oxford: Oxford Centre for Staff and Learning Development, 2002.

Carter, Rebekah, Yenna Salamonson, Lucie M. Ramjan and Elizabeth Halcomb. 'Students Use of Exemplars to Support Academic Writing in Higher Education: An Integrative Review', Nurse Education Today 65 (2018): 87-93.

Cartney, Patricia. 'Exploring the Use of Peer Assessment as a Vehicle for Closing the Gap between Feedback Given and Feedback Used'. In Approaches to Assessment That Enhance Learning in Higher Education, edited by Stylianos Hatzipanagos and Rebecca Rochon, 61-74. London: Routledge, 2014.

Chang, Hasok. 'Turning an Undergraduate Class into a Professional Research Community', Teaching in Higher Education 10, no. 3 (2005): 387-94.

Chang, Hasok and Catherine Jackson, eds. An Element of Controversy: The Life of Chlorine in Science, Medicine, Technology and War. London: British Society for the History of Science, 2007.

Chatterjee, Helen J. and Leonie Hannan, eds. Engaging the Senses: Object-Based Learning in Higher Education. London: Routledge, 2016.

Citizens UK. Accessed 10 November 2019. https://www.citizensuk.org/east_london.

Crenshaw, Kimberlé. 'Mapping the Margins: Intersectionality, Identity Politics, and Violence Against Women of Color', Stanford Law Review 43 (1990): 1241.

Crenshaw, Kimberle. 'Demarginalizing the Intersection of Race and Sex: A Black Feminist Critique of Antidiscrimination Doctrine, Feminist Theory, and Antiracist Politics [1989]'. In Feminist Legal Theory: Readings in Law and Gender, edited by Katharine T. Bartlett and Rosanne Kennedy, 57-80. New York: Routledge, 2018.

Crossley, Scott A., David R. Russell, Kristopher Kyle and Ute Römer. 'Applying Natural Language Processing Tools to a Student Academic Writing Corpus: How Large Are Disciplinary Differences across Science and Engineering Fields?', Journal of Writing Analytics 1 (2017): 48-81.

Dawson, Phillip, Rola Ajjawi, David Boud and Joanna Tai. 'Introduction: What is Evaluative Judgement?'. In Developing Evaluative Judgement in Higher Education: Assessment for Knowing and Producing Quality Work, edited by David Boud, Rola Ajjawi, Phillip Dawson and Joanna Tai, 1-4. London: Routledge, 2018.

De Vita, Glauco. 'Integration and Independent Learning in a Business Synoptic Module for International Credit Entry Students', Teaching in Higher Education 9, no. 1 (2004): 69-81.

Divan, Aysha, Marion Bowman and Anna Seabourne. 'Reducing Unintentional Plagiarism amongst International Students in the Biological Sciences: An Embedded Academic Writing Development Programme', Journal of Further and Higher Education 39, no. 3 (2015): 358-78.

Duhs, Rosalind. 'Learning from University Museums and Collections in Higher Education: University College London (UCL)', University Museums and Collections Journal 3 (2010): 183-86.

Dwyer, Claire. 'Linking Research and Teaching: A Staff-Student Interview Project', Journal of Geography in Higher Education 25, no. 3 (2001): 357-66.

Dymond-Green, Neil. 'Is Being the First in Your Family to Attend University a Sign of Success of Widening Participation?', Data Impact Blog, 1 October 2018. Accessed 10 November 2019. http://blog.ukdataservice.ac.uk/first-in-family-students/.

Elbaz, Freema. Teacher Thinking: A Study of Practical Knowledge. London: Routledge, [1983] 2019.

Entwistle, Noel. 'Learning Outcomes and Ways of Thinking across Contrasting Disciplines and Settings in Higher Education', Curriculum Journal 16, no. 1 (2005): 67-82.

Epstein, Ronald M. 'Assessment in Medical Education', New England Journal of Medicine 356, no. 4 (2007): 387-96.

Evans, Julie, Alex Standen, Alastair McClelland and Siir Saydam. 'Meet the Researcher: The Use of Interviews to Connect First-Year Undergraduate Students to Research Staff at UCL'. In Shaping Higher Education with Students: Ways to Connect Research and Teaching, edited by Vincent C.H. Tong, Alex Standen and Mina Sotiriou, 303-10. London: UCL Press, 2018.

Falchikov, Nancy. 'Involving Students in Assessment', Psychology Learning and Teaching 3, no. 2 (2004): 102-8. 
Felten, Peter and H-Dirksen L. Bauman. 'Reframing Diversity and Student Engagement: Lessons from Deaf-Gain'. In The Student Engagement Handbook: Practice in Higher Education, edited by Elisabeth Dunne and Derfel Owen, 367-78. Bingley: Emerald Group Publishing, 2013.

French, Sarah. The Benefits and Challenges of Modular Higher Education Curricula (Issues and Ideas Paper). Melbourne: Melbourne Centre for the Study of Higher Education, 2015. Accessed 10 November 2019. https://melbourne-cshe.unimelb.edu.au/_data/assets/ pdf_file/0006/2774391/Benefits_Challenges_Modular_Higher_Ed_Curricula_SFrench_ v3-green-2.pdf.

Fryar, James. Response to 'A University Blog: Diary of Life and Strategy inside and outside the University, by Ferdinand von Prondzynski: Academic Years', 8 May 2012. Accessed 10 November 2019. https://universitydiary.wordpress.com/2012/05/08/ academic-years/\#comment-19138.

GDC (General Dental Council). 'Dental Education'. Accessed 10 November 2019. www.gdc-uk. org/professionals/education.

Gibbs, Graham and Claire Simpson. 'Conditions under Which Assessment Supports Students' Learning', Learning and Teaching in Higher Education 1 (2005): 3-31.

Gishen, Faye and Amali Lokugamage. 'Diversifying the Medical Curriculum', British Medical Journal 364, Article 1300 (2019): 1-2. Accessed 9 November 2019. https://doi. org/10.1136/bmj.1300.

Graham, P. 'Classroom-Based Assessment: Changing Knowledge and Practice Through Preservice Teacher Education', Teaching and Teacher Education 21, no. 6 (2005): 607-21.

Grainger, Peter, Ken Purnell and Reyna Zipf. 'Judging Quality through Substantive Conversations between Markers', Assessment and Evaluation in Higher Education 33, no. 2 (2008): 133-42.

Guraya, Salman Y., Shaista S. Guraya, Fawzia Habib, Khalid W. AlQuiliti and Khalid I. Khoshhal. 'Medical Students' Perception of Test Anxiety Triggered by Different Assessment Modalities', Medical Teacher 40, Supplement 1 (2018): S49-55.

Hannan, Leonie, Rosalind Duhs and Helen Chatterjee. 'Object-Based Learning: A Powerful Pedagogy for Higher Education'. In Museums and Higher Education Working Together: Challenges and Opportunities, edited by Anne Boddington, Jos Boys and Catherine Speight, 159-68. Farnham: Ashgate Publishing, 2013.

Harackiewicz, Judith M., Elizabeth A. Canning, Yoi Tibbetts, Cynthia J. Giffen, Seth S. Blair, Douglas I. Rouse and Janet S. Hyde. 'Closing the Social Class Achievement Gap for FirstGeneration Students in Undergraduate Biology', Journal of Educational Psychology 106, no. 2 (2014): 375-89.

Harland, Tony, Angela McLean, Rob Wass, Ellen Miller and Kwong Nui Sim. 'An Assessment Arms Race and Its Fallout: High-Stakes Grading and the Case for Slow Scholarship', Assessment and Evaluation in Higher Education 40, no. 4 (2015): 528-41.

Hendry, Graham D. and Martin Tomitsch. 'Implementing an Exemplar-Based Approach in an Interaction Design Subject: Enhancing Students' Awareness of the Need to Be Creative', International Journal of Technology and Design Education 24, no. 3 (2014): $337-48$.

Henrich, Joseph, Steven J. Heine and Ara Norenzayan. 'Most People Are Not WEIRD', Nature 466, no. 7302 (2010): 29.

Hughes, Gwyneth. Ipsative Assessment: Motivation through Marking Progress. Basingstoke: Palgrave Macmillan, 2014.

Hughes, Gwyneth, Holly Smith and Brian Creese. 'Not Seeing the Wood for the Trees: Developing a Feedback Analysis Tool to Explore Feed Forward in Modularised Programmes', Assessment and Evaluation in Higher Education 40, no. 8 (2015): 1079-94.

Hunter, Kerry and Peter Docherty. 'Reducing Variation in the Assessment of Student Writing', Assessment and Evaluation in Higher Education 36, no. 1 (2011): 109-24.

Hussey, Trevor and Patrick Smith. 'Learning Outcomes: A Conceptual Analysis', Teaching in Higher Education 13, no. 1 (2008): 107-15.

Hutchings, Pat, Mary Taylor Huber and Anthony Ciccone. The Scholarship of Teaching and Learning Reconsidered: Institutional Integration and Impact. San Francisco: Jossey-Bass, 2011.

Hyland, Ken. Academic Discourse: English in a Global Context. London: Continuum, 2009.

Iannone, Paola and Adrian Simpson. 'University Students' Perceptions of Summative Assessment: The Role of Context', Journal of Further and Higher Education 41, no. 6 (2017): 785-801.

Ivanič, Roz, Romy Clark and Rachel Rimmershaw. 'What Am I Supposed to Make of This? The Messages Conveyed to Students by Tutors' Written Comments'. In Student Writing in Higher 
Education: New Contexts, edited by Mary R. Lea and Barry Stierer, 47-65. Buckingham: SRHE and Open University Press, 2000.

Jessop, Tansy, Yassein El Hakim and Graham Gibbs. 'TESTA in 2014: A Way of Thinking about Assessment and Feedback', Educational Developments 15, no. 2 (2014a): 21-4.

Jessop, Tansy, Yassein El Hakim and Graham Gibbs. 'The Whole is Greater Than the Sum of Its Parts: A Large-Scale Study of Students' Learning in Response to Different Programme Assessment Patterns', Assessment and Evaluation in Higher Education 39, no. 1 (2014b): 73-88.

Jessop, Tansy and Gwyneth Hughes. 'Beyond Winners and Losers in Assessment and Feedback'. In Teaching and Learning in Higher Education: Perspectives from UCL, edited by Jason P. Davies and Norbert Pachler, 64-84. London: UCL Institute of Education Press, 2018.

Kador, Thomas, Leonie Hannan, Julianne Nyhan, Melissa Terras, Helen J. Chatterjee and Mark Carnall. 'Object-Based Learning and Research-Based Education: Case Studies from the UCL Curricula'. In Teaching and Learning in Higher Education: Perspectives from UCL, edited by Jason P. Davies and Norbert Pachler, 157-76. London: UCL Institute of Education Press, 2018.

Kember, David. 'A Reconceptualisation of the Research into University Academics' Conceptions of Teaching', Learning and Instruction 7, no. 3 (1997): 255-75.

Kim, Minjeong. 'The Impact of an Elaborated Assessee's Role in Peer Assessment', Assessment and Evaluation in Higher Education 34, no. 1 (2009): 105-14.

Kvale, Steinar. InterViews: An Introduction to Qualitative Research Interviewing. Thousand Oaks, CA: SAGE Publications, 1996.

Lave, Jean and Etienne Wenger. Situated Learning: Legitimate Peripheral Participation. Cambridge: Cambridge University Press, 1991.

Lea, Mary R. and Brian V. Street. 'Student Writing in Higher Education: An Academic Literacies Approach', Studies in Higher Education 23, no. 2 (1998): 157-72.

Levy, Philippa and Robert Petrulis. 'How Do First-Year University Students Experience Inquiry and Research, and What Are the Implications for the Practice of Inquiry-Based Learning?', Studies in Higher Education 37, no. 1 (2012): 85-101.

Lewis, Emma-Ben, Ben Vincent, Alex Brett, Sarah Gibson and Reubs J. Walsh. 'I Am Your Trans Patient', British Medical Journal 357, Article j2963 (2017): 1-2. Accessed 9 November 2019. https://doi.org/10.1136/bmj.j2963.

Li, Hongbin, Prashant Loyalka, Scott Rozelle, Binzhen Wu and Jieyu Xie. 'Unequal Access to College in China: How Far Have Poor, Rural Students Been Left Behind?', China Quarterly 221 (2015): 185-207.

Lillis, Theresa M. Student Writing: Access, Regulation, Desire. London: Routledge, 2001.

Lillis, Theresa, Kathy Harrington, Mary R. Lea and Sally Mitchell, eds. Working with Academic Literacies: Case Studies towards Transformative Practice. Anderson, SC: Parlor Press, 2015.

Lillis, Theresa, and Mary Scott. 'Defining Academic Literacies Research: Issues of Epistemology, Ideology and Strategy', Journal of Applied Linguistics 4, no. 1 (2007): 5-32.

Lillis, Theresa, and Jackie Tuck. 'Academic Literacies: "A Critical Lens on Writing and Reading in the Academy'." In The Routledge Handbook of English for Academic Purposes, edited by Ken Hyland and Philip Shaw, (2016): 30-43. London: Routledge, 2016.

Lincoln, Yvonna S. and Egon G. Guba. Naturalistic Inquiry. Newbury Park, CA: SAGE Publications, 1985.

Liu, Ngar-Fun and David Carless. 'Peer Feedback: The Learning Element of Peer Assessment', Teaching in Higher Education 11, no. 3 (2006): 279-90.

Lunt, Tom and John Curran. "Are You Listening Please?": The Advantages of Electronic Audio Feedback Compared to Written Feedback', Assessment and Evaluation in Higher Education 35, no. 7 (2010): 759-69.

Luo, Yan, Fei Guo and Jinghuan Shi. 'Expansion and Inequality of Higher Education in China: How Likely Would Chinese Poor Students Get to Success?', Higher Education Research and Development 37, no. 5 (2018): 1015-34.

McConlogue, Teresa. 'But is It Fair? Developing Students' Understanding of Grading Complex Written Work through Peer Assessment', Assessment and Evaluation in Higher Education 37, no. 1 (2012): 113-23.

McConlogue, Teresa. 'Making Judgements: Investigating the Process of Composing and Receiving Peer Feedback', Studies in Higher Education 40, no. 9 (2015): 1495-506. 
McConnell, David. 'The Experience of Collaborative Assessment in e-Learning', Studies in Continuing Education 24, no. 1 (2002): 73-92.

McConnell, David. E-Learning Groups and Communities. Maidenhead: Open University Press, 2006.

McCune, Velda and Noel Entwistle. 'Cultivating the Disposition to Understand in 21st Century University Education', Learning and Individual Differences 21, no. 3 (2011): 303-10.

McCune, Velda and Dai Hounsell. 'The Development of Students' Ways of Thinking and Practising in Three Final-Year Biology Courses', Higher Education 49, no. 3 (2005): 255-89.

McNiff, Jean. Action Research: Principles and Practice. 3rd ed. London: Routledge, 2013.

Medland, Emma. 'Examining the Assessment Literacy of External Examiners', London Review of Education 13, no. 3 (2015): 21-33.

Medway, Dominic, Stuart Roper and Leah Gillooly. 'Contract Cheating in UK Higher Education: A Covert Investigation of Essay Mills', British Educational Research Journal 44, no. 3 (2018): 393-418.

Meekosha, Helen. 'Decolonising Disability: Thinking and Acting Globally', Disability and Society 26, no. 6 (2011): 667-82.

Molloy, Elizabeth and David Boud. 'Changing Conceptions of Feedback'. In Feedback in Higher and Professional Education: Understanding It and Doing It Well, edited by David Boud and Elizabeth Molloy, 11-33. London: Routledge, 2013.

Moodle. 'Workshop Module'. Accessed 10 November 2019. https://docs.moodle.org/22/en/ Workshop_module.

Moon, Jennifer A. A Handbook of Reflective and Experiential Learning: Theory and Practice. London: Routledge Falmer, 2004.

Moore-Cherry, Niamh, Ruth Healey, Dawn T. Nicholson and Will Andrews. 'Inclusive Partnership: Enhancing Student Engagement in Geography', Journal of Geography in Higher Education 40, no. 1 (2016): 84-103.

Morgan, Lydia. 'Understanding Dworkin through Art: Object-Based Learning and Law', The Law Teacher 52, no. 1 (2018): 53-67.

Mountford-Zimdars, Anna, John Sanders, Joanne Moore, Duna Sabri, Steven Jones and Louise Higham. 'What Can Universities Do to Support All Their Students to Progress Successfully throughout Their Time at University?', Perspectives: Policy and Practice in Higher Education 21, no. 2/3 (2017): 101-10.

Muthukrishna, Michael, Adrian V. Bell, Joseph Henrich, Cameron M. Curtin, Alexander Gedranovich, Jason McInerney and Braden Thue. 'Beyond WEIRD Psychology: Measuring and Mapping Scales of Cultural and Psychological Distance', Social Science Research Network, 2 October 2018. Accessed 10 November 2019. http://dx.doi.org/10.2139/ ssrn.3259613.

Nicol, David. 'From Monologue to Dialogue: Improving Written Feedback Processes in Mass Higher Education', Assessment and Evaluation in Higher Education 35, no. 5 (2010): 501-17.

Nicol, David, Avril Thomson and Caroline Breslin. 'Rethinking Feedback Practices in Higher Education: A Peer Review Perspective', Assessment and Evaluation in Higher Education 39, no. 1 (2014): 102-22.

Office for Students. 2019. National Student Survey 2019 Results. Accessed 24 February 2020. https://tinyurl.com/v5pzomh.

O'Connell, Brendan, Paul De Lange, Mark Freeman, Phil Hancock, Anne Abraham, Bryan Howieson and Kim Watty. 'Does Calibration Reduce Variability in the Assessment of Accounting Learning Outcomes?', Assessment and Evaluation in Higher Education 41, no. 3 (2016): 331-49.

O’Donovan, Berry M. 'Patchwork Quilt or Woven Cloth? The Student Experience of Coping with Assessment across Disciplines', Studies in Higher Education 44, no. 9 (2019): 1579-90.

Oliver, Michael. Understanding Disability: From Theory to Practice. London: Macmillan, 1995.

Oliver, Mike. 'The Social Model in Action: If I Had a Hammer'. In Implementing the Social Model of Disability: Theory and Research, edited by Colin Barnes and Geof Mercer, 18-31. Leeds: Disability Press, 2004.

O'Neill, Geraldine, ed. A Practitioner's Guide to Choice of Assessment Methods within a Module: Case Studies for University College Dublin. Dublin: UCD Teaching and Learning, 2011.

O'Neill, G. 'Choice of Assessment Methods: Designing, Implementing and Evaluating Equity'. (unpublished) 2013.

Orsmond, Paul. Self- and Peer-Assessment: Guidance on Practice in the Biosciences. Leeds: Centre for Bioscience, 2004. 
Orsmond, Paul and Stephen Merry. 'Feedback Alignment: Effective and Ineffective Links between Tutors' and Students' Understanding of Coursework Feedback', Assessment and Evaluation in Higher Education 36, no. 2 (2011): 125-36.

Panadero, Ernesto and Anders Jonsson. 'The Use of Scoring Rubrics for Formative Assessment Purposes Revisited: A Review', Educational Research Review 9 (2013): 129-44.

Planas Lladó, Anna, Lídia Feliu Soley, Rosa Maria Fraguell Sansbelló, Gerard Arbat Pujolras, Joan Pujol Planella, Núria Roura-Pascual, Joan Josep Suñol Martínez and Lino Montoro Moreno. 'Student Perceptions of Peer Assessment: An Interdisciplinary Study', Assessment and Evaluation in Higher Education 39, no. 5 (2014): 592-610.

Polanyi, Michael. The Tacit Dimension. Chicago: University of Chicago Press, 2009.

Price, Margaret, Karen Handley, Jill Millar and Berry O’Donovan. 'Feedback: All That Effort, but What is the Effect?', Assessment and Evaluation in Higher Education 35, no. 3 (2010): 277-89.

Price, Margaret, Chris Rust, Berry O’Donovan, Karen Handley and Rebecca Bryant. Assessment Literacy: The Foundation for Improving Student Learning. Oxford: Oxford Centre for Staff and Learning Development, 2012.

QAA (Quality Assurance Agency for Higher Education). UK Quality Code for Higher Education, Part A: Setting and Maintaining Academic Standards: The Frameworks for Higher Education Qualifications of UK Degree-Awarding Bodies. Gloucester: Quality Assurance Agency for Higher Education, 2014. Accessed 10 November 2019. www.qaa.ac.uk/docs/qaa/quality-code/ qualifications-frameworks.pdf?sfvrsn=170af781_16.

QAA (Quality Assurance Agency for Higher Education). 'Subject Benchmark Statements' (2019a). Accessed 10 November 2019. www.qaa.ac.uk/quality-code/subject-benchmark-statements.

QAA (Quality Assurance Agency for Higher Education). 'UK Quality Code for Higher Education' (2019b). Accessed 10 November 2019. www.qaa.ac.uk/quality-code.

QAA (Quality Assurance Agency for Higher Education). 'External Expertise' (2019c). Accessed 10 November 2019. www.qaa.ac.uk/en/quality-code/advice-and-guidance/ external-expertise.

QMUL (Queen Mary University of London). 'Thinking Writing: A Resource for Teachers in Higher Education, Exploring Connections between Thinking and Writing'. Accessed 10 November 2019. www.thinkingwriting.qmul.ac.uk.

Raes, Annelies, Ellen Vanderhoven and Tammy Schellens. 'Increasing Anonymity in Peer Assessment by Using Classroom Response Technology within Face-to-Face Higher Education', Studies in Higher Education 40, no. 1 (2015): 178-93.

Rai, Lucy. 'Owning (up to) Reflective Writing in Social Work Education', Social Work Education 25, no. 8 (2006): 785-97.

Richardson, John T.E. Degree Attainment, Ethnicity and Gender: A Literature Review. York: Higher Education Academy, 2008.

Ross, Jen. 'Traces of Self: Online Reflective Practices and Performances in Higher Education', Teaching in Higher Education 16, no. 1 (2011): 113-26.

Ross, Jen. 'Performing the Reflective Self: Audience Awareness in High-Stakes Reflection', Studies in Higher Education 39, no. 2 (2014): 219-32.

Rotthoff, Thomas. 'Standing up for Subjectivity in the Assessment of Competencies', GMS Journal for Medical Education 35, no. 3 (2018): 1-11.

Rudy, David W., Michele C. Fejfar, Charles H. Griffith and John F. Wilson. 'Self- and Peer Assessment in a First-Year Communication and Interviewing Course', Evaluation and the Health Professions 24, no. 4 (2001): 436-45.

Russell, David R. Writing in the Academic Disciplines: A Curricular History. 2nd ed. Carbondale: Southern Illinois University Press, 2002.

Ryan, Tracii and Michael Henderson. 'Feeling feedback: students' emotional responses to educator feedback', Assessment \& Evaluation in Higher Education, 43, no. 6 (2018): 880-92.

Sadler, D. Royce. 'Formative Assessment and the Design of Instructional Systems', Instructional Science 18, no. 2 (1989): 119-44.

Sadler, D. Royce. 'Interpretations of Criteria-Based Assessment and Grading in Higher Education', Assessment \& evaluation in higher education 30, no. 2 (2005): 175-94.

Sadler, D. Royce. 'Transforming Holistic Assessment and Grading into a Vehicle for Complex Learning'. In Assessment, Learning and Judgement in Higher Education, edited by Gordon Joughin, 45-63. Dordrecht: Springer, 2009. 
Sadler, D. Royce. 'Beyond Feedback: Developing Student Capability in Complex Appraisal', Assessment and Evaluation in Higher Education 35, no. 5 (2010): 535-50.

Sadler, D. Royce. 'The Futility of Attempting to Codify Academic Achievement Standards', Higher Education 67, no. 3 (2014): 273-88.

Salmi, Jamil. All around the World: Higher Education Equity Policies across the Globe. Indianapolis: Lumina Foundation, 2018. Accessed 10 November 2019. https://worldaccesshe.com/ wp-content/uploads/2019/02/All-around-the-world-Higher-education-equity-policiesacross-the-globe-FINAL-COPY-2.pdf.

Salmon, Gilly. 'The Five Stage Model'. Accessed 10 November 2019. www.gillysalmon.com/fivestage-model.html.

Salmon, Gilly, Ming Nie and Palitha Edirisingha. 'Developing a Five-Stage Model of Learning in Second Life', Educational Research 52, no. 2 (2010): 169-82.

Sambell, Kay, Liz McDowell and Catherine Montgomery. Assessment for Learning in Higher Education. London: Routledge, 2013.

Samuelowicz, Katherine and John D. Bain. 'Revisiting Academics' Beliefs about Teaching and Learning', Higher Education 41, no. 3 (2001): 299-325.

Schön, D. A. The reflective practitioner: How professionals think in action. New York: Basic Books, 1983.

Shakespeare, Tom. 'The Social Model of Disability'. In The Disability Studies Reader, edited by Lennard J. Davis, 197-204. 2nd ed. New York: Routledge, 2006.

Shay, Suellen. 'The Assessment of Complex Tasks: A Double Reading', Studies in Higher Education 30, no. 6 (2005): 663-79.

Simons, Helen. 'Case Study Research: In-Depth Understanding in Context'. In The Oxford Handbook of Qualitative Research, edited by Patricia Leavy, 455-70. New York: Oxford University Press, 2014.

Sluijsmans, Dominique M.A, Saskia Brand-Gruwel and Jeroen J.G. van Merriënboer. 'Peer Assessment Training in Teacher Education: Effects on Performance and Perceptions', Assessment and Evaluation in Higher Education 27, no. 5 (2002): 443-54.

Smyth, Lillian, Federico Davila, Thomas Sloan, Ellen Rykers, Sam Backwell and Stephen B. Jones. 'How Science Really Works: The Student Experience of Research-Led Education', Higher Education 72, no. 2 (2016): 191-207.

Stake, Robert E. The Art of Case Study Research. Thousand Oaks, CA: SAGE Publications, 1995.

Stephens, Nicole M., MarYam G. Hamedani and Mesmin Destin. 'Closing the Social-Class Achievement Gap: A Difference-Education Intervention Improves First-Generation Students' Academic Performance and All Students' College Transition', Psychological Science 25, no. 4 (2014): 943-53.

Tai, Joanna, Rola Ajjawi, David Boud, Phillip Dawson and Ernesto Panadero. 'Developing Evaluative Judgement: Enabling Students to Make Decisions about the Quality of Work', Higher Education 76, no. 3 (2018): 467-81.

Tennant, Mark, Cathi McMullen and Dan Kaczynski. Teaching, Learning and Research in Higher Education: A Critical Approach. New York: Routledge, 2010.

Tisi, Jo, Gillian Whitehouse, Sarah Maughan and Newman Burdett. A Review of Literature on Marking Reliability Research (Ofqual/13/5285). Slough: National Foundation for Educational Research, 2013.

Topping, Keith J. 'Methodological Quandaries in Studying Process and Outcomes in Peer Assessment', Learning and Instruction 20, no. 4 (2010): 339-43.

Troy, Cary, Brent K. Jesiek, Josh Boyd, Natascha Michele Trellinger and Rebecca R. Essig. 'Writing to Learn Engineering: Identifying Effective Techniques for the Integration of Written Communication into Engineering Classes and Curricula (NSF RIGEE Project)'. Paper presented at the American Society for Engineering Education (ASEE) Annual Conference and Exposition, New Orleans, 26-29 June 2016.

UCL (University College London). 'Inquiry Launches into History of Eugenics at UCL', UCL News, 5 December 2018. Accessed 10 November 2019. www.ucl.ac.uk/news/2018/dec/ inquiry-launches-history-eugenics-ucl.

UDL. 'UDL on Campus: Universal Design for Learning in Higher Education'. Accessed 10 November 2019. http://udloncampus.cast.org/page/assessment_udl.

Universities UK. Quality and Standards in UK Universities: A Guide to How the System Works. London: Universities UK, 2008. 
University of Plymouth. Inclusive Assessment: Good Practice Guide. Plymouth: University of Plymouth, 2016. Accessed 10 November 2019. www.plymouth.ac.uk/uploads/production/ document/path/2/2516/Good_practice_inclusive_assessment_updated_May_2016.pdf.

University of Plymouth. 'Inclusive Assessment'. Accessed 10 November 2019. www.plymouth. ac.uk/about-us/teaching-and-learning/inclusivity/inclusive-assessment.

University of Suffolk. Student Assessment: An Overview. Ipswich: University of Suffolk, 2016. Accessed 10 November 2019. www.uos.ac.uk/sites/default/files/assessment-overview. pdf.

UNSW (University of New South Wales). 'Assessing Authentically'. Accessed 10 November 2019. https://teaching.unsw.edu.au/authentic-assessment.

Van Zundert, Marjo, Dominique Sluijsmans and Jeroen van Merriënboer. 'Effective Peer Assessment Processes: Research Findings and Future Directions', Learning and Instruction 20, no. 4 (2010): 270-9.

Villarroel, Verónica, Susan Bloxham, Daniela Bruna, Carola Bruna and Constanza Herrera-Seda. 'Authentic Assessment: Creating a Blueprint for Course Design', Assessment and Evaluation in Higher Education 43, no. 5 (2018): 840-54.

Visser-Wijnveen, Gerda J., Roeland M. van der Rijst and Jan H. van Driel. 'A Questionnaire to Capture Students' Perceptions of Research Integration in Their Courses', Higher Education 71, no. 4 (2016): 473-88.

Voss, James F. and Timothy A. Post. 'On the Solving of Ill-Structured Problems'. In The Nature of Expertise, edited by Michelene T.H. Chi, Robert Glaser and Marshall J. Farr, 261-85. Hillsdale, NJ: Lawrence Erlbaum Associates, 1988.

Watson, P. 'Conformity and commitment in writing', Visible Language, 14 (1980): 351-63.

Watty, Kim, Mark Freeman, Bryan Howieson, Phil Hancock, Brendan O'Connell, Paul de Lange and Anne Abraham. 'Social Moderation, Assessment and Assuring Standards for Accounting Graduates', Assessment and Evaluation in Higher Education 39, no. 4 (2014): 461-78.

Wen, Meichun Lydia and Chin-Chung Tsai. 'Online Peer Assessment in an Inservice Science and Mathematics Teacher Education Course', Teaching in Higher Education 13, no. 1 (2008): 55-67.

Wenger, Etienne. Communities of Practice: Learning, Meaning, and Identity. Cambridge: Cambridge University Press, 1999.

Wenger, Etienne, Nancy White and John D. Smith. Digital Habitats: Stewarding Technology for Communities. Portland, OR: CPsquare, 2009.

Wenger-Trayner, Etienne, Mark Fenton-O'Creevy, Steven Hutchinson, Chris Kubiak and Beverly Wenger-Trayner, eds. Learning in Landscapes of Practice: Boundaries, Identity, and Knowledgeability in Practice-Based Learning. London: Routledge, 2015.

Wentworth, Diane Keyser and Lona Whitmarsh. 'Thinking Like a Psychologist Introductory Psychology Writing Assignments: Encouraging Critical Thinking and Resisting Plagiarism', Teaching of Psychology 44, no. 4 (2017): 335-41.

Williams, Logan and Simon Kemp. 'Independent Markers of Master's Theses Show Low Levels of Agreement', Assessment and Evaluation in Higher Education 44, no. 5 (2019): 764-71.

Wills, Jane. 'Engaging'. In The SAGE Handbook of Human Geography, edited by Roger Lee, Noel Castree, Rob Kitchin, Vicky Lawson, Anssi Paasi, Chris Philo, Sarah Radcliffe, Susan M. Roberts and Charles W.J. Withers, 363-80. London: SAGE Publications, 2014.

Wilson, Michael John, Ming Ming Diao and Leon Huang. "'I'm Not Here to Learn How to Mark Someone Else's Stuff": An Investigation of an Online Peer-to-Peer Review Workshop Tool', Assessment and Evaluation in Higher Education 40, no. 1 (2015): 15-32.

Woolf, Katherine, Henry W.W. Potts and I.C. McManus. 'Ethnicity and Academic Performance in UK Trained Doctors and Medical Students: Systematic Review and Meta-Analysis', British Medical Journal 342, Article d901 (2011): 1-14. Accessed 9 November 2019. https://doi. org/10.1136/bmj.d901.

Yorke, Mantz. 'Formative Assessment in Higher Education: Moves towards Theory and the Enhancement of Pedagogic Practice', Higher Education 45, no. 4 (2003): 477-501.

Zimbardi, Kirsten, Kay Colthorpe, Andrew Dekker, Craig Engstrom, Andrea Bugarcic, Peter Worthy, Ruban Victor, Prasad Chunduri, Lesley Lluka and Phil Long. 'Are They Using My Feedback? The Extent of Students' Feedback Use Has a Large Impact on Subsequent Academic Performance', Assessment and Evaluation in Higher Education 42, no. 4 (2017): 625-44. 


\section{Index}

academic literacies $\quad 20,43,123$

academic standards $2,5-6,11,13$,

16-19, 41, 57, 62, 66, 85, 92, 96,

99-104, 108, 112-15, 122-3, 126,

148, 151-3; co-construction

of 100; students' understanding

of 104

accountancy 93

action research 4, 9, 114

Aditomo, Anindito 69-71

Ajjawi, Rola 124

Anders, Jake 140

anonymisation 93-4

applied research $\quad 70-1$

apprenticeships 13

Arana, Fernán G. 145

Ashwin, Paul 75

assessment across a

programme 53-63; choice in 144-9; influence on students' learning 118; key ideas in current thinking on 11; and modularisation 55-6; practice with different varieties of 123; preparation of students for 41-3; problems with 1-2; seen as an integral part of learning 101-2, 114; students' criticism of 8 ; students' involvement in 11, 19,99-102, 138; sustainable 118-19, 124; traditional and non-traditional 75-6

assessment briefs $\quad 46-51$

assessment criteria 17, 26, 42, 87, 91-7, 115; limitations of 91; paraphrasing of 101 assessment of learning and assessment for learning 19, 65

assessment literacy 19, 41-2, 90, 100-4; definition of 100-1 assessment load on teachers $120-1$ assessment for a module $31-52$ assessment standards $105,108,122$ assessment tasks 44 audio feedback 130 Australia 88, 92-3, 97 authenticity, concept of $37-8,45$, 65-7, 71, 79

authoring of research $24,69,72-6$ autonomous learners 100

Barnett, Ronald 33

benchmark statements 18

black and minority ethnic (BME) students 141

Boud, David $\quad 2,34,65-6,118-19$, 124-6

Brew, Angela $\quad 68,81,153$

Burns, Shannon M. 139

Butler Shay, Suellen 92

calibration $16,18,27,90-8,122-6$, 152; in the United Kingdom 95

Carless, David 103

case studies 4, 40

Chang, Hasok 24, 68, 77-81, 152

Chatterjee, Helen J. 72

cheating 121

China 140-1

Citizens UK 66, 77-8

codification $91-2,97$

cohesive assessment 53

collaborative assessment $17,112,115$, 143-9, 153 
commodification of knowledge 37

communities of practice $5,12-19,92$, 99, 104

community activities 13

community issues 66,78

community-linked assessments 64

community organisations $\quad 64,77,81$

competency-based education 37

complaints procedures 110, 112

complex learning 32, 95-6

conferencing software 114

consensual understanding 152

consolidation of learning 22

core modules 54-5

Crenshaw, Kimberlé 138

criticality 18,106

Cuba 141

cultural distance $139-40$

curricula inclusive 138; transformational 33

Dawson, Phillip 123

deafness 142-3

debriefing 108, 110

degree programmes, reviewing of 58-61

Degree Standards Project 92, 95

developing countries 139

Dewey, John 68

directed community model of research 79-80

disability, medical and social models of 142

disciplinary communities $\quad 20,24,33-4$, 42, 92

disciplinary differences 38

disciplinary knowledge 75

discourse communities 20, 27

discriminatory practices $137-8$

Divan, Aysha 145

diversity of learners 137-9, 142

Drage, Ginger 143

Dunstan, David 26

Dwyer, Clairev15

Dymond-Green, Neil 43

dyslexia 138

'edge words' 26

Einstein, Albert 26

El Hakim, Yassein 57

engagement of students $\quad 67,75$

Entwistle, Noel 33

epistemic beliefs of students 38

epistemology 20,123

essays $\quad 40-5,122,137-8$

European Credit Transfer and

Accumulation System 56

evaluative judgement $2,11,118$, 123-6; definition of 123 examinations, increasing use of 121

examplars 18, 42, 62, 96, 98, 106

external examining 89-92

'fair test' cartoon 137

Falchikov, Nancy $\quad 34,105,118-19$

feedback 7-8, 14-15, 45, 100, 103-10, 118-33, 153; active participation in 124; dialogic 119; emotional aspect of 121 ; exchange of 109; inclusive practices 6; learning from 122; 'mark one' and 'mark two' 124-6, 129; profiling tool 127-8; purpose of 126; review of teachers' contribution to 127-9; solicitation of 124; students' contribution to 118; students' dissatisfaction with 119-23; teaching teams' development of good practices 126-33; use made of $120,125-7$

formative assessment $11,56-7,102$, 109, 121

fragmentation, academic 55

Framework for Higher Education

Qualifications (FHEQ) 58

Fryar, James 62

Furlan, Luis 145

genres of assessment $\quad 66,77$

Gibbs, Graham 41, 57

Gilbert, Rosie 143

Gishen, Faye 141-2

Graham, P. 34

Grant Museum of Zoology 73-4 guided marking 105-6, 117

Hannan, Leonie 72

Harland, Tony 56

harmonisation discussions $\quad 86-7$

hedge words 91

Heinrich, Joseph 139

Henderson, Michael 121-2

higher-order thinking 26, 32

Hounsell, Dai 67

Hughes, Gwyneth 126-9

Hussey, Trevor 34

Iannone, Paola 38

inclusive assessment $\quad 137,143-5$

independent learners 118

'inheritance mechanisms' $68,77,80-1$

inquiry-based learning (IBL) 68-71; examples of 70-1; see also objectbased learning

integrity, need for 103

intended learning outcomes 
interpretivist research 4

'intersectionality' (Crenshaw) 138

ipsative assessment 129-30

Jackson, Catherine 81

Jessop, Tansy $57-8$

Jonsson, Anders 26

Kador, Thomas 72

Kemp,, Simon 25

knowledge-building $\quad 67-8,71-2,80$, 91,152

lab reports 40

Lave, Jean $\quad 12-13,16$

Lea, Mary R. 20

'learned dependence' 100, 105, 119

learning, nature of 11-12, 37, 91

learning environments 10

learning hours 31

legitimate peripheral participation 13-14, 153

Levy, Philippa $\quad 24,68,71,76$

Li, Hongbin 140

Lillis, Theresa 43, 137

literature-based inquiry 70

Lokugamage, Amali 141-2

London South Bank University 146

'lurkers' 13

McCune, Velsa 67

marginalised groups $138,141-3,152$

markers' commentaries $105-7$

marketability of standalone modules 54

markets, internal and external 25-6

marking 7, 85-98, 152; reasons for variation in judgements $86-7$

massification of higher education 119

material culture 72

'Meet the Researcher' 13-14

Merry, Stephen 126

model answers 42

modified assessment provisions (MAP) 144

modularisation $31,53-6,62,102$, 120, 129; advantages and disadvantages of 54-6; and assessment 55-6; dilemma of $54-8$

Molloy, Elizabeth $\quad 124-6$

Moodle workshops 110-11

Mountford-Zimdars, Anna 141

multi-disciplinary studies 16

multiple-choice questions $\quad 32,38-9$

multiple disadvantage 138

Muthukrishna, Michael 139

mystery specimens $\quad 72-5$
Newton, Sir Isaac 62

object-based learning (OBL) 72-5

O'Neill, Geraldine 144

ontology 123

open-ended tasks 26

Orsmond, Paul 126

overarching questions $\quad 34-5$

overassessment $56,62,120$

Panadero, Ernesto 26

participation, barriers to $138-9$

peer assessment $17,19,102-5$, 109-12, 117, 152-3; drawbacks of $102-3$; organisation and moderation of 110-11;

preparation of students for $102-5$, 108,112 ; student resistance to 102 ; use of software for management of 111-12

peer review 107-9, 115

Petrulis, Robert 24, 68, 71, 76

plagiarism 45-6, 121

Plymouth University $\quad 51,137,147-8$

portfolios 41

power dynamics 17

praise for students 126

Price, Margaret 100

problem-based learning (PBL) 40, 66

professional bodies 55

'protected characteristics' 138

quality assurance 113,119

Quality Assurance Agency

(QAA) 17-18, 85, 88

Queen Mary College 77

reaching out to the wider

community 64

reading $116-17,149$

reading grids 35

reflection and reflective writing 43-4

rehearsal marking 109

reliability of assessment $\quad 6,24-6,94-5$

research-based learning (RBL) 11,

23-7, 66-8, 76-81, 153;

advantages and disadvantages of

76-8; different views of $67-8$

research skills $73-4,78$

rhetorical conventions 20,33

Roehampton University 146

role-playing 71

Ross, Jen 44

Rotthoff, Thomas 37

rubrics 26

Ryan, Tracii 121-2 
Sadler, D. Royce $\quad 2,26,42,91-2$, 99-100, 104

Salkind, Jess 143

Salmi, Jamil 140-1

Sambell, Kay 38

scaffolding 18, 35, 67, 152-3

scenarios and scenario-based assessments 40,65

scholarly research $70-2$

self-assessment $\quad 6,108,118,152$

self-directed learners 102,152

seminar groups 14

short writing tasks $20-3,144$; in engineering 22-3

simplified research 70

Simpson, Adrian 38

Simpson, Claire 41

simulated research 71

situated learning 12

Smith, Patrick 34

social background 140

social construction of standards 16-17, 41, 92, 104, 122, 151; of knowledge 13

social participation 12

socialisation 114, 116

software, use of 111-14

Soler, Rebeca 65-6

Stake, Robert E. 4

standalone units of learning 54-5

standards 87-92; comparability of 90 ; created by practitioners, not regulations 16; definition of 91; disciplinary 88; documentation of 26,87-91; fixed over time 92; national 88-9; sector-wide 88

'strategic' learners 121

Street, Brian V. 20

structuring of tasks 26, 37

students from non-traditional backgrounds 43, 137-8, 144; understanding of assessment processes 41,44

subjectivity and subjective judgements 25, 86

Suffolk University 51

summative assessment $11,38,41$, 44-5, 54-8, 102, 109

supercomplexity 33

sustainable assessment $\quad 65-6$

syllabus content $\quad 32-3$

synoptic assessment $\quad 56-7$

tacit knowledge $\quad 17,26-7,87$

Tai, Joanna 11,123 teachers judgements made by 98 ; practical knowledge of $3-4,151$; role of $78-9$, 115-16

teaching assistants (TAs) 122

theory's link with practice 3

Thinking Writing website 21, 35, 144

threshold standards 93-4

time, commitment of 77,79

Toolbox Diversity in Education website 150

Transforming the Experience of Students through Assessment (TESTA) project $53,57-8$

Trends in Ecology and Evolution (journal) 73

Troy, Cary 22-3

trust, establishment of 5, 102-3, 109-10

Tuck, Jackie 43, 137

uniqueness of each learner and teacher 4

United Nations Educational, Scientific and Cultural Organisation (UNESCO) 140

Universal Design for Learning (UDL) project 145

Universities UK 89

use-oriented and non use-oriented tasks 69

Utrecht University 150

validity, concept of $24-5,44,62,94-5$

vicarious learners 13

virtual learning environments 120, 129-30

vivas 39

Watty, Kim 27, 88-9, 93-4

ways of thinking and practising (WTP) 33, 67

Wenger[-Trayner], Etienne 5, 12-13, 16

Williams, Logan 25

Wills, Jane 77, 152

Wilson, Michael John 102

Woolf, Katherine 141

world views 33

'writing in the disciplines' (WID)

movement 19

writing-to-learn tasks 21,144

Zimbardi, Kirsten 130 
Teachers in higher education spend much of their time on assessment, yet many have received minimal guidance on assessment design and marking. This means assessment can often be a source of stress and frustration. Assessment and Feedback in Higher Education aims to solve these problems. Offering a concise overview of assessment theory and practice, this guide provides teachers with the help they need.

In education, theory and practice are often poorly linked. In this guide, Teresa McConlogue presents theoretical ideas and research findings and links them to practice. She considers recent theoretical work on feedback and suggests ways of developing evaluative judgement. Throughout the book, teachers are encouraged to examine their practice critically, and there are ideas for small-scale educational investigations, involving teachers, their colleagues and students, such as using the Assessment Review Questionnaire to adapt assessments.

A key principle of Assessment and Feedback in Higher Education is that an understanding of academic standards is fundamental to good assessment design and more reliable marking. The guide explores the concept of academic standards and proposes methods of co-constructing shared standards within a teaching team and with students through calibration activities.

Teresa McConlogue is Principal Teaching Fellow in the UCL Arena Centre. She has worked co-operatively with higher education teachers and their students in a range of contexts and countries. She is interested in how teachers can explore and make sense of their practice through small-scale, context-rich investigations, and has investigated ways of involving students in assessment judgements and what teachers and students learn from collaborative assessment practices.

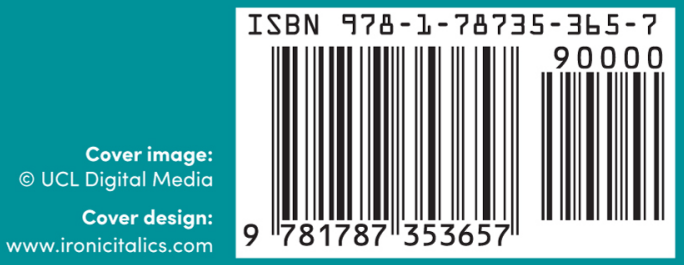

